\author{
Universidade de Brasília \\ Instituto de Química \\ Programa de Pós-Graduação em Química \\ Laboratório de Materiais e Combustíveis
}

\title{
ESTUDO DOS TRATAMENTOS TÉRMICOS DOS \\ TRIACILGLICERÍDEOS, ÁCIDOS GRAXOS E ÉSTERES METÍLICOS: \\ PERFIL REACIONAL E MECANISMOS
}

Vinicius Moreira Mello

Orientador: Prof. Paulo A. Z. Suarez 


\author{
Universidade de Brasília \\ Instituto de Química \\ Programa de Pós-Graduação em Química \\ Laboratório de Materiais e Combustíveis
}

\title{
ESTUDO DOS TRATAMENTOS TÉRMICO DOS \\ TRIACILGLICERÍDEOS, ÁCIDOS GRAXOS E ÉSTERES METÍLICOS: \\ PERFIL REACIONAL E MECANISMOS
}

Tese de Doutorado, área de concentração Físico-Química, Apresentada ao Instituto de Química da Universidade de Brasília, como requisito para obtenção do título de Doutor em Química.

\footnotetext{
Vinicius Moreira Mello

Mestre em Química

Orientador: Paulo Anselmo Ziani Suarez
} 
Folha de Aprovação 
"A imaginação é mais importante que o conhecimento" 


\section{Agradecimentos}

Gostaria de agradecer aos meus pais, Dimas e Enir, e aos meus irmãos, Débora e José Vicente, que me apoiaram e me auxiliaram durante tantos anos nos projetos que me propus a realizar.

A minha querida e amada Joanna, por estar comigo durante tantos anos compartilhando tantas alegrias, sempre com otimismo e muita felicidade. Ao Pedro Octávio, por me ensinar que a vida é pra ser levada com suavidade e com muita bondade.

Aos meus amigos de longa data Letícia, Zoran, Raul, Vinícius, Fábio, Nayara, Gaúcho, DVD, Marcelão, Miagui, Baby, Eduardo, Jeffão, Vanda, Maria Clara, Arilson e aos demais por tantos momentos especiais. Aos novos amigos que venho conhecendo nos últimos anos, pelos momentos e as novas oportunidades.

As pessoas que fazem ou já fizeram parte do Laboratório de Materiais e Combustíveis, pela dedicação a química, pelo auxílio e pela amizade criada durante vários anos de trabalho em conjunto.

Aos professores que tive a honra de ser aluno, por me ensinarem a ser químico.

Ao Prof. Paulo Suarez, pela orientação e amizade.

A UnB e o Instituto de Química, por proporcionar tantos anos de aprendizados e convivências.

Ao CNPq: Pelo suporte financeiro e bolsa de estudo. 


\section{Resumo}

O tratamento térmico acima de $260{ }^{\circ} \mathrm{C}$ dos triacilglicerídeos demonstrou que a formação de materiais com alta massa molar (polímeros) e de baixa (bio-óleos) estão correlacionado e ocorrem ao mesmo tempo, sendo dependentes da temperatura, tempo reacional, pureza da matéria prima e presença de catalisador. Utilizando a variação da viscosidade, foi possível observar que o aumento da massa molar é inicialmente favorecido, ocorrendo predominantemente nas reações com temperaturas próximas a $300{ }^{\circ} \mathrm{C}$ e nos tempos iniciais nas reações a temperaturas mais altas. A decomposição ocorre em paralelo à polimerização e passa a ser expressiva em temperaturas próximas de $350{ }^{\circ} \mathrm{C}$ e nas reações com tempo prolongado. Observou-se também que complexos de $\mathrm{Ni}^{2+}, \mathrm{Pb}^{2+}, \mathrm{Al}^{3+}, \mathrm{Ni}^{2+}$, $\mathrm{Mn}^{2+}$ e $\mathrm{Zn}^{2+}$, aumentam a quantidade de bio-óleo produzidos em até $20 \%$ e de polímeros com viscosidade de até $46 \%$ superiores as obtidas nas reações sem catalisador. As informações obtidas indicam que os íons de metais favorecem a decomposição dos grupos ésteres e a formação de ácidos carboxílicos. Ao avaliar os ácidos graxos, o aumento de viscosidade é exponencial e ocorre paralelamente a decomposição dos grupos ácidos carboxílicos. Ao tratar termicamente os ésteres metílicos, observou-se um perfil de linear de aumento de viscosidade, com maior inclinação da reta ao se aumentar a temperatura. Análises por espectroscopia na região do infravermelho indicaram que, para as três matérias primas estudadas, as duplas ligações na conformação cis são consumidas durante todo o tempo reacional, tendo como intermediários duplas ligações na conformação trans e trans-trans conjugadas. Em paralelo, foi demonstrado que os radicais formados a partir da decomposição dos ácidos carboxílicos, atuam como catalisadores nas reações de polimerização dos ésteres metílicos e nas reações de polimerização e decomposição dos triacilglicerídeos. 


\begin{abstract}
The thermal treatment above $260^{\circ} \mathrm{C}$ of triacylglycerides demonstrated that the formation of materials with high molecular (polymer) and low (bio-oil) weight are correlated and occur at the same time being dependent on temperature, reaction time, purity of the raw material and the presence of a catalyst. Using the variation in viscosity was observed that the increase of molar mass is initially favored at temperatures around $300{ }^{\circ} \mathrm{C}$ and at higher temperatures in the inicial times. Decomposition occurs in parallel to polymerization and becomes significant next to $350{ }^{\circ} \mathrm{C}$ and in the reactions with prolonged times. It was also observed that complex $\mathrm{Ni}^{2+}, \mathrm{Pb}^{2+}, \mathrm{Al}^{3+}, \mathrm{Ni}^{2+}, \mathrm{Mn}^{2+}$ and $\mathrm{Zn}^{2+}$, increases the amount of bio-oil produced by $20 \%$ and polymers having a viscosity of up to $46 \%$ higher than those obtained in without catalyst reactions. Information obtained indicates that metal ions increase the decomposition of ester groups and the formation of carboxylic acids. When evaluating the fatty acids, the viscosity increase is exponentially and occurs in parallel with decomposition of the carboxylic acid groups. By thermally treating the methyl ester, there was a linear increase viscosity profile, with a greater slope of the line by increasing the temperature. Analysis by infrared spectroscopy indicated that the region for the three materials studied, the double bonds in cis conformation are consumed during the reaction time, taking as intermediates double bonds in the trans conformation and transtrans conjugated. In parallel, it was demonstrated that the radicals formed from the decomposition of carboxylic acids act as catalysts in polymerization reactions of methyl esters and the polymerization reactions and decomposition of the triacylglycerides.
\end{abstract}




\section{Sumário}

Lista de Abreviaturas $\quad$ xi

Lista de Figuras $\quad$ xii

Lista de Tabelas $\quad$ xvi

1. Capítulo 1: Introdução Geral e Objetivos 1

1.1. Introdução Geral 2

1.2. Modificações Químicas dos TAGs, EMs e AGs utilizando o Tratamento Térmico 6

1.3. Objetivos do Trabalho

1.4. Objetivos Específicos 7

2. Capítulo 2: Revisão Bibliográfica 8

2.1. Composição Química e Obtenção dos TAGs, EMs, AGs e OGRs 9

2.2. Modificações Térmicas dos TAGs, EMs, AGs 12

2.3. Obtenção de Polímeros para Uso em Tintas 14

2.4. Obtenção de Solventes e Combustíveis 16

3. Capítulo 3: Material e Métodos 17

3.1. Materiais e Sínteses 18

$\begin{array}{lr}\text { 3.1.1. Materiais } & 18\end{array}$

3.1.2. Síntese de Ácido Graxo 18

3.1.3. Síntese do Éster Metílico 18

3.1.4. Síntese de Catalisador Ni(Carboxilato) 2

3.2. Sistemas Reacionais 19

3.3. Análises 20

3.3.1. Viscosidade Cinemática 20

3.3.2. Índice de Acidez 21

3.3.3. Massa Específica 21

3.3.4. Poder Calorífico 22

3.3.5. Análise do Teor de Metal 22

3.3.6. Análise Termogravimétrica 22

3.3.7. Cromatografia Líquida de Alta Performace 22

3.3.8. Espectroscopia de Absorção na Região do Infravermelho 23

3.3.9. Cromatografia Gasosa Acoplada à Espectroscopia de Massa 23 
3.3.11. Difração de Raio X

\section{Capítulo 4: Tratamento Térmico do Óleo de Soja}

4.1. Tratamento Térmico do Óleo de Soja: Primeira Parte

4.1.1. Caracterização dos Complexos Metálicos

4.1.2. Balanço de Massa

4.1.3. Polímeros

4.1.4. Bio-Óleo

4.1.5. Análise dos Catalisadores Pós-Reação

4.2. Tratamento Térmico do Óleo de Soja: Segunda Parte

4.2.1. Polímeros

4.2.2. Bio-Óleo

4.3. Considerações do capítulo

5. Capítulo 5: Tratamento Térmico dos Ácidos Graxos de Soja

5.1. Polímeros

5.2. Bio-Óleo

5.3. Considerações do Capítulo

6. Capítulo 6: Tratamento Térmico do Éster Metílico de Soja

6.1. Polímeros

6.2. Bio-Óleo

6.3. Considerações do Capítulo

7. Capítulo 7: Polimerização dos Triacilglicerídeos e Ésteres Metílicos na Presença de aditivos

7.1. Polimerização dos EMs e TAGs na presença de AGs

7.2. Polimerização dos EM na presença de $\mathrm{H}_{3} \mathrm{PO}_{4}$ e Ni(carboxilato)

7.3. Polimerização dos TAGs na presença de $\mathrm{Ca}(\mathrm{OH})_{2}$ e $\mathrm{Na}_{2} \mathrm{CO}_{3}$.

7.4. Considerações do Capítulo

8. Capítulo 8: Tratamento Térmico dos Óleos e Gorduras Residuais

8.1. Balanço de Massa 75

8.2. Polímeros 76

8.3. Bio-Óleo 76 
8.4. Considerações do Capítulo

9. Discussão dos Resultados

10.Conclusões Gerais

11. Referências 


\section{Lista de Abreviaturas}

TAGs Triacilglicerídeos

OGRs Óleos e gorduras residuais

AG Ácido graxo

EM Ester Metílico

TG Análise termogravimétrica

CHN Análise elementar de carbono, hidrogênio e nitrogênio

IV-ATR Espectroscopia de absorção na região do infravermelho utilizando célula de ATR e transformada de Fourier

IV-KBr Espectroscopia de absorção na região do infravermelho utilizando pastilha de $\mathrm{KBr}$ e transformada de Fourier

CG-MS Cromatografia gasosa acoplada à espectroscopia de massa

IA Índice de acidez

ICP-OES Plasma indutivamente acoplado

u.a. Unidade arbitrária

DRX Difração por Raios X 


\section{Lista de Figuras}

Figura 1.1 - Produção mundial de oleaginosas na última década. ${ }^{2}$

Figura 1.2 - Produção de oleaginosas por país no período de 2014/2015, adaptado de United States Department of Agriculture. ${ }^{2}$

Figura 1.3 - Produção mundial dos TAGs no período entre 2010 e $2015 .^{2}$

Figura 1.4 - Produção Mundial de EM até 2014 e projeções para os próximos oito anos. ${ }^{8}$

Figura 1.5 - Principais países produtores de AGs no ano de $2011 .{ }^{9}$

Figura 2.1 - Formula estrutural dos TAGs.

Figura 2.2 - Formula estrutural dos AGs encontrados nos TAGs.

Figura 2.3 - Reação de hidrólise do TAG e obtenção do AG e glicerol.

Figura 2.4 - Esquema geral da reação de transesterificação para a obtenção de éster.

Figura 2.5 - Reações entre os TAGs e o $\mathrm{O}_{2}$ presente no ar atmosférico: (1) Abstração do hidrogênio alílico e formação de radicais estabilizados por ressonância; (2) formação de hidroperóxidos; (3) oxidação da cadeia (A) e decomposição homolítica (B).

Figura 2.6 - Etapas reacionais do processo de tratamento térmico a altas temperaturas na ausência de contaminantes: (1) isomerização e conjugação de duplas; (2) Reação tipo Diels-Alder; (3) reação tipo radicalar.

Figura 2.7 - Pirólise dos TAGs: craqueamento primário via: (1) mecanismo de eliminação de H beta do fragmento glicerol; (2) mecanismo de eliminação de H gama na cadeia do AG. Compostos químicos: (A) TAG, (B) ácido carboxílico, (C) acroleína, (D) ceteno, (E) hidrocarbonetos saturados, (F) triacetin e (G) enol.

Figura 2.8 - Desoxigenação dos ácidos carboxílicos AG via descarboxilação (A) e descarbonilação (B).

Figura 2.9 - Mecanismo alternativo da decomposição do AG.

Figura 2.10 - Esquema da decomposição do EM.

Figura 3.1 - Sistemas utilizados no processo de polimerização/pirólise dos TAGs e seus derivados: na presença (A) e ausência (B) de agitação mecânica. Sistemas compostos por: reator de vidro (1), manta de aquecimento (2), termopar (3), fluxo de $\mathrm{N}_{2}$ (4), condensador (5), recipiente para a obtenção de bio-óleo (6), seringa para retirar alíquotas e agitador mecânico (8).

Figura 4.1 - IV-KBr dos complexos metálicos: (A) Ni(acetato) $)_{2}$, (B) $\mathrm{Zn}(\text { acetato })_{2}$, (C) $\mathrm{Cu}(\text { acetato })_{2}$, (D) $\mathrm{Mn}\left((\text { acetato })_{2} \text {, (E) } \mathrm{Pb} \text { (acetato }\right)_{2}$ e (F) $\mathrm{Al}$ (acetato $)_{3}$.

Figura 4.2 - Análise Termogravimétrica dos complexos metálicos. (A): - Ni(acetato) $)_{2}$, - $\mathrm{Cu}(\text { acetato })_{2} \mathrm{e}-$ $\mathrm{Al}(\text { acetato })_{3}$. (B): - $\mathrm{Pb}$ (acetato $)_{2},-\mathrm{Zn}(\text { acetato })_{2},-\mathrm{Mn}(\text { acetato })_{2} \mathrm{e}-\mathrm{Co}$ (acetato $)_{2}$.

Figura 4.3 - Massa residual do polímero (A) e bio-óleo (B) na ausência de catalisador $(\mathbf{\square}), \operatorname{Pb}(\text { acetato })_{2}(\bullet)$, $\mathrm{Ni}(\text { acetato })_{2}(), \mathrm{Cu}(\text { acetato })_{2}(\triangleright), \operatorname{Al}(\text { acetato })_{3}(\triangleleft), \mathrm{Zn}(\text { acetato })_{2}(\triangle)$ e $\operatorname{Mn}(\text { acetato })_{2}(\nabla)$. Reações realizadas no período de $1 \mathrm{~h}$. Reações na ausência de agitação.

Figura 4.4 - Viscosidade dos polímeros obtidos no balanço de massa: Reação na ausência de catalisador (ש), na presença de $\mathrm{Pb}(\text { acetato })_{2}(\bullet), \mathrm{Ni}(\text { acetato })_{2}(*), \mathrm{Cu}(\text { acetato })_{2}(\triangleright), \operatorname{Al}(\text { acetato })_{3}(\varangle), \operatorname{Mn}(\text { acetato })_{2}(\Delta)$ e $\mathrm{Zn}(\text { acetato })_{2}(\boldsymbol{\nabla})$.Reações na ausência de agitação.

Figura 4.5 - Viscosidade dos polímeros obtidos nas reações de 2 h a $330{ }^{\circ} \mathrm{C}$ : Reação na ausência de catalisador $(\bullet)$, na presença de $\mathrm{Pb}(\text { acetato })_{2}(\bullet), \mathrm{Ni}(\text { acetato })_{2}(*), \mathrm{Cu}(\text { acetato })_{2}(\triangleright), \operatorname{Al}(\text { acetato })_{3}(\varangle), \operatorname{Mn}(\text { acetato })_{2}(\triangle)$ e $\mathrm{Zn}(\text { acetato })_{2}(\boldsymbol{\nabla})$.Reações na ausência de agitação. 
Figura 4.6 - Porcentagem da área total do cromatograma relacionados com (A) Ácidos carboxílicos, (B) hidrocarbonetos saturados, (C) hidrocarbonetos insaturados, compostos contendo em sua estrutura a faixa de carbonos de (D) 5-7, (E) 8-10 e (F) 11-17. Reações sem agitação na ausência de catalisador (ロ) e na presença dos catalisadores: $\mathrm{Pb}(\text { acetato })_{2}(\bullet), \mathrm{Ni}(\text { acetato })_{2}(), \mathrm{Cu}(\text { acetato })_{2}(\triangleright), \operatorname{Al}(\text { acetato })_{3}(\varangle), \operatorname{Mn}(\text { acetato })_{2}(\triangle)$ e $\mathrm{Zn}(\text { acetato })_{2}(\nabla)$.

Figura 4.7 - Porcentagem da área total do cromatograma relacionada com os seguintes compostos: (A) Ácido heptanóico, (B) ácido palmítico, (C) ácido decanóico e (D) undeceno. Reações sem agitação na ausência de

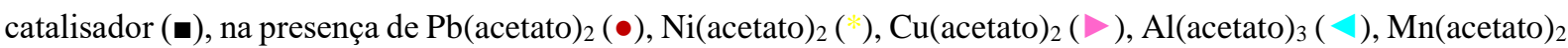
$(\Delta)$ e $\mathrm{Zn}(\text { acetato })_{2}(\boldsymbol{\nabla})$.

Figura 4.8 - Índice de acidez (A) e viscosidade (B) do bio-óleo: Reação sem agitação na ausência de catalisador

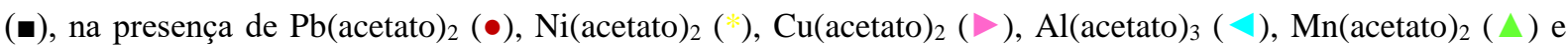
$\mathrm{Zn}(\text { acetato })_{2}(\nabla)$.

Figura 4.9 - Difratograma de Raios X do precipitado obtido na reação utilizando Ni(acetato) 2 . Em vermelho os picos característicos de carbeto de $\mathrm{Ni}$ e em azul os característicos de $\mathrm{Ni}^{0}$.

Figura 4.10 - Difratograma de Raios X do precipitado obtido na reação utilizando Cu(acetato) 2 . Em vermelho os picos característicos do $\mathrm{Cu}^{0}$.

Figura 4.11 - Espectros obtidos por IV-ATR dos precipitados obtidos utilizando os seguintes catalisadores: (1)

$\mathrm{Zn}$ (acetato $)_{2},(2) \mathrm{Ni}$ (acetato $)_{2}$ e (1) $\mathrm{Cu}$ (acetato $)_{2}$.

Figura 4.12 - Viscosidade dos polímeros obtidos em reações sem agitação na ausência (A) e na presença (B) de

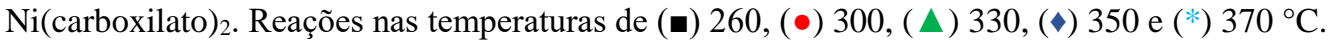

Figura 4.13 - Índice de acidez dos polímeros obtidos em reações sem agitação na ausência (A) e na presença (B)

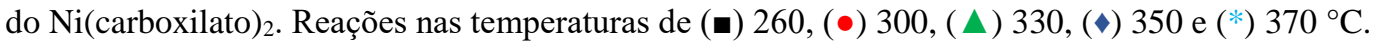

Figura 4.14 - Absorbâncias relacionadas às duplas ligações conjugadas na conformação trans-trans em $987 \mathrm{~cm}^{-1}$ na ausência (A) e na presença (B) do Ni(carboxilato) ${ }_{2}$. Reações sem agitação nas temperaturas de (•) 260, (•) 300, ( $\Delta$ ) $330,(\diamond) 350 \mathrm{e}(*) 370{ }^{\circ} \mathrm{C}$.

Figura 4.15 - Absorbância em $1741 \mathrm{~cm}^{-1}$ relacionada a carbonila de grupo éster (A, B) e absorbância em 1708 $\mathrm{cm}^{-1}$ relacionada a carbonila de ácido carboxílico (C, D). Na ausência (A, C) e na presença (B, D) de

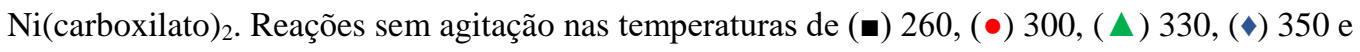
$370{ }^{\circ} \mathrm{C}$.

Figura 4.16 - Difratograma de Raios X do precipitado obtido na reação utilizando Ni(acetato) 2 . Em vermelho os picos característicos de carbeto de $\mathrm{Ni}$ e em azul os característicos de $\mathrm{Ni}^{0}$. 38

Figura 4.17 - Exemplo de um cromatograma obtido do bio-óleo de óleo de soja.

Figura 4.18 - Presença do ácido heptadecanóico nas amostras de bio-óleo na ausência (A) e presença (B) de

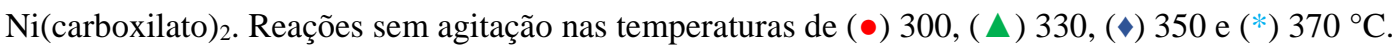

Figura 4.19 - Porcentagem de pentadecano nas amostras de bio-óleo na ausência (A) e presença (B) de $\mathrm{Ni}\left(\right.$ carboxilato)2. Reações sem agitação nas temperaturas de (•) 300, ( $\Delta$ ) 330, (•) 350 e (*) $370{ }^{\circ} \mathrm{C}$.

Figura 4.20 - Porcentagem de heptadecano nas amostras de bio-óleo na ausência (A) e presença (B) de $\mathrm{Ni}$ (carboxilato) 2 . Reações sem agitação nas temperaturas de (•) 300, (ム) 330, (•) 350 e (*) $370{ }^{\circ} \mathrm{C}$.

Figura 4.21 - Índice de acidez das amostras de bio-óleo obtidas na ausência (A) e presença (B) de Ni(carboxilato) ${ }_{2}$. Reações sem agitação a $(\bullet) 300{ }^{\circ} \mathrm{C}$; ( $\Delta$ ) $330{ }^{\circ} \mathrm{C}$; (•) $350{ }^{\circ} \mathrm{Ce}(*) 370{ }^{\circ} \mathrm{C}$. 
Figura 4.19 - Porcentagem de pentadecano nas amostras de bio-óleo na ausência (A) e presença (B) de

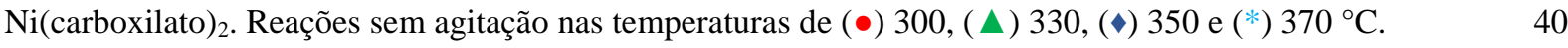

Figura 4.20 - Porcentagem de heptadecano nas amostras de bio-óleo na ausência (A) e presença (B) de

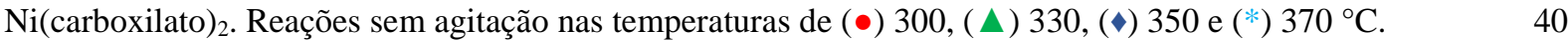

Figura 4.21 - Índice de acidez das amostras de bio-óleo obtidas na ausência (A) e presença (B) de Ni(carboxilato) ${ }_{2}$. Reações sem agitação a (•) $300{ }^{\circ} \mathrm{C}$; ( $\Delta$ ) $330{ }^{\circ} \mathrm{C}$; (•) $350{ }^{\circ} \mathrm{C}$ e $(*) 370{ }^{\circ} \mathrm{C}$.

Figura 5.1 - Viscosidade do AG na ausência (A) e na presença (B) de Ni(carboxilato) ${ }_{2}$. Reações sem agitação a (匹) $260{ }^{\circ} \mathrm{C},(\bullet) 300{ }^{\circ} \mathrm{C},(\Delta) 330{ }^{\circ} \mathrm{C}$ e $(\diamond) 350{ }^{\circ} \mathrm{C}$.

Figura 5.2 - Índice de acidez dos AGs obtidos em reações sem agitação nas temperaturas de (ロ) $260{ }^{\circ} \mathrm{C},(\bullet) 300$

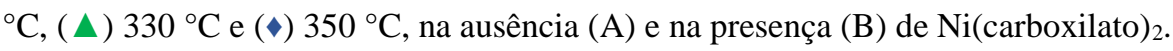

Figura 5.3 - Absorbâncias relacionadas às duplas ligações conjugadas na conformação trans-trans em $987 \mathrm{~cm}^{-1}$. Reações sem agitação na ausência (A) e na presença (B) do Ni(carboxilato) 2 . Reações a (•) $260^{\circ} \mathrm{C},(\bullet) 300^{\circ} \mathrm{C}$,

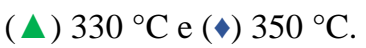

Figura 5.5 - Absorbância em $1708 \mathrm{~cm}^{-1}$ (A e B) relacionada a carbonila de grupo ácido carboxílico e em 1818 $\mathrm{cm}^{-1}(\mathrm{C}, \mathrm{D})$ relacionada a carbonila de anidrido. Reações na ausência de agitação, na ausência (A, C) e na presença

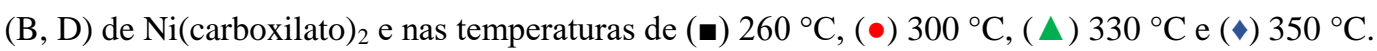

Figura 5.6 - Absorbância em $2982 \mathrm{~cm}^{-1}$ relacionada $\mathrm{CH}_{2} \mathrm{sp}^{3}$ na ausência (A) e na presença (B) do Ni(carboxilato) 2 .

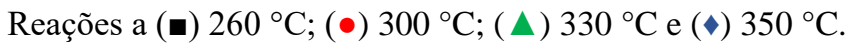

Figura 5.7 - IV-ATR do ácido carboxílico (A) utilizado como matéria prima e das amostras obtidas a $350{ }^{\circ} \mathrm{C}$ no tempo de $4 \mathrm{~h}$ na ausência (B) e presença de Ni(carboxilato) $)_{2}(\mathrm{C})$.

Figura 5.8 - Composição em porcentagem relativa dos bio-óleos obtidos a partir dos AGs de soja: (A) Ácidos carboxílicos totais; (B) hidrocarbonetos totais; (C) hidrocarbonetos saturados; (D) hidrocarbonetos insaturados. Reações sem agitação, na temperatura de $330^{\circ} \mathrm{C}$ na ausência (•) e presença de catalisador $(\bullet)$, e reações a $350{ }^{\circ} \mathrm{C}$ na ausência $(\Delta)$ e presença de catalisador $(\diamond)$.

Figura 5.9 - Concentrações relativas dos ácidos decanóicos (A) e pentadeceno (B) presentes nos bio-óleos obtidos dos AGs de soja. Reações sem gitação na temperatura de $330^{\circ} \mathrm{C}$ na ausência $(\mathbf{\square})$ e presença de catalisador $(\bullet)$, e reações a $350{ }^{\circ} \mathrm{C}$ na ausência $(\Delta)$ e presença de catalisador $(\diamond)$.

Figura 5.10 - Índice de acidez dos bio-óleos obtidos nas reações sem agitação na ausência (•) e presença (•) de catalisador na temperatura de $330{ }^{\circ} \mathrm{C}$ e bio-óleos obtidos na ausência $(\Delta)$ e presença $(\diamond)$ de catalisador a $350{ }^{\circ} \mathrm{C}$.

Figura 6.1 - Viscosidade dos EMs obtidos na ausência (A) e na presença (B) de Ni(carboxilato) ${ }_{2}$. Reações na ausência de agitação nas temperaturas de $(\bullet) 260{ }^{\circ} \mathrm{C},(\bullet) 300{ }^{\circ} \mathrm{C},(\Delta) 330{ }^{\circ} \mathrm{C}$ e (४) $350{ }^{\circ} \mathrm{C}$.

Figura 6.2 - Índice de acidez das reações com os EMs, sem agitação, nas temperaturas de (•) $260{ }^{\circ} \mathrm{C},(\bullet) 300^{\circ} \mathrm{C}$, ( $\Delta$ ) $330{ }^{\circ} \mathrm{C} \mathrm{e} \mathrm{( \diamond )} 350^{\circ} \mathrm{C}$ na ausência (A) e na presença (B) de Ni(carboxilato) 2 .

Figura 6.3 - Absorbâncias relacionadas às duplas ligações conjugadas na conformação trans-trans em $987 \mathrm{~cm}^{-1}$ na ausência (A) e na presença (B) do $\mathrm{Ni}$ (carboxilato) 2 . Reações sem agitação nas temperaturas de (ロ) $260{ }^{\circ} \mathrm{C}$; (•) $300{ }^{\circ} \mathrm{C} ;(\Delta) 330{ }^{\circ} \mathrm{C}$ e $(\diamond) 350{ }^{\circ} \mathrm{C}$.

Figura 6.4 - Absorbância em $1743 \mathrm{~cm}^{-1}$ relacionada a carbonila de grupo éster (A, B) e absorbância em $1708 \mathrm{~cm}^{-}$ ${ }^{1}$ relacionada a carbonila de ácido carboxílico $(\mathrm{C}, \mathrm{D})$. Na ausência $(\mathrm{A}, \mathrm{C})$ e na presença $(\mathrm{B}, \mathrm{D})$ de $\mathrm{Ni}(\text { carboxilato })_{2}$. 
Figura 6.5 - Absorbância em $2982 \mathrm{~cm}^{-1}$ relacionada $\mathrm{CH}_{2} \mathrm{sp}^{3}$ na ausência (A) e na presença (B) do Ni(carboxilato) 2 . Reações sem agitação nas temperaturas de (•) $260^{\circ} \mathrm{C},(\bullet) 300^{\circ} \mathrm{C},(\Delta) 330{ }^{\circ} \mathrm{C}$ e (४) $350{ }^{\circ} \mathrm{C}$.

Figura 6.6 - Composição em porcentagem relativa dos principais grupos de compostos observados: (घ) Ésteres metílicos, $(\bullet)$ hidrocarbonetos totais, $(\Delta)$ hidrocarbonetos saturados, $(\diamond)$ hidrocarbonetos insaturados e $\left(^{*}\right)$ ácidos carboxílicos. Reações sem agitação na (A) ausência e (B) presença de Catalisador na temperatura de 350 ${ }^{\circ} \mathrm{C}$.

Figura 6.7 - Concentração dos principais ésteres de metila obtidos na reação sem agitação a $350{ }^{\circ} \mathrm{C}$ na presença de catalisador: $(\boldsymbol{\bullet})$ octadecenoato de metila, $(\bullet)$ undecenoato de metila, $(\boldsymbol{\Delta})$ decadienoato de metila, $(\diamond)$ nonoato de metila e $\left(^{*}\right)$ heptanoato de metila.

Figura 6.8 - Concentração dos principais hidrocarbonetos obtidos na reação sem agitação, a temperatura de 350 ${ }^{\circ} \mathrm{C}$ e presença de catalisador: $(\boldsymbol{\square})$ undeceno, $(\bullet)$ hexadeceno, $(\Delta)$ octano, $(\diamond)$ nonano e $\left(^{\star}\right)$ tetradeceno.

Figura 6.9 - Índice de acidez dos bio-óleos obtidos nas reações sem agitação na temperatura de $350{ }^{\circ} \mathrm{C}$ na (घ) ausência e $(\bullet)$ presença de catalisador de $\mathrm{Ni}^{2+}$.

Figura 7.1 - Análises de viscosidade (A) e índice de acidez (B) nas reações sem agitação a $300{ }^{\circ} \mathrm{C}$ utilizando

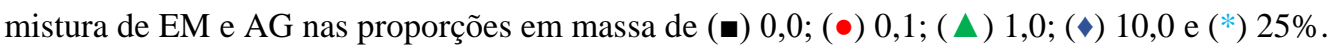

Figura 7.2 - Absorbâncias nos números de onda relacionados com carbonilas dos grupos éster (A) e ácidos carboxílicos (B), assim como duplas ligações totais (C), na conformação cis não conjugada (D), conformação trans (E) e trans-trans conjugadas (F). Reações sem agitação, na temperatura de $300{ }^{\circ} \mathrm{C}$ contento misturas de TAGs e

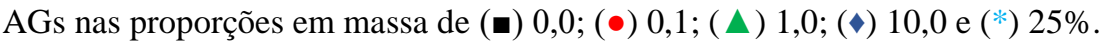

Figura 7.3 - Possíveis reações na polimerização dos EMs na presença de AGs.

Figura 7.4 - Analises de viscosidade (A) e índice de acidez (B) das reações sem agitação a temperatura de $300{ }^{\circ} \mathrm{C}$ contendo TAGs e AGs nas proporções em massa de (ロ) 0,$0 ;(\bullet) 0,1 ;(\Delta) 1,0 ;(\bullet) 10,0$ e (*) 25\%. 64

Figura 7.5 - Absorbâncias nos números de onda relacionados com carbonilas dos grupos éster (A) e ácidos carboxílicos (B), assim como duplas ligações totais (C), na conformação cis não conjugada (D), conformação trans (E) e trans-trans conjugadas (F). Reações sem agitação na temperatura de $300{ }^{\circ} \mathrm{C}$ contento TAGs e AGs nas relações em massa de $(\boldsymbol{\bullet}) 0,0 ;(\bullet) 0,1 ;(\Delta) 1,0 ;(\diamond) 10,0$ e (*) $25 \%$.

Figura 7.6 - Reações de polimerização/pirólise dos TAGs na presença de AGs.

Figura 7.7 - Análises de viscosidade (A) e índice de acidez (B) nas reações sem agitação, a $300{ }^{\circ} \mathrm{C}$ contendo

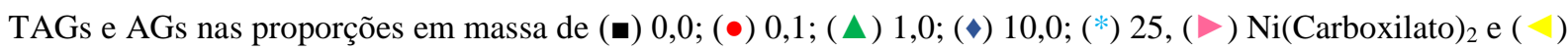
$\mathrm{H}_{3} \mathrm{PO}_{4}$.

Figura 7.8 - Absorbâncias nos números de onda relacionados com carbonilas dos grupos éster (A) e ácidos carboxílicos (B), assim como duplas ligações totais (C), na conformação cis não conjugada (D), conformação trans (E) e trans-trans conjugadas (F). Reações sem agitação, a $300{ }^{\circ} \mathrm{C}$ contento EM puro (匹) e na presença de $\mathrm{Ni}(\text { Carboxilato })_{2}(\triangleright)$ e $\mathrm{H}_{3} \mathrm{PO}_{4}(4)$.

Figura 7.9 - Análises de viscosidade (A) e índice de acidez (B) das reações sem agitação a $300{ }^{\circ} \mathrm{C}$ utilizando TAGs puro (ם), na presença de $\mathrm{Ni}(\text { Carboxilato })_{2}(\triangleright)$ e $\mathrm{H}_{3} \mathrm{PO}_{4}(\hookrightarrow)$. 
Figura 7.10 - Absorbâncias nos números de onda relacionados com carbonilas dos grupos éster (A) e ácidos carboxílicos (B), assim como duplas ligações totais (C), na conformação cis não conjugada (D), conformação trans (E) e trans-trans conjugadas (F). Reações sem agitação a $300{ }^{\circ} \mathrm{C}$ contento EM puro (घ) e na presença de $\mathrm{Ni}(\text { Carboxilato })_{2}(\triangleright)$ e $\mathrm{H}_{3} \mathrm{PO}_{4}(4)$.

Figura 7.11 - Reações de polimerização/pirólise dos TAGs na presença de $\mathrm{Ni}\left(\right.$ Carboxilato) ${ }_{2}$ e $\mathrm{H}_{3} \mathrm{PO}_{4}$.

Figura 7.12 - Absorbâncias nos números de onda relacionados com carbonilas dos grupos éster (A), de ácidos carboxílicos (B) e carboxilatos (C), assim como duplas ligações totais (D), na conformação trans (E) e trans-trans conjugadas (F). Reações sem agitação a $300{ }^{\circ} \mathrm{C}$ com TAG puro (•), $\mathrm{Ca}(\mathrm{OH})_{2} 0,1 \%(\bullet) ; \mathrm{Ca}(\mathrm{OH})_{2} 1,0 \%(\Delta) \mathrm{CaCO}$ $5 \%(\diamond)$.

Figura 8.1 - Balanço de massa do processo de polimerização/pirólise por $1 \mathrm{~h}$ em sistema com agitação mecânica utilizando como matéria prima os (A) OGRs e (B) óleo de soja refinado. Massa percentual dos polímeros na ( ausência e $(\bullet)$ presença de catalisador e bio-óleo $(\Delta)$ na ausência e $(\boldsymbol{\nabla})$ presença de catalisador.

Figura 8.2 - Análises de (A) viscosidade e (B) índice de acidez dos polímeros obtidos nas reações com agitação mecânica utilizando como matéria prima os OGRs na (•) ausência e na (•) presença de catalisador e óleo de soja refinado na $(\Delta)$ ausência e $(\boldsymbol{\nabla})$ presença de catalisador. 


\section{Lista de Tabelas}

Tabela 2.1- AGs predominantes nas principais oleaginosas. ${ }^{25} 10$

Tabela 4.1 - Valores de $\mathrm{mg} / \mathrm{kg}_{\text {óleo }}$ e $\mathrm{mmol} / \mathrm{kg}_{\text {óleo }}$ usados como referência nas reações catalíticas. 26

Tabela 8.1 - Produtos detectados nos bio-óleos produzidos a partir da pirólise. 77

Tabela 8.2 - Análises de composição química dos bio-óleos formados nas reações com agitação mecânca em diferentes temperaturas com OGRs e óleo de soja refinado sem catalisador e na presença de $\mathrm{Ni}^{2+}$. 77

Tabela 8.3 - Análises físico-químicas dos bio-óleos e valores de referência do Diesel de petróleo. 78 


\section{Capítulo 1}

Introdução Geral e Objetivos 


\subsection{Introdução geral}

Com a crise do abastecimento de petróleo na década de 1970, pesquisadores foram encorajados a desenvolver produtos que utilizavam os derivados de oleaginosas como matériaprima. Particularmente, foi estimulada a utilização dos triacilglicerídeos e derivados em processos a altas temperaturas com o objetivo de produzir compostos com variadas massa molares, tendo como objetivo a substituição de derivados do petróleo em formulações de combustíveis, lubrificantes, tintas, aditivos e outros. ${ }^{1}$

Inicialmente, são denominadas oleaginosas as plantas que possuem a capacidade de armazenamento de energia através da produção dos triacilglicerídeos (TAGs), principalmente armazenados em suas sementes. Devido à possibilidade de extração, as oleaginosas passaram a ser amplamente cultivadas ao longo da história e devido ao aumento da demanda no século XX, houve uma busca por espécies que gerassem sementes com alto teor de TAGs e que pudessem ser produzidas em larga escala. Entre elas, destacam-se as espécies comumente chamadas de algodão, palma, amendoim, coco, canola, girassol e soja.

Ao avaliar a produção mundial de oleaginosas (Figura 1.1), é observado que o valor supera 400 milhões de toneladas e que a semente de soja representa aproximadamente $70 \%{ }^{2}$ Esta produção ainda pode ser ampliada devido a possibilidade de expansão da fronteira agrícola e pelo aumento de produtividade por hectare. Entre as regiões produtoras (Figura 1.2), a América do sul se destaca por produzir de mais de 1/3 de todas as oleaginosas no período de 2014 a 2015.

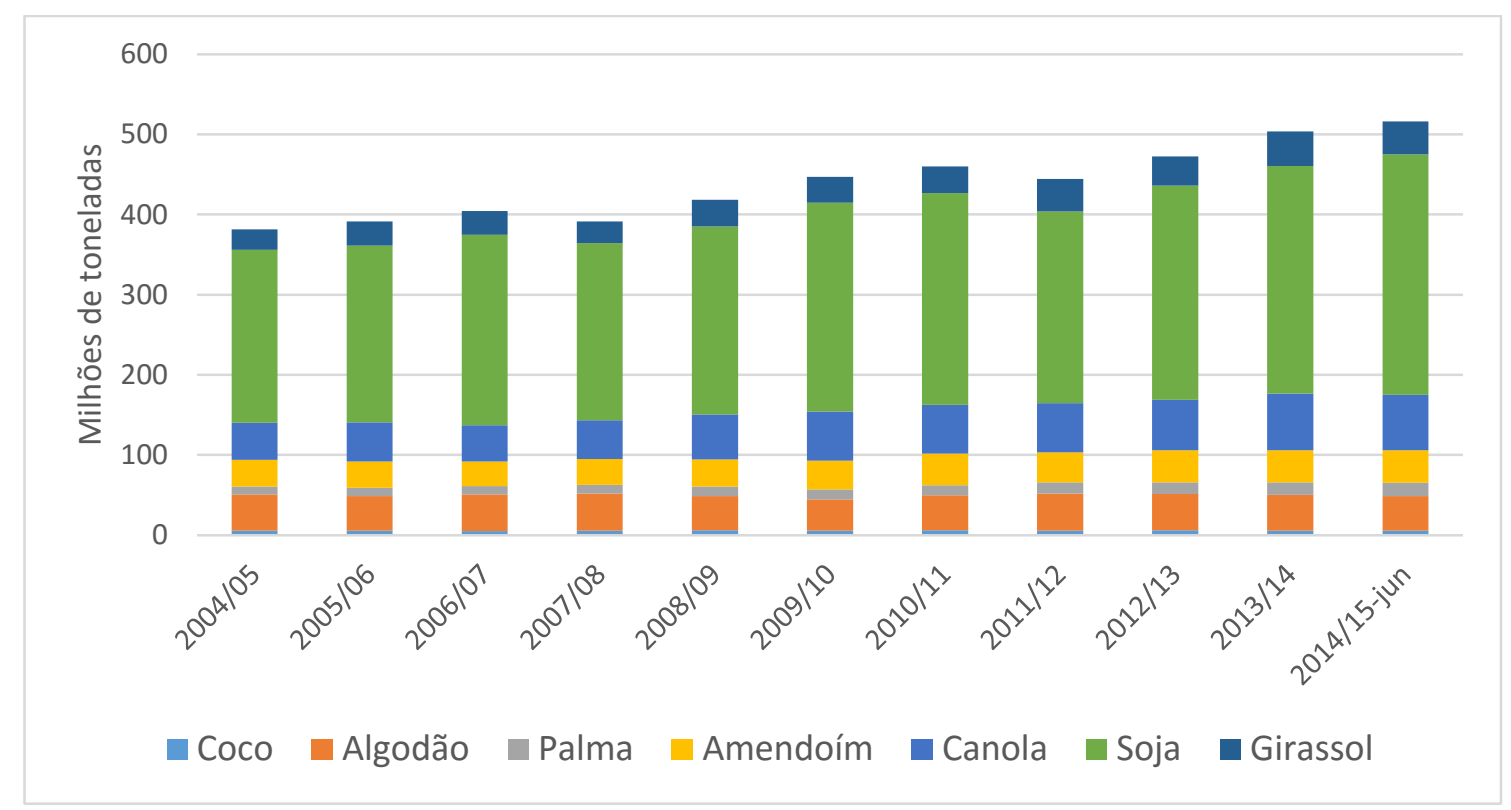

Figura 1.1 - Produção mundial de oleaginosas na última década. ${ }^{2}$ 


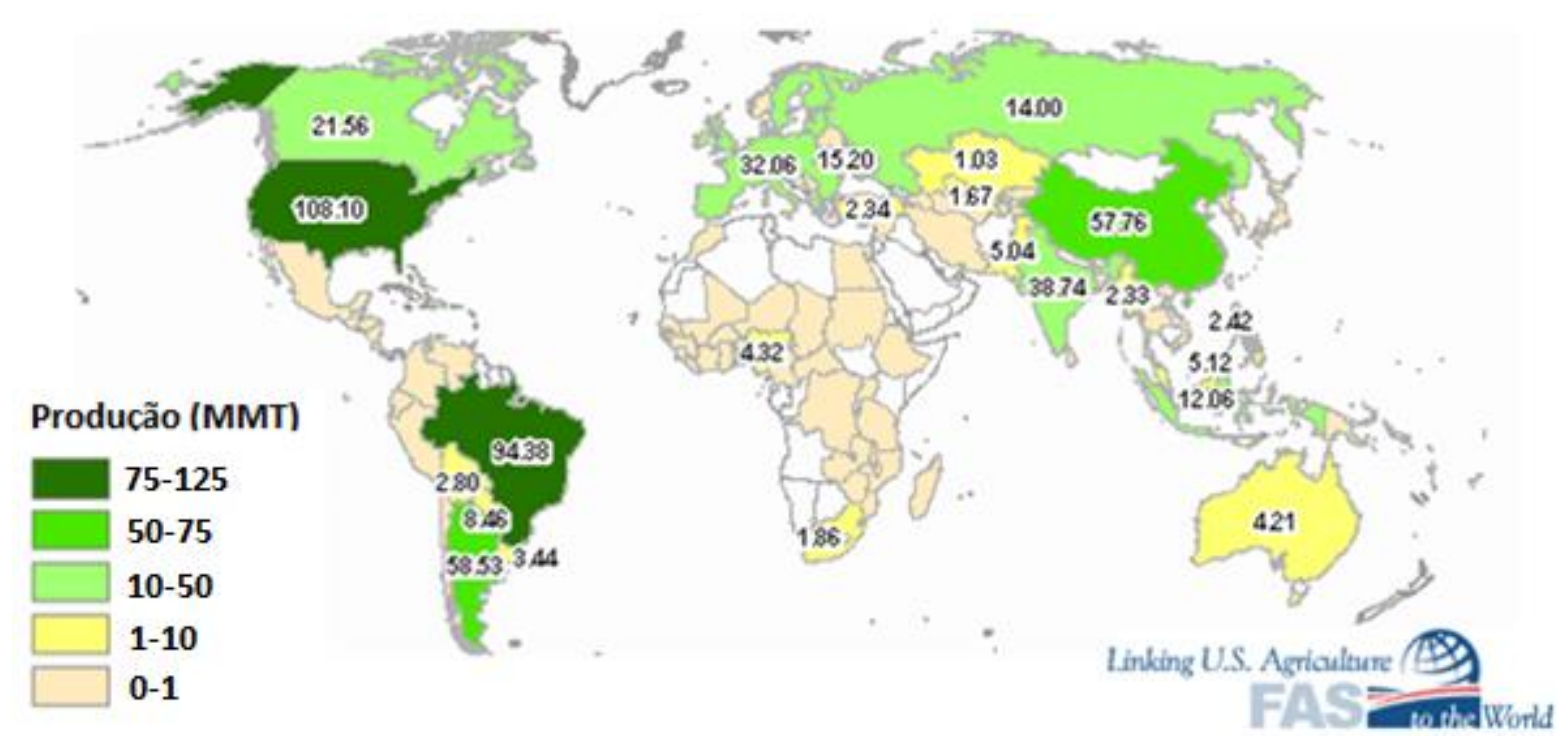

Figura 1.2 - Produção de oleaginosas por país no período de 2014/2015, adaptado de United States Department of Agriculture. ${ }^{2}$

Os TAGs podem ser obtidos após processos que envolvem inicialmente a extração, degomagem e neutralização. Sua produção vem crescendo ano após ano e se encontra principalmente associada a expansão do cultivo da soja e de diferentes tipos de palma. A produção mundial do período entre 2010 e 2015 pode ser observada na Figura 1.3.

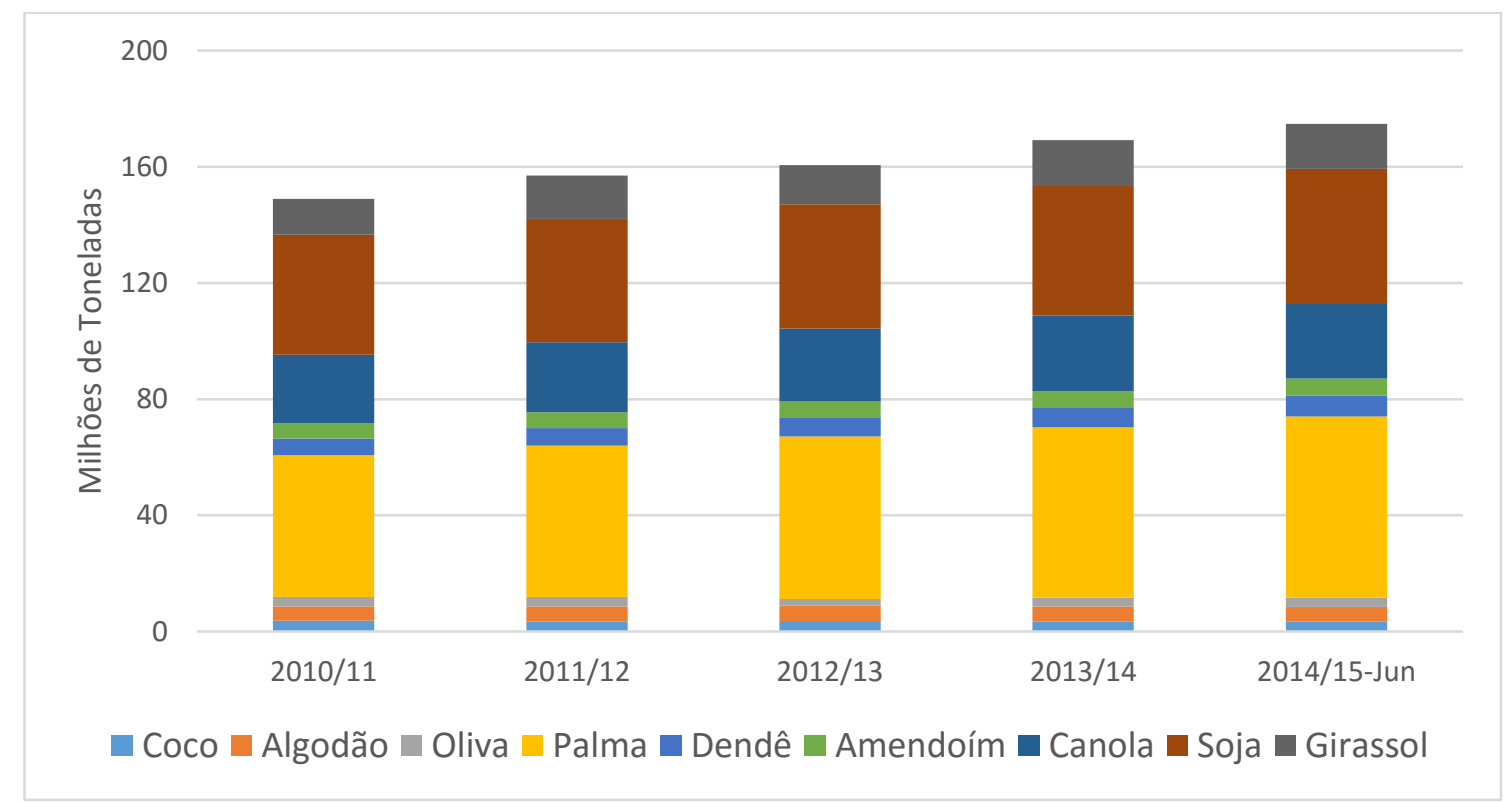

Figura 1.3 - Produção mundial dos TAGs no período entre 2010 e $2015 .^{2}$

Entre os vários fatores que influenciaram a expansão da produção de oleaginosas, destaca-se o desenvolvimento de tecnologias que possibilitaram a utilização dos Ésteres Metílicos (EMs) e Ésteres Etílicos (EEs) na substituição completa ou parcial do diesel de 
petróleo em motores de combustão interna. Estes compostos são obtidos principalmente pela transesterificação dos triacilgicerídeos com metanol e etanol e obtenção dos EM e EE, respectivamente.

Entre os dois, se destaca o EM como o mais produzido mundialmente devido a menores custos e facilidade de produção. ${ }^{1}$ Além de substituir o diesel, podem também sofrer modificações químicas para obtenção de diferentes combustíveis líquidos e gasosos, solventes, aditivos e outros. ${ }^{3-7}$ Os dados da produção mundial dos EM (Figura 1.4) demonstram que no período entre 2003 e 2015 ocorreu uma expansão de aproximadamente 25 mil toneladas e, de acordo com projeções de mercado até 2022, a produção mundial poderá superar a barreira das 40 mil toneladas. $^{8}$

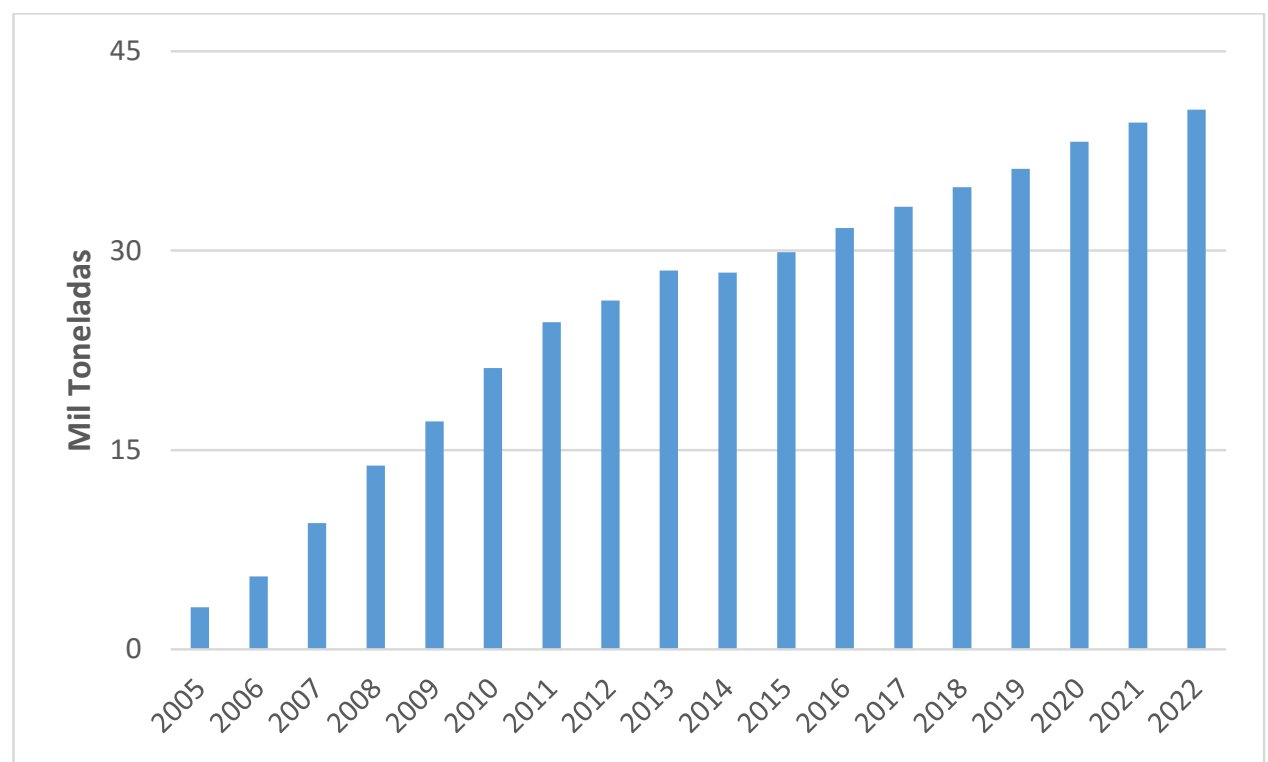

Figura 1.4 - Produção Mundial de EM até 2014 e projeções para os próximos oito anos. ${ }^{8}$

Outro derivado dos TAGs são os chamados Ácidos Graxos (AGs) e estes podem ser obtidos como subproduto do processo de refino, assim como em processos de hidrólise ou saponificação dos TAGs. Entre as possibilidades de obtenção, estima-se que aproximadamente $3 \%$ da massa total dos TAGs in natura são constituídos por AGs e seus respectivos sais. Nos processos industriais, as estimativas do ano de 2011 sugerem que a produção mundial se aproxima das dez mil toneladas por ano, com perspectiva de expansão do mercado em mais 3 mil toneladas para o ano de 2015 (Figura 1.5). ${ }^{9}$ 


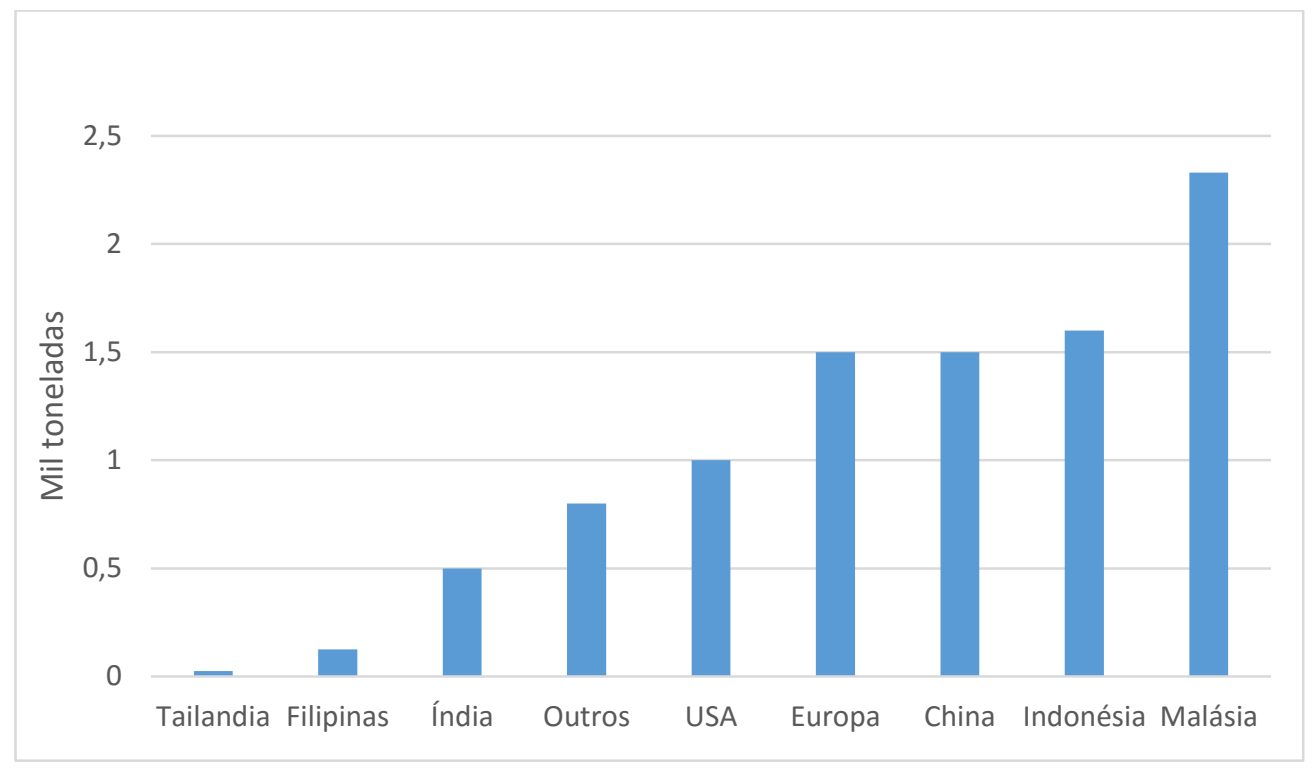

Figura 1.5 - Principais países produtores de AGs no ano de $2011 .^{9}$

Dos TAGs é possível obter também os chamados Óleos e Gorduras Residuais (OGRs), que são uma mistura de compostos químicos obtidos após o uso dos OG refinados em processos industriais, comércios ou em residências. Normalmente, o uso ocorre em condições adversas, como altas temperaturas e/ou em contato com água. ${ }^{10}$ Sua reutilização é particularmente importante, pois se sabe que os OGRs não podem ser diretamente lançados ao meio ambiente devido ao alto impacto ambiental. As estimativas do poder de contaminação de OGRs aceitas pelas empresas de saneamento é que um litro de OGRs contamina até vinte mil litros de efluentes. Além disso, o descarte incorreto pode aumentar em até $40 \%$ os custos das empresas de saneamento na limpeza de depósitos de gorduras em tubulações e galerias fluviais. ${ }^{11} \mathrm{~A}$ estimativa de produção anual dos OGRs reciclados no Brasil é da ordem de 30 milhões de litros ou 24.000 toneladas, incluindo tanto a coleta para processo industrial, como a reciclagem caseira na fabricação de sabão. ${ }^{11}$

Vale mencionar que a utilização dos TAGs para a obtenção de novos compostos químicos são vastas e ainda não atingiram o ápice de uso. Assim, é possível prever que expansão de oferta das oleaginosas ocorrerá por período ainda indeterminado. Este quadro é importante do ponto de vista científico, pois a tendência é o fortalecimento de pesquisas visando novas aplicações e aprimorando às já existentes, principalmente visando à substituição dos derivados do petróleo. 


\subsection{Modificações Químicas dos TAGs, EMs e AGs utilizando o Tratamento Térmico}

Neste estudo, o tratamento térmico é definido como o aquecimento da matéria prima a altas temperaturas, normalmente acima de $300{ }^{\circ} \mathrm{C}$. Assim, ao submeter os TAGs e seus derivados a este tratamento, é possível obter combustíveis, solventes e insumos para confecção de tintas.

O tratamento térmico pode ser explicado quimicamente de duas formas diferentes: (1) através de reações que envolvem a formação de ligações entre as cadeias, por meio dos mecanismos via Diels-Alder ou radicalares, com consequente produção de um polímero com alta viscosidade, normalmente associado a processos em temperatura próxima a $300{ }^{\circ} \mathrm{C}$; (2) pode acarretar na ruptura das ligações através de reações de pirólise, com consequente formação de uma mistura de compostos de baixa massa molar, comumente chamada de bio-óleo. Para isto, são necessárias temperaturas superiores a $350{ }^{\circ} \mathrm{C}$, devido a necessidade de quebra das ligações. ${ }^{12}$

O primeiro relato da obtenção do bio-óleo utilizando TAGs ocorreu durante a segunda guerra mundial, em que foi mencionada a formação uma mistura de diferentes compostos químicos que podem ser utilizados como substituintes do Diesel de petróleo sem alteração nos motores. ${ }^{3}$ Posteriormente, a utilização do tratamento térmico foi estendida para os AGs e os EMs, demonstrando que os produtos obtidos a partir destas novas fontes também podiam ser utilizados como combustíveis. ${ }^{13-21}$

Os relatos da aplicação dos polímeros obtidos a partir dos TAGs para obtenção de novos produtos são mais recentes do que o uso bio-óleo, pois começou a ser utilizado após pesquisas desenvolvidas nas décadas de 1970 e 1980 visando à substituição de derivados de petróleo na composição de tintas de jornais e revistas. Os novos produtos demonstraram viabilidade tanto técnica, quanto econômica, ao serem comparados com os similares obtidos a partir das tradicionais fontes não renováveis. Devido a esses fatores, os produtos utilizando esta tecnologia, batizada de "SoyInk", foram amplamente aceitos pela sociedade e atualmente se encontram presentes em mais de $90 \%$ das gráficas norte-americanas, assim como em $60 \%$ das japonesas. ${ }^{22,23}$

Os estudos encontrados na literatura avaliam os processos de polimerização e de formação de bio-óleo como sendo independentes. Por este motivo, o presente estudo tem como objetivo principal demonstrar como ambas as reações estão relacionadas e são complementares durante a decomposição a altas temperaturas. 


\subsection{Objetivos do Trabalho}

O objetivo deste trabalho é estudar o tratamento térmico dos TAGs, AGs e EMs, a temperaturas superiores a $260{ }^{\circ} \mathrm{C}$, visando relacionar os processos de polimerização e queda das cadeias.

\subsection{Objetivos Específicos}

- Avaliar o perfil reacional durante o tratamento térmico do óleo refinado de soja, AG e EM, através do monitoramento do polímero e do bio-óleo formados durante o tempo reacional.

- Demonstrar a possibilidade do uso dos OGRs como possíveis substituintes do óleo refinado de soja.

- Avaliar íons de metais como possíveis catalisadores para o processo de polimerização e pirólise dos TAGs, AGs, EMs e OGRs.

- Demonstrar a influência da presença dos AGs nas polimerizações dos TAGs e EMs.

- Buscar novas informações dos mecanismos reacionais que envolvem tanto a polimerização quanto a pirólise dos TAGs, AGs e EMs. 


\section{Capítulo 2}

Revisão Bibliográfica 


\subsection{Composição Química e Obtenção dos TAGs, EMs, AGs e OGRs}

A composição química dos TAGs, EMs, AGs e OGRs irá depender da oleaginosa utilizada como matéria-prima. Na composição química dos TAGs in natura, são encontrados corantes, antioxidantes, aldeídos, cetonas, terpenos e outros. Entretanto, a maior parte é constituída por triacilglicerídeos diacilglicerídeos, monoacilglicerídeos e fosfatídeos. Os TAGs in natura são purificados através dos processos de degomagem, desacidificação, clarificação e desodorização, passando a conter alto teor de TAGs em sua composição final. ${ }^{24}$ Quimicamente, os TAGs são constituídos por um resíduo de glicerol ligado a até três AGs através das ligações éster, como demonstrado na Figura 2.1.

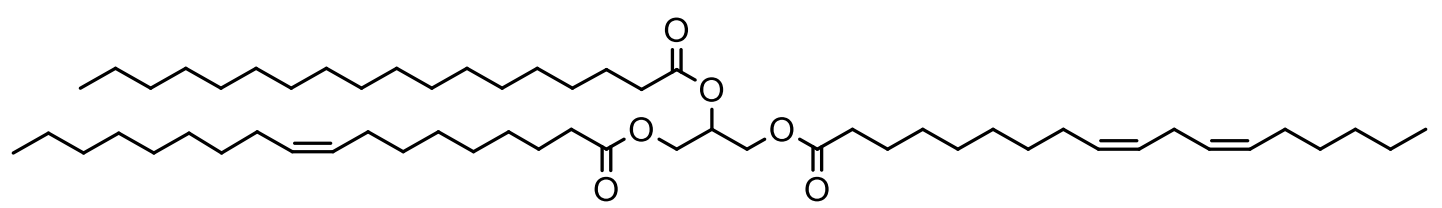

Figura 2.1 - Formula estrutural dos TAGs.

A estrutura dos AGs apresenta algumas peculiaridades, pois são observadas cadeias com até 24 carbonos, sendo usualmente múltiplos de 2. Caso os AGs possuam duplas ligações, encontram-se, na maior parte dos casos, na conformação cis $(\mathrm{Z})$. Quando estão presentes mais de uma insaturação, usualmente se verifica a presença de um grupo metileno $\left(-\mathrm{CH}_{2}-\right)$ entre elas, sendo raramente encontrados AGs com duplas conjugadas. Estas características podem ser observadas na Figura 2.2, em que são encontrados os principais AGs presentes na composição química dos TAGs.

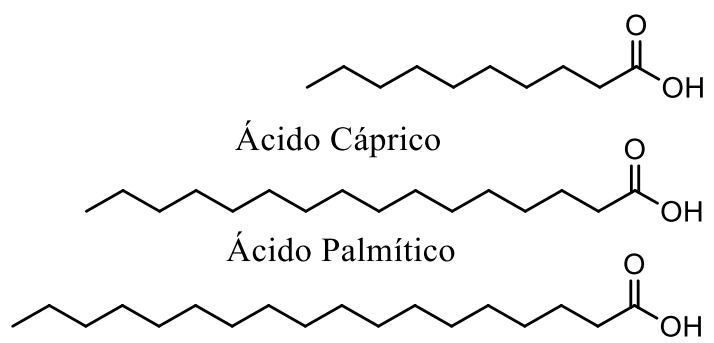

Ácido Esteárico

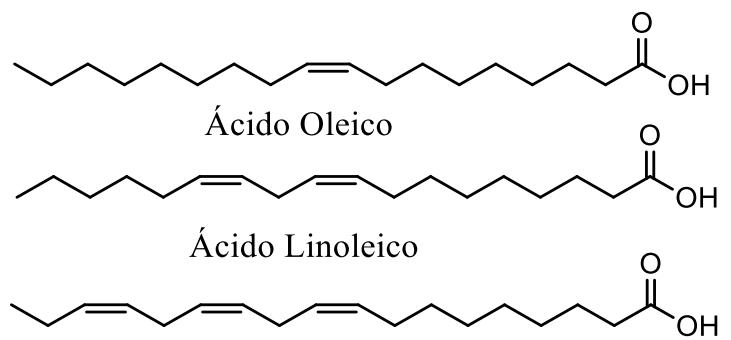

Ácido Linolênico

Figura 2.2 - Formula estrutural dos AGs encontrados nos TAGs.

A porcentagem de cada AG nos TAGs irá depender da fonte de matéria prima e das condições do plantio e colheita. Por estes motivos, a composição dos AGs em cada óleo é representada por faixas de porcentagem (Tabela 2.1). Por exemplo, o óleo de soja possui o ácido linoléico como predominante, podendo apresentar entre 44 a $62 \%$ em sua composição. ${ }^{25}$ 
Tabela 2.1- AGs predominantes nas principais oleaginosas. ${ }^{25}$

\begin{tabular}{cccc}
\hline & \multicolumn{3}{c}{ AGs Predominantes (\%) } \\
\hline Óleo & Linolênico & Linoléico & Oléico \\
\hline Soja & $4-11$ & $44-62$ & $19-30$ \\
\hline Girassol & $<3$ & $55-75$ & $14-35$ \\
\hline Canola & $5-13$ & $15-30$ & $53-70$ \\
\hline Algodão & $<3$ & $33-59$ & $13-59$ \\
\hline Amendoim & $<1$ & $13-45$ & $35-72$ \\
\hline Palma & $<1$ & $6-15$ & $36-47$ \\
\hline Coco & $<1$ & $1-7$ & $9-20$ \\
\hline
\end{tabular}

Industrialmente, é possível obter os AGs em processos de hidrólise ou saponificação dos TAGs, podendo também ser obtido como subproduto em diversos processos industriais. A hidrólise é mais utilizada industrialmente devido a sua facilidade e obtenção do subproduto glicerol com alto grau de pureza. As condições de hidrólise irão depender da planta utilizada, normalmente ocorrem em temperaturas entre 100 e $250{ }^{\circ} \mathrm{C}$, sob pressão de até 70 bar tanto na presença como na ausência de catalisador. ${ }^{26}$ Nas metodologias alternativas, são citados o uso de enzimas, sistemas supercríticos e ultrassom. ${ }^{27-29}$ A reação de hidrólise pode ser observada na Figura 2.3.

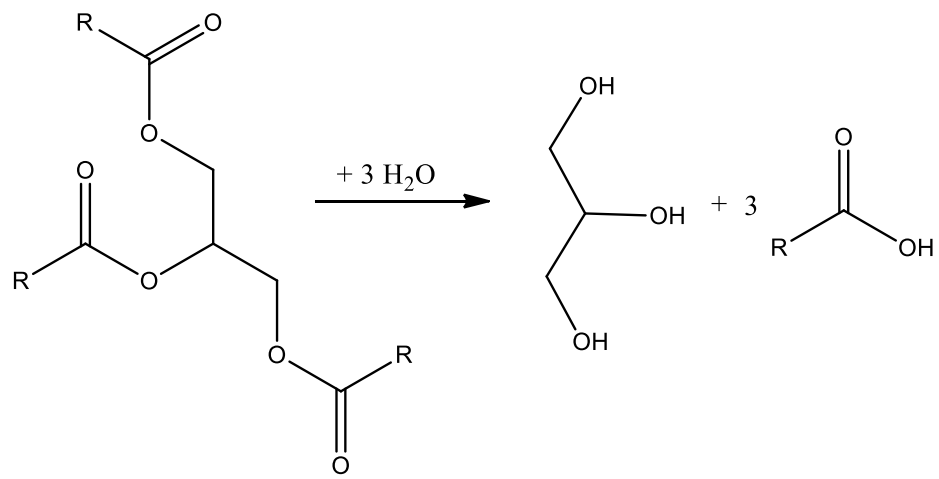

Figura 2.3 - Reação de hidrólise do TAG e obtenção do AG e glicerol.

Os EM, também chamados de biodiesel, podem ser obtidos a partir da reação de transesterificação dos TAGs com os alcoóis metanol ou etanol (Figura 2.4), com a possibilidade de se utilizar catalisadores básicos ou ácidos para a redução do tempo reacional. ${ }^{1}$ Além do uso como substituinte do Diesel, o EM pode também sofrer modificações químicas para obtenção de diferentes combustíveis líquidos e gasosos, solventes, aditivos e outros. ${ }^{3-7}$ 


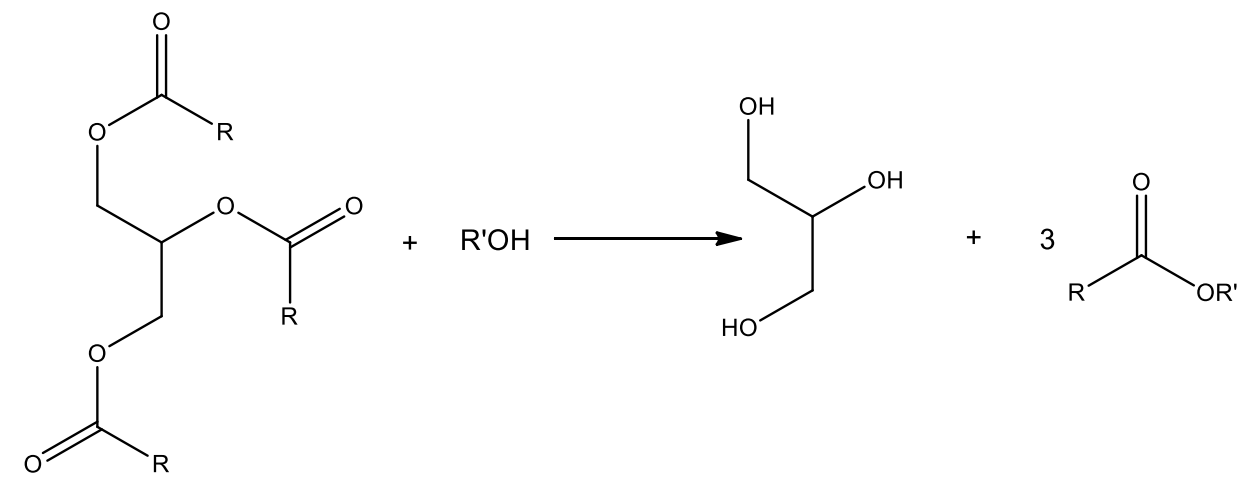

Figura 2.4 - Esquema geral da reação de transesterificação para a obtenção de éster.

Para a obtenção dos OGRs, os TAGs refinados podem sofrer hidrólise quando em contato com água, formando diacilglicerídeos, monoacilglicerídeos glicerol e AGs. Na presença de ar atmosférico (ver Figura 2.5), o $\mathrm{O}_{2}$ tende a reagir com o hidrogênio na posição alílica a dupla ligação, formando radical estabilizado por ressonância (1). Em seguida, pode ocorrer a formação dos chamados hidroperóxidos (2), que são facilmente decompostos com consequente formação de novos compostos químicos (3). Este tipo de reação pode gerar materiais de complexa composição com elevada acidez e viscosidade. ${ }^{11,30}$

(1)

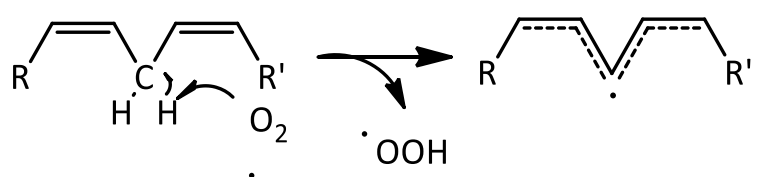

(2)

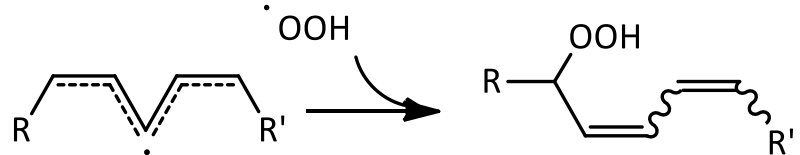

(3)

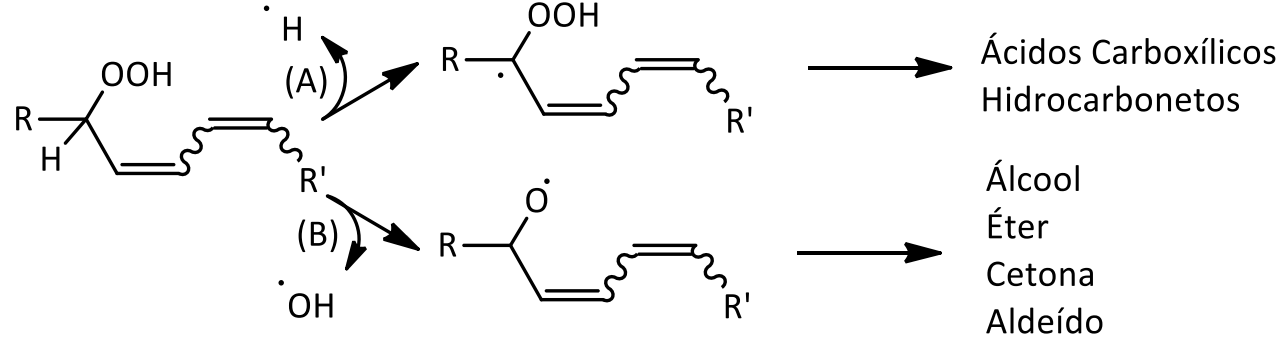

Figura 2.5 - Reações entre os TAGs e o $\mathrm{O}_{2}$ presente no ar atmosférico: (1) Abstração do hidrogênio alílico e formação de radicais estabilizados por ressonância; (2) formação de hidroperóxidos; (3) oxidação da cadeia (A) e decomposição homolítica (B).

\subsection{Modificações Térmicas dos TAGs, EMs, AGs}


As reações químicas envolvendo os TAGs, EMs e AG a altas temperaturas começam em aproximadamente $220^{\circ} \mathrm{C}$, com a mudança da dupla ligação da conformação cis para a trans. Quando na presença de mais de uma dupla ligação, ocorre a isomerização e conjugação levando a estruturas mais estáveis. Ao aumentar a temperatura para aproximadamente $300{ }^{\circ} \mathrm{C}$ é possível observar reações entre cadeias de duas formas diferentes: (1) via radicalar, em que os radicais estabilizados por ressonância reagem entre si formando ligação carbono-carbono; (2) via DielsAlder, que ocorre por meio da reação entre duas duplas conjugadas na conformação trans (dieno) com uma dupla na conformação cis, formando um ciclo-hexeno tetra substituído. Ressalta-se que ambos os processos são dependentes da presença de duplas ligações, sendo mais bem observados ao utilizar cadeias com altos graus de insaturação. Outra possibilidade reacional consiste no (3) encontro de dois radicais para formação de uma ligação propriamente dita. ${ }^{31,32}$ Estas reações podem ser visualizadas na Figura 2.6.

(1)

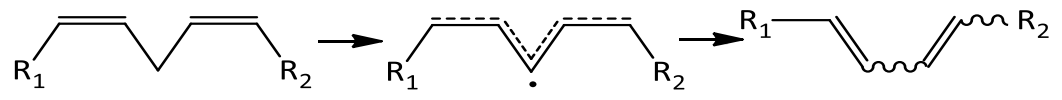

(2)

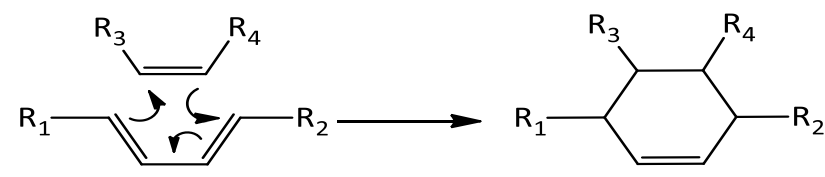

(3)

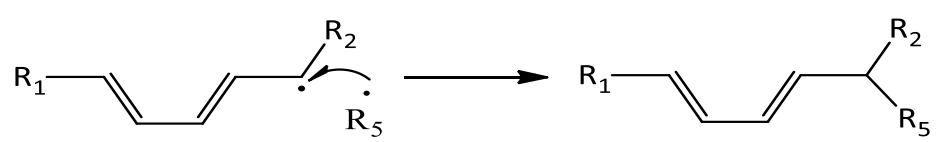

Figura 2.6 - Etapas reacionais do processo de tratamento térmico a altas temperaturas na ausência de contaminantes: (1) isomerização e conjugação de duplas; (2) Reação tipo Diels-Alder; (3) reação tipo radicalar.

Ao aumentar a temperatura para valores próximos a $350{ }^{\circ} \mathrm{C}$, os TAGs, EMs, e AGs podem sofrer uma série de reações químicas chamadas de forma genérica de pirólise ou craqueamento. ${ }^{33,34}$ No caso dos TAGs, as reações podem ser explicadas através das seguintes etapas:

Craqueamento Primário: O mecanismo é complexo e controverso, sendo aceitos dois mecanismos possíveis: (1) A $\beta$-eliminação, a qual se inicia através da reação entre o oxigênio da carbonila com o hidrogênio $\beta$ do resíduo glicerol, gerando ácidos carboxílicos, cetenos e acroleína; ${ }^{32,33}$ (2) A $\gamma$-eliminação, onde é proposta a reação entre o oxigênio ligado à carbonila e um hidrogênio ligado ao carbono $\gamma$ do resíduo AG, gerando hidrocarbonetos insaturados e triacetin (estabilizado pelo equilíbrio ceto-enólico). Entre essas propostas de mecanismo, que 
podem ser visualizadas na Figura 2.7, o $\gamma$ é o menos aceito por não ter sido encontrado traços de triacetin, mas somente produtos gerados na sua decomposição. ${ }^{35}$

(1)

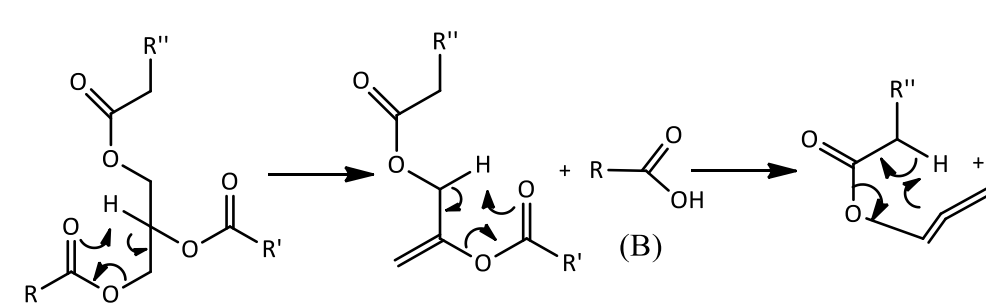

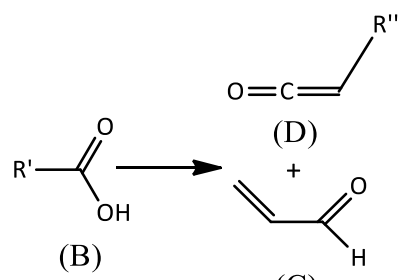

(C)

(A)

(2)

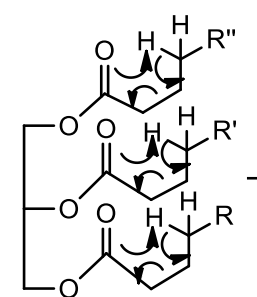

(A)

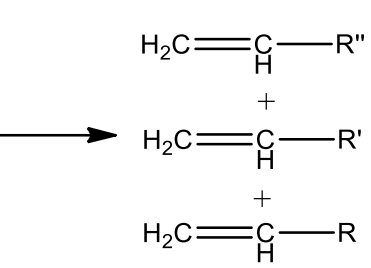

(E)

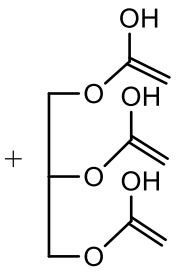

(F)<smiles></smiles>

(G)

Figura 2.7 - Pirólise dos TAGs: craqueamento primário via: (1) mecanismo de eliminação de H beta do fragmento glicerol; (2) mecanismo de eliminação de H gama na cadeia do AG. Compostos químicos: (A) TAG, (B) ácido carboxílico, (C) acroleína, (D) ceteno, (E) hidrocarbonetos saturados, (F) triacetin e (G) enol.

Craqueamento Secundário: O craqueamento secundário consiste na desoxigenação dos ácidos carboxílicos formados na primeira etapa, podendo ocorrer, conforme a Figura 2.8, de duas formas: (A) descarboxilação, em que há a formação de hidrocarbonetos saturados e $\mathrm{CO}_{2} ;(\mathbf{B})$ na descarbonilação, em que ocorre a formação de hidrocarbonetos insaturados, $\mathrm{CO}$ e $\mathrm{H}_{2} \mathrm{O}{ }^{35,36}$

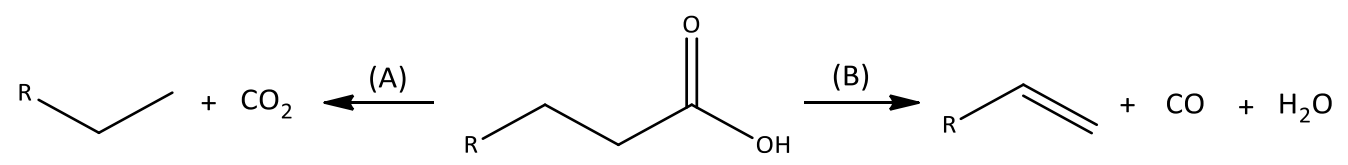

Figura 2.8 - Desoxigenação dos ácidos carboxílicos AG via descarboxilação (A) e descarbonilação (B).

A decomposição dos AGs consiste principalmente na desoxigenação através descarboxilação e descarbonilação, como demonstrado anteriormente na Figura 2.8. É Encontra-se também na literatura evidências de que em altas concentrações de AGs ocorre a 
formação de grupos anidridos como intermediários, como demonstrado na Figura 2.9. É relatado o emprego de catalisadores baseados em íons de metais para reduzir o tempo de decomposição, assim como para diminuir a temperatura necessária para a desoxigenação. ${ }^{37}$

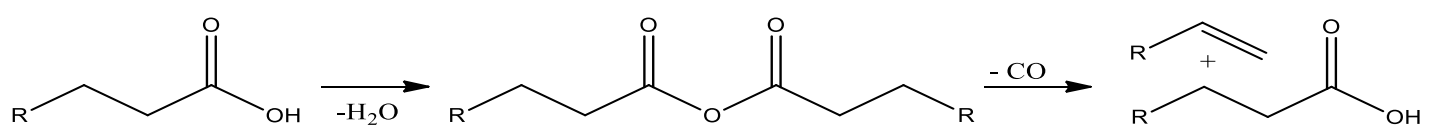

Figura 2.9 - Mecanismo alternativo da decomposição do AG.

Assume-se que a decomposição dos EM ocorre através da desmetilação, descarboxilação e descetonização. Estas reações produzem uma mistura de compostos químicos formados por hidrocarbonetos saturados e insaturados, alcoóis, ácidos carboxílicos e outros (Figura 2.10).
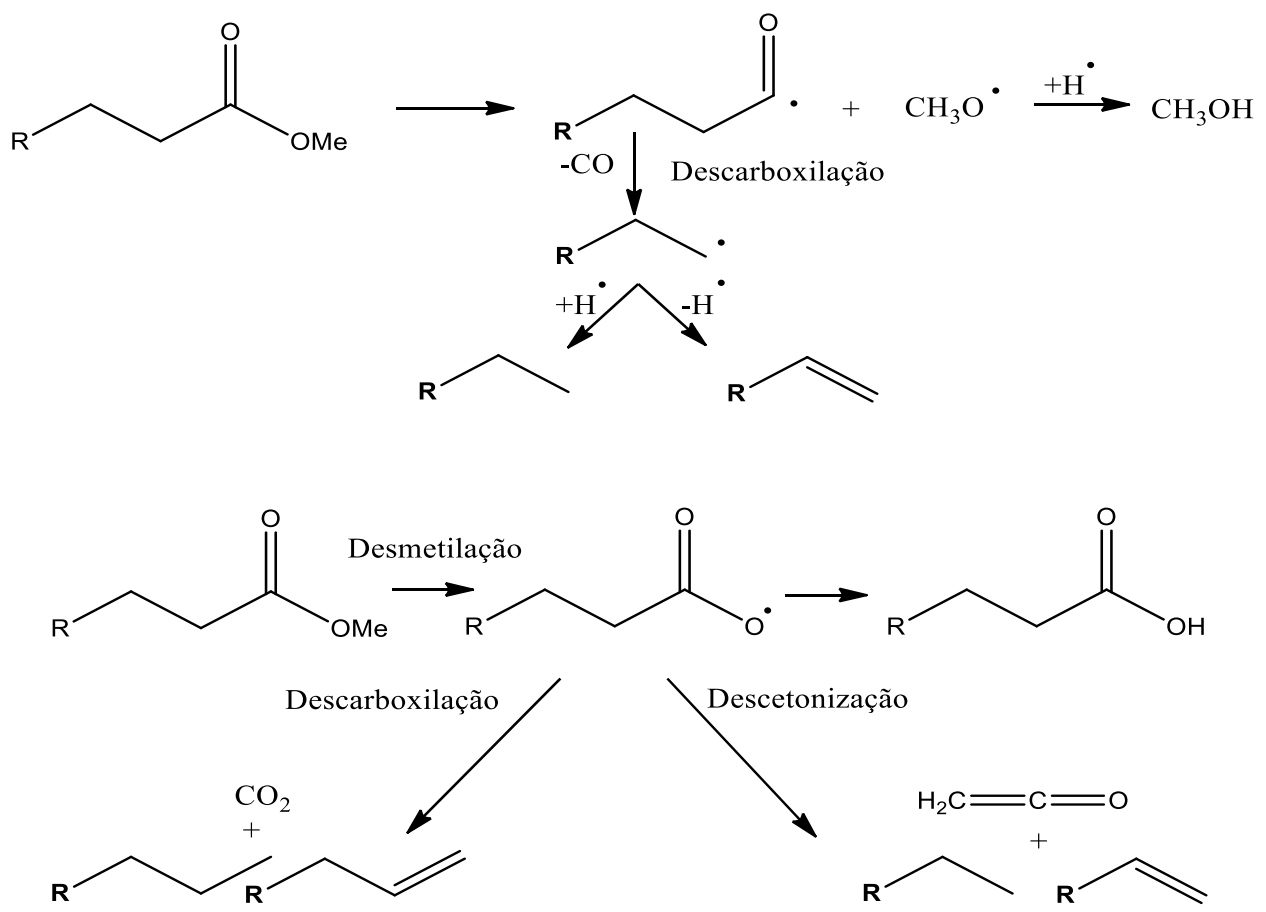

Figura 2.10 - Esquema da decomposição do EM.

\subsection{Obtenção de Polímeros para Uso em Tintas}

A utilização dos óleos na composição de tintas Offset inicia a partir da crise do petróleo da década de 1970, através do incentivo em pesquisas realizado pela Newspapper Association of America visando à substituição das resinas obtidas de derivados de petróleo por materiais de 
fontes renováveis. A opção adotada foi a obtenção de polímeros produzidos através do aquecimento dos TAGs a temperaturas próximas a $300{ }^{\circ} \mathrm{C}$ em atmosfera inerte. ${ }^{38,39}$

Nos estudos iniciais foram testados diferentes tipos de TAGs como matéria-prima, entretanto, observaram-se problemas na qualidade e inviabilidade financeira das tintas produzidas. No fim da década de 1980, este contexto começou a mudar devido à obtenção de tintas a base de óleo de soja com qualidade técnica e com valores competitivos com as obtidas a base de fontes tradicionais. ${ }^{22,23} \mathrm{Em}$ 1993, foi criado o National Soy Ink Information com o objetivo de divulgar a tinta batizada de "SoyInk" e controlar questões relacionadas à propriedade intelectual. Logo nos primeiros anos, foi observada uma considerável aceitação deste tipo de tecnologia, o que acarretou em sua rápida disseminação.

A aceitação desta tecnologia ocorreu não só devido aos benefícios relacionados com a substituição de compostos de maior toxidez de origem petroquímica, mas também devido à obtenção de tintas com maior resistência ao atrito, viscosidade e adesividade que as obtidas de fontes tradicionais. Outras características são a maior absorção do pigmento negro de fumo e a facilidade de confecção de tintas coloridas devido à coloração extremamente clara dos materiais obtidos a base de TAGs em comparação com os derivados de petróleo usados tradicionalmente. 40,41

Outro enfoque nas pesquisas com óleos está relacionado com a busca de catalisadores visando à redução do tempo e temperatura reacional. As atenções inicialmente se voltaram para a utilização da antraquinona devido à possibilidade de reações redox e estabilidade em altas temperaturas, sendo relatadas reduções de até $50 \%$ do tempo reacional, ${ }^{25,35}$ assim como atividade catalítica nos óleos secativos e semissecativos. ${ }^{39,42,43}$

Outros catalisadores também foram estudados. Por exemplo, compostos contendo pelo menos uma fenila e uma carboxila (ex.: difenol carboxilantraceno) foram sugeridos por Spencer et al. como catalisadores capazes de reduzir pela metade o tempo reacional para se atingirem viscosidades Gardner Holdt próximas a Z6 (aprox. $15.080 \mathrm{cSt}$ ). ${ }^{44}$ Nos últimos anos, foram relatadas atividades catalíticas de complexos metálicos a base de Ni, Fe, Co, Sn e Mn, tanto na polimerização de óleos refinados, como de OGRs. Neles, foi demonstrado que o níquel é o catalisador de maior atividade catalítica na polimerização, propiciando a redução de até $60 \%$ no tempo reacional. ${ }^{45,46}$

\subsection{Obtenção de Solventes e Combustíveis}


A partir do aquecimento térmico dos TAGs ou seus derivados, é possível obter uma variedade de compostos químicos. Pode ser produzido fração gasosa (com até 4 carbonos) que pode ser utilizada como substituto do gás natural, frações líquidas que podem ser utilizadas como solvente e também como substituinte da gasolina (com 5 a 12 carbonos), do diesel (com 12 a 18 carbonos) e parafina (acima de 20 carbonos). ${ }^{47-50}$

Para melhorar as propriedades físico-químicas e a seletividade dos produtos, são utilizados diferentes tipos de catalisadores. Ao utilizar como matéria-prima os TAGs, são relatados que zeólitas podem gerar compostos aromáticos e de baixa massa molar, aluminas dopadas com estanho ou zinco para a diminuição da acidez, ou óxidos de magnésio e cálcio para compostos ácidos. Normalmente a atividade catalítica se encontra relacionada com a decomposição do grupo éster (pirólise primária) ou grupo ácido carboxílico (pirólise secundária). ${ }^{50-53}$

Ao utilizar os EM, são relatados sistemas que podem utilizar altas temperaturas, na ausência ou presença de catalisadores, visando a redução da temperatura, tempo de residência e aumento de seletividade. ${ }^{20,21,54}$ Nestes sistemas, são mencionados a obtenção de compostos passíveis de serem utilizados como combustível líquido ou gasoso. Utilizando os AGs, relatase que catalisadores podem atuar na seletividade dos produtos formados. ${ }^{15-17}$ Por exemplo, o uso de $\mathrm{Al}$ e $\mathrm{Pb}$ acarretam a formação de hidrocarbonetos saturados e que na presença de íons de $\mathrm{Cu}$, a formação majoritária é de hidrocarbonetos insaturados. ${ }^{55}$ Para a descarboxilação dos AGs, é relatado o uso de $\mathrm{Pd}, \mathrm{Ni}, \mathrm{Ru}$, Ir, Os e Rh como possíveis catalisadores para a reação, tanto na forma de complexos, ${ }^{56-58}$ como suportados em sílica ou alumina. ${ }^{59,60}$ 


\section{Capítulo 3}

Material e Métodos 


\subsection{Materiais e Síntese}

\subsubsection{Materiais}

Os óleos de soja foram adquiridos de fonte comercial e utilizados como recebido. O óleo residual de soja foi obtido de comércio local após o uso em processos alimentícios, sendo necessária filtração para retirada de materiais em suspensão. Os reagentes $\mathrm{NiCl}_{2} \cdot 6 \mathrm{H}_{2} \mathrm{O}, \mathrm{HCl}$, $\mathrm{NaOH}, \mathrm{KOH}, \mathrm{MeOH}, \mathrm{Na}_{2} \mathrm{SO}_{4}, \mathrm{Hexano}, \mathrm{Ni}$ (acetato) $2, \mathrm{Cu}$ (acetato) $2, \mathrm{Mn}$ (acetato) $2, \mathrm{Zn}$ (acetato) 2 , $\mathrm{Pb}$ (acetato)2, $\mathrm{Al}$ (acetato) 3 e glicerol. foram obtidos da empresa Vetec e utilizados sem tratamento prévio.

\subsubsection{Síntese do Ácido Graxo}

Para a obtenção do AG derivado do TAGs de óleo de soja, foi utilizado o processo de saponificação com $\mathrm{NaOH}$ na relação molar de TAG/NaOH de 1/6. Para a acidificação, foi adicionado $\mathrm{HCl}$ até a completa formação dos AGs. Para avaliar esta formação, foi utilizada a espectroscopia de absorção na região do infravermelho, avaliando o desaparecimento da carbonlia do grupo carboxilato em $1650 \mathrm{~cm}^{-1}$ e o aparecimento da carbonila de ácido carboxílico em $1708 \mathrm{~cm}^{-1}$. Para a purificação, o AG foi dissolvido em hexano, lavado com água destilada e filtrado. O hexano retirado em evaporador rotatório.

\subsubsection{Síntese do Éster Metílico}

O EM foi produzido através da transesterificação básica do óleo de soja. Neste procedimento, foi adicionado a um helermaier de $2 \mathrm{~L}, 10 \mathrm{~g}$ do catalisador $\mathrm{KOH}$ dissolvido em $400 \mathrm{~mL}$ de metanol em $1000 \mathrm{~g}$ de óleo de soja. A reação foi mantida em agitação por $2 \mathrm{~h}$ a temperatura ambiente. A purificação ocorreu através da lavagem com água destilada e secagem a vácuo. O procedimento foi repetido 3 vezes para a obtenção de pureza superior a $97 \%$, de acordo com a metodologia descrita no item 3.3.7. 


\subsubsection{Síntese do Catalisador Ni(Carboxilato)2}

Inicialmente, foi realizada a reação de neutralização de 0,02 mol do AG com 0,025 mol de $\mathrm{NaOH}$ por um tempo de $3 \mathrm{~h}$ e temperatura próxima a $70^{\circ} \mathrm{C}$. Posteriormente, foi adicionado $0,01 \mathrm{~mol}$ de $\mathrm{NiCl}_{2} \cdot 6 \mathrm{H}_{2} \mathrm{O}$ e a reação perdurou por mais $2 \mathrm{~h}$. $\mathrm{O} \mathrm{pH}$ foi mantido próximo a 8 por toda a reação utilizando soluções de $1 \mathrm{~mol} / \mathrm{L}$ de $\mathrm{HCl}$ e $\mathrm{NaOH}$. Para a purificação, utilizou-se hexano para a solubilização do complexo e a lavagem com água destilada para a retirada dos resíduos de reagentes. Por fim, o hexano foi retirado utilizando evaporador rotativo a vácuo e obtido um sólido de coloração verde. ${ }^{46}$

\subsection{Sistemas Reacionais}

Para as reações de polimerização/pirólise, foram utilizados dois sistemas reacionais (Figura 3.1). Ambos foram constituídos por reator de vidro de 1 L com cinco entradas, termopar, fluxo de $\mathrm{N}_{2}$, manta de aquecimento, atmosfera de $\mathrm{N}_{2}$, sistema de condensação, recipiente para a retirada de condensados e seringa para retirada de amostra. A diferença entre eles consiste em que o (A) possui agitação mecânica (padronizada para 100 rpm) e o (B) não o possui. 


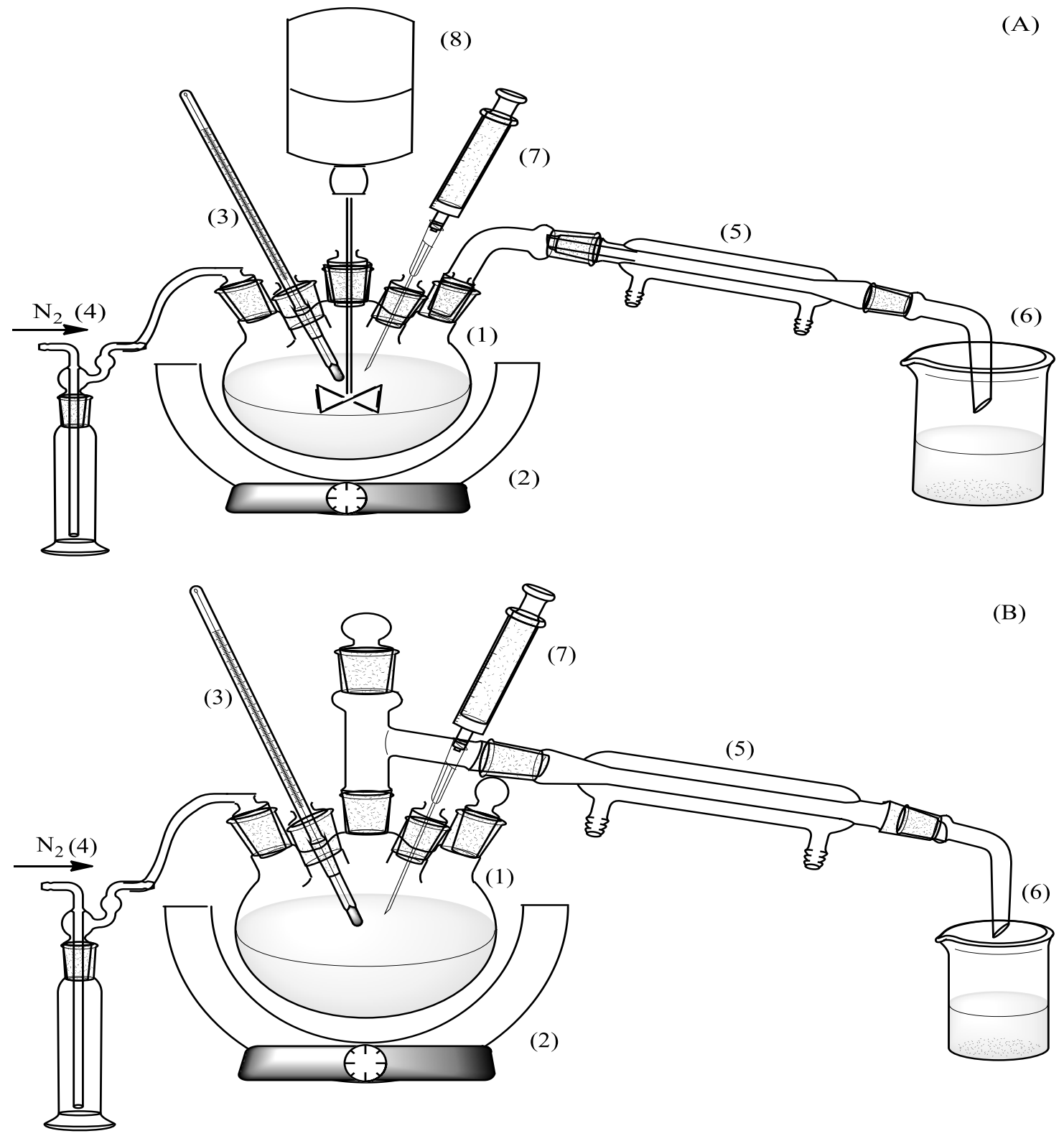

Figura 3.1 - Sistemas utilizados no processo de polimerização/pirólise dos TAGs e seus derivados: na presença (A) e ausência (B) de agitação mecânica. Sistemas compostos por: reator de vidro (1), manta de aquecimento (2), termopar (3), fluxo de $\mathrm{N}_{2}$ (4), condensador (5), recipiente para a obtenção de bio-óleo (6), seringa para retirar alíquotas e agitador mecânico (8).

\subsection{Análises}

\subsubsection{Viscosidade Cinemática}

Para analisar a viscosidade cinemática de todas as amostras, foi utilizado o viscosímetro de Ubbelohde, aclimatado a $40{ }^{\circ} \mathrm{C}$ utilizando banho de viscosidade Herzog modelo HVB-438, 
de acordo com a norma ASTM D445. O cálculo da viscosidade pode ser observado na Equação 3.1 .

Equação 3.1: $\quad$ Viscosidade cinemática $\left(\mathrm{mm}^{2} / \mathrm{s}^{2}\right)=$ c.t

Onde:

$\mathrm{t}=$ tempo de escoamento da amostra (s)

$\mathrm{c}=$ constante do viscosímetro $\left(0,1039 ; 0,3086 ; 0,3135 ; 1,024 \mathrm{e} 2,894 \mathrm{~mm}^{2} / \mathrm{s}^{2}\right)$

\subsection{2 Índice de Acidez}

De acordo com método AOCS Cd3d63, o índice de acidez (IA) foi obtido utilizando 1 g de amostra, $25 \mathrm{~mL}$ da solução de isopropanol: tolueno 1:1 (solvente), solução metanólica de $\mathrm{KOH} 0,1 \mathrm{~mol} / \mathrm{L}$ (titulante) e fenolftaleína (indicador). O IA de todas as amostras foi calculado pela Equação 3.2.

Equação 3.2: $\quad \mathrm{IA}=\left[\mathrm{OH}^{-}\right] \times \mathrm{V} \times 56,1 / \mathrm{g}_{\text {amostra }}$

Onde:

$\left[\mathrm{OH}^{-}\right]=$concentração da solução básica.

$\mathrm{V}=$ volume gasto na titulação até o ponto de viragem.

$\mathrm{g}_{\mathrm{amostra}}=$ massa de amostra utilizada na titulação.

$56,1=$ massa molar da base $\mathrm{KOH}$.

\subsubsection{Massa Específica}

Para analisar a massa específica foi utilizado o densímetro digital Anton Paar (DMA $35 \mathrm{~N}$ ), sendo que as amostras foram acondicionadas e banhos térmicos e as medidas foram obtidas a $20^{\circ} \mathrm{C}$. Para a obtenção do resultado final, foram realizadas triplicatas e obtida a média.

\subsubsection{Poder Calorífico}


O poder calorífico (ASTM D240) foi obtido em equipamento Parr, Modelo 6725, utilizando uma pastilha 30 psi de pressão de oxigênio e ácido benzóico como referência. Após a obtensão da capacidade calorífica do sistema, foi obtido o poder calorífico dos bio-óleos.

\subsubsection{Análise do Teor de Metal}

O Teor de Metal dos complexos a base de $\mathrm{Ni}^{2+}, \mathrm{Cu}^{2+}, \mathrm{Mn}^{2+}, \mathrm{Zn}^{2+}, \mathrm{Pb}^{2+}$ e $\mathrm{Al}^{3+}$, foram obtidos pesando $1 \mathrm{~g}$ do material em cadinho e levado à mufla a $600{ }^{\circ} \mathrm{C}$ durante $24 \mathrm{~h}$. Posteriormente, o cadinho foi pesado e obtido a massa residual. Atribuiu-se a massa residual a formação dos óxidos mais estáveis de cada metal e, consequentemente, pode-se calcular a massa do metal presente na amostra.

\subsubsection{Análise Termogravimétrica}

Para avaliar a estabilidade térmica dos complexos a base de $\mathrm{Ni}^{2+}, \mathrm{Cu}^{2+}, \mathrm{Mn}^{2+}, \mathrm{Zn}^{2+}, \mathrm{Pb}^{2+}$ $\mathrm{e}^{3+}$, foram realizadas analises termogravimétricas em um equipamento SHIMADZU DTG60, com panelas de platina, fluxo de $30 \mathrm{~mL} / \mathrm{min}$, atmosfera de nitrogênio, taxa de aquecimento de $10^{\circ} \mathrm{C} / \mathrm{min}$ até a temperatura de $800{ }^{\circ} \mathrm{C}$. As amostras analisadas foram as

\subsubsection{Cromatografia Líquida de Alta Performance}

Para analisar a quantidade de EMs formados na reação de transesterificação, foi utilizada a técnica de Cromatografia Líquida de Alta Performance (HPLC) no equipamento modelo CTO-20ª da marca Shimadzu, utilizando detector de radiação ultravioleta (UV), fixado em $205 \mathrm{~nm}$. As amostras foram dissolvidas em isopropanol: hexano (5:4) com volume total de injeção de $10 \mu \mathrm{L}$ e vazão do fluxo de solvente de $1 \mathrm{~mL} / \mathrm{min}$. Os cromatogramas foram gerados pelo software LabSolutions da Shimadzu. A análise perdurou por 23 min utilizando solvente metanol e isopropanol/hexano (5/4) como eluentes em forma gradiente, iniciando com metanol, atingindo 50:50 em $15 \mathrm{~min}$ e após $17 \mathrm{~min}$ a quantidade de metanol foi gradativamente aumentando até $100 \%$ em $20 \mathrm{~min}$.

\subsubsection{Espectroscopia de Absorção na Região do Infravermelho}


As análises por espectroscopia de absorção na região do infravermelho foram realizadas em equipamento Shimadzu IR Prestige-21 usando um detector DLATGS. As amostras dos polímeros foram analisadas em célula de ATR (Ateunated Total Reflectance) da Pike Tecnologies, com comprimento de $7 \mathrm{~cm}$ (10 reflexões). As amostras dos catalisadores foram obtidos utilizando pastilha de $\mathrm{KBr}$. Em ambas as metodologias, utilizou-se a faixa de 600 a $4000 \mathrm{~cm}^{-1}$, resolução de $4 \mathrm{~cm}^{-1}$ e 32 interferogramas acumulados.

\subsubsection{Cromatografia Gasosa Acoplada à Espectroscopia de Massa}

As composições químicas dos bio-óleos foram obtidas por Cromatografia gasosa acoplada à espectroscopia de massa (CG-MS), sendo realizadas no equipamento CG-EMQP5050 (Shimadzu), com coluna capilar de sílica CBPI PONA com $50 \mathrm{~m}$ de tamanho, 0,15 $\mu \mathrm{m}$ de diâmetro e $0,42 \mu \mathrm{m}$ de largura. A coluna foi aquecida a $250{ }^{\circ} \mathrm{C}$, com taxa de aquecimento de $10{ }^{\circ} \mathrm{C} / \mathrm{min}$, a injeção das amostras foi realizada na temperatura de $250{ }^{\circ} \mathrm{C}$.

\subsubsection{Espectrometria de Emissão Atômica com Plasma Indutivamente Acoplado}

As análises por Espectrometria de Emissão Atômica com Plasma Indutivamente Acoplado (ICP-OES) foram realizadas utilizando equipamento Thermo Fisher Scientific (Cambridg, Inglaterra), modelo iCAP 6300 Duo, com vista axial, com detector simultâneo CID (charge Injection Device), óptica purgada com argônio, que permite um intervalo espectral de medidas que vai de 166 a $847 \mathrm{~nm}$, com $383 \mathrm{~mm}$ de distância focal, policromador Echelle de 52,91 linhas/mm e fonte de radiofrequência de 27,12 $\mathrm{MHz}$, que permite o ajuste de potência aplicada de 750 a $1350 \mathrm{~W}$. O gás utilizado para purgar a ótica e formar o plasma foi de Argônio 99,998 \% v/v. O padrão utilizado nas análises foi S21 + K500 ppm. As amostras foram preparadas dissolvendo $0,5 \mathrm{~g}$ da amostra em 4,5 $\mathrm{g}$ de querosene.

\subsubsection{Difração de Raios $X$}

As analises por Difração por Raios X (DRX) foram realizadas no equipamento D8 Focus (Brucker), com Faixa $2 \theta$ entre $10-90^{\circ}$, velocidade de varredura de $1 \% \mathrm{~min}$. Os resultados foram analisados utilizando banco de dados pdf-2. 


\section{Resultados}

\section{Capítulo 4}

Tratamento Térmico do Óleo de Soja 


\subsection{Tratamento Térmico do Óleo de Soja: Primeira Parte}

O presente estudo tem como objetivo avaliar a atividade catalítica de íons de metais utilizando balanço de massa entre o polímero no interior do reator e o bio-óleo condensado, para isto, as reações ocorreram com a quantidades de íon de metal entre 0,15 e $0,18 \mathrm{mmol} / \mathrm{kg}$ de óleo. Para tal, foi utilizado o sistema descrito no Item 3.2.1A. Neste sistema, encontra-se presente agitação com rotação de $100 \mathrm{rpm}$.

\subsubsection{Caracterização dos Complexos Metálicos}

Os complexos metálicos $\mathrm{Ni}$ (acetato)2, $\mathrm{Zn}$ (acetato)2, $\mathrm{Cu}$ (acetato)2, $\mathrm{Mn}(($ acetato)2, $\mathrm{Pb}$ (acetato $)_{2}$ e $\mathrm{Al}$ (acetato) 3 , obtidos de fontes comerciais e utilizados como recebido, foram caracterizados por espectroscopia na região do Infravermelho e por termogravimetria. $\mathrm{Na}$ Figura 4.1, são observadas absorções características da complexação do grupo carboxilato ao íon de metal entre 1700 a $1450 \mathrm{~cm}^{-1} .{ }^{61}$ É observada também que a presença de vibrações -OH em $3250 \mathrm{~cm}^{-1}$ características de $\mathrm{H}_{2} \mathrm{O}$.

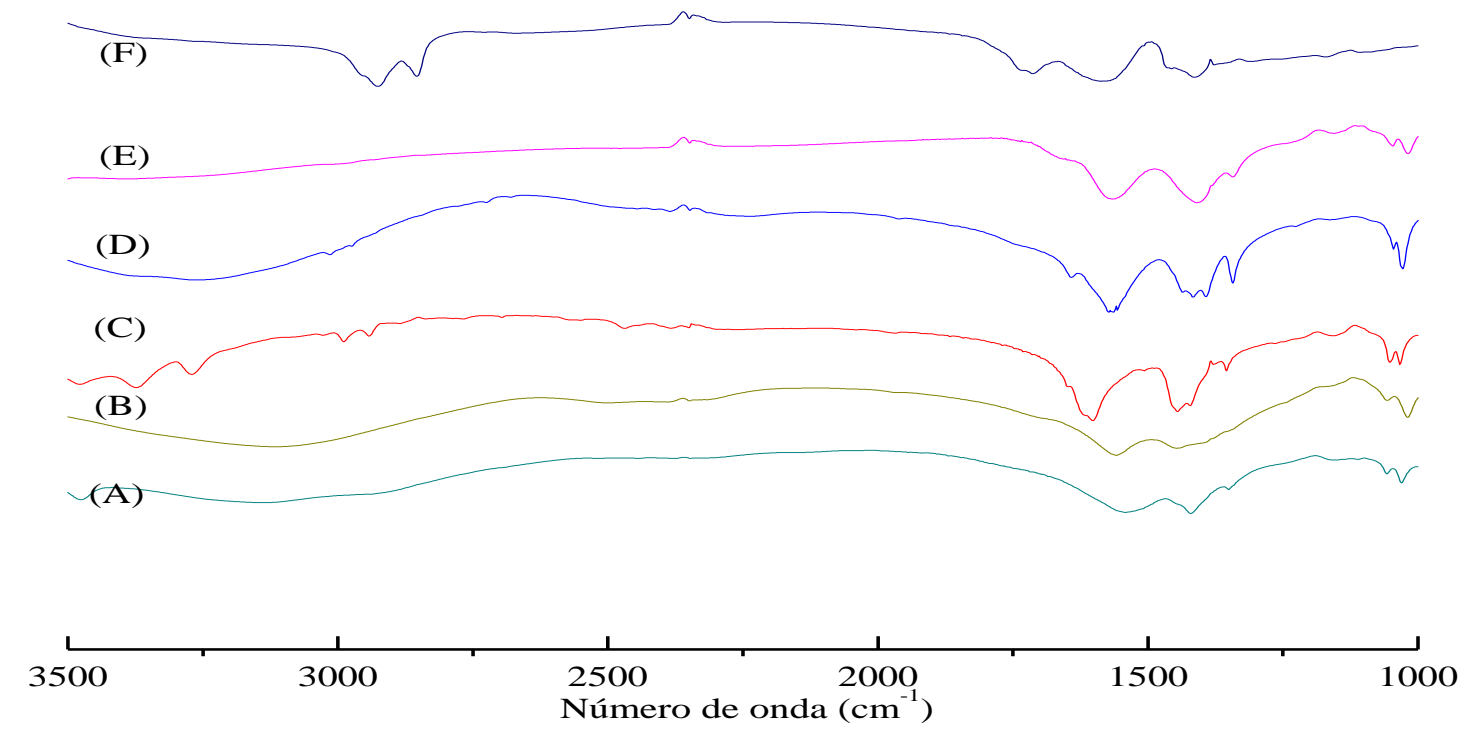

Figura 4.1 - IV-KBr dos complexos metálicos: (A) Ni(acetato $)_{2}$, (B) $\mathrm{Zn}$ (acetato) $)_{2}$, (C) $\mathrm{Cu}(\text { acetato })_{2}$, (D) $\mathrm{Mn}\left((\text { acetato })_{2},(\mathrm{E}) \mathrm{Pb} \text { (acetato }\right)_{2}$ e (F) $\mathrm{Al}$ (acetato $)_{3}$.

Nas análises por TG, é possível observar a saída de água de hidratação e complexada ao metal nas temperaturas entre 100 e $220{ }^{\circ} \mathrm{C}$, respectivamente. Posteriormente, se verifica a decomposição dos ligantes em temperaturas superiores a $280^{\circ} \mathrm{C}$. 

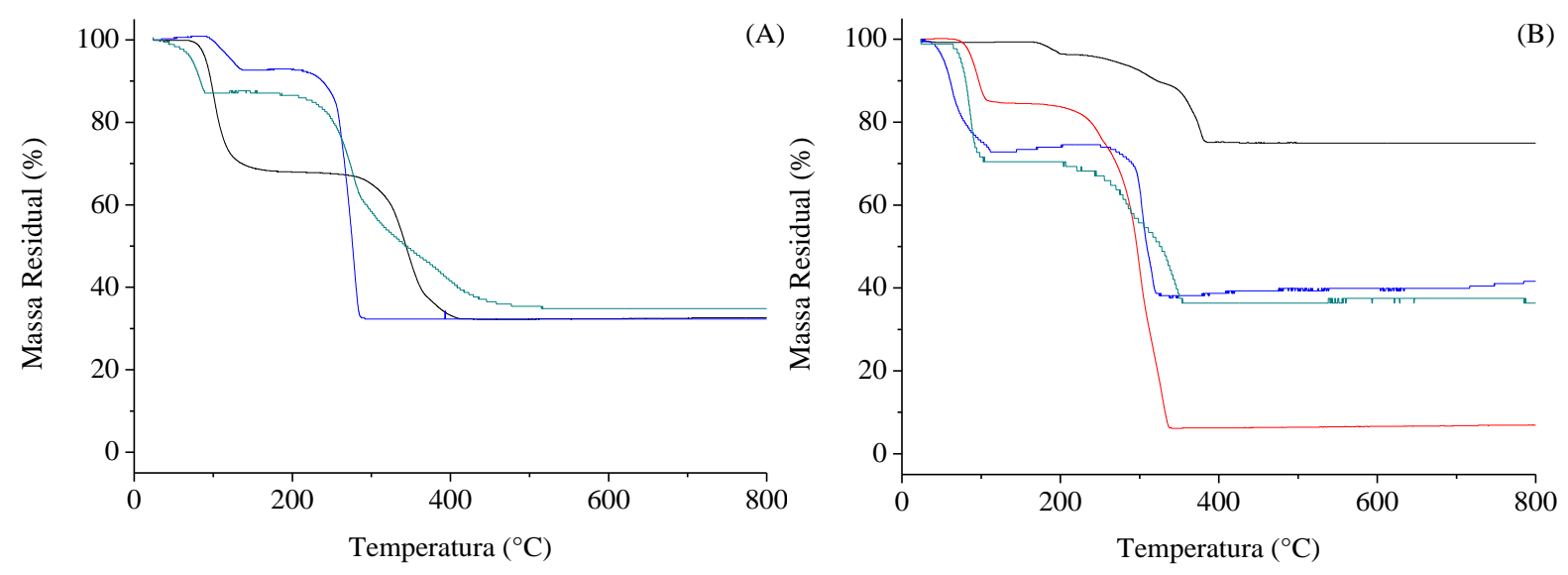

Figura 4.2 - Análise Termogravimétrica dos complexos metálicos. (A): - $\mathrm{Ni}(\text { acetato })_{2},-\mathrm{Cu}(\text { acetato })_{2}$ e $\mathrm{Al}(\text { acetato })_{3}$. (B): - $\mathrm{Pb}$ (acetato $)_{2},-\mathrm{Zn}(\text { acetato })_{2},-\mathrm{Mn}(\text { acetato })_{2} \mathrm{e}-\mathrm{Co}$ (acetato $)_{2}$.

\subsubsection{Balanço de Massa}

Para possibilitar a comparação dos diversos catalisadores empregados no estudo, foi necessário padronizar a quantidade de mmol de íon de metal por $\mathrm{kg}$ de óleo. Os dados obtidos por ICP-OES podem ser observados na Tabela 4.1. É importante mencionar que foram escolhidos os ligantes acetatos devido à solubilidade em óleo, possibilitando uma comparação mais precisa do efeito do íon de metal nos processos de polimerização/pirólise.

Tabela 4.1 - Valores de $\mathrm{mg} / \mathrm{kg}_{\text {óleo }}$ e $\mathrm{mmol} / \mathrm{kg}_{\text {óleo }}$ usados como referência nas reações catalíticas.

\begin{tabular}{ccc}
\hline Metal & $\mathrm{mg} / \mathrm{kg}$ & $\mathrm{mmol} / \mathrm{kg}$ \\
\hline $\mathrm{Pb}$ & 31,9 & 0,15 \\
\hline $\mathrm{Zn}$ & 10,8 & 0,17 \\
\hline $\mathrm{Mn}$ & 10,0 & 0,18 \\
\hline $\mathrm{Al}$ & 4,7 & 0,18 \\
\hline $\mathrm{Cu}$ & 9,9 & 0,16 \\
\hline $\mathrm{Ni}$ & 9,5 & 0,16 \\
\hline
\end{tabular}

Para avaliar a atividade catalítica dos diferentes íons de metais, foram realizadas reações em batelada com duração de uma hora, na presença e ausência de catalisador, e avaliada a massa final do polímero (Figura 4.3 A) e bio-óleo (Figura 4.3 B). Assim, é possível observar ocorre a formação do bio-óleo na ausência de catalisador apenas nas temperaturas de 370 e $380{ }^{\circ} \mathrm{C}$. Ao utilizar os diferentes íons de metais, foi possível verificar que o catalisador permitiu uma redução da temperatura de formação do bio-óleo em $20{ }^{\circ} \mathrm{C}$, assim como a formação de uma 
maior quantidade no mesmo período de tempo. No final de cada reação foram retiradas alíquotas do material polimérico para futuras análises.
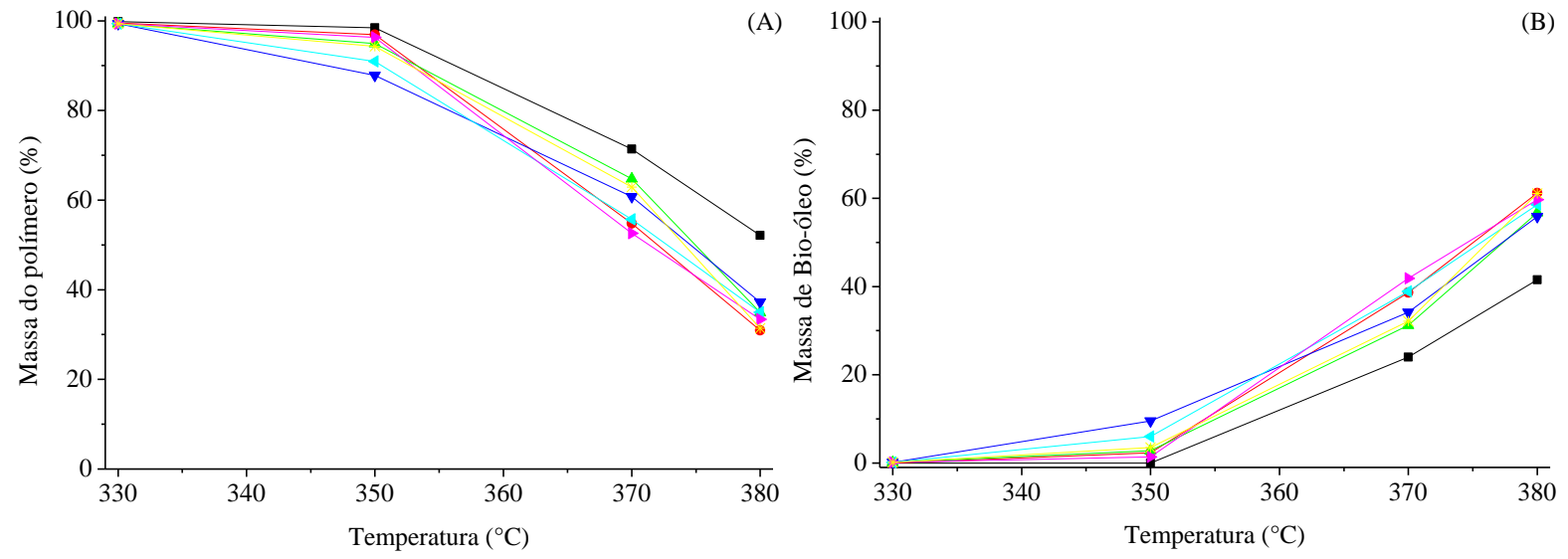

Figura 4.3 - Massa residual do polímero (A) e bio-óleo (B) na ausência de catalisador (•), $\mathrm{Pb}(\text { acetato) })_{2}(\bullet)$, $\mathrm{Ni}(\text { acetato })_{2}(), \mathrm{Cu}(\text { acetato })_{2}(\triangleright), \mathrm{Al}(\text { acetato })_{3}(\triangleleft), \mathrm{Zn}(\text { acetato })_{2}(\triangle)$ e $\mathrm{Mn}(\text { acetato })_{2}(\boldsymbol{\nabla})$. Reações realizadas no período de $1 \mathrm{~h}$. Reações na ausência de agitação.

\subsubsection{Polímeros}

Para avaliar o efeito catalítico no processo de polimerização, os polímeros obtidos no balanço de massa foram analisados por viscosidade (Figura 4.4). Observando assim que, até a temperatura de $370{ }^{\circ} \mathrm{C}$, as viscosidades nas reações na presença de íons de metais foram maiores que a obtida na reação sem catalisador. Entretanto, na temperatura de $380{ }^{\circ} \mathrm{C}$, o perfil de viscosidade se inverte, com maior valor na ausência que na presença de catalisador. Este perfil sugere atividade catalítica tanto nas reações relacionadas a polimerização e na decomposição das cadeias.

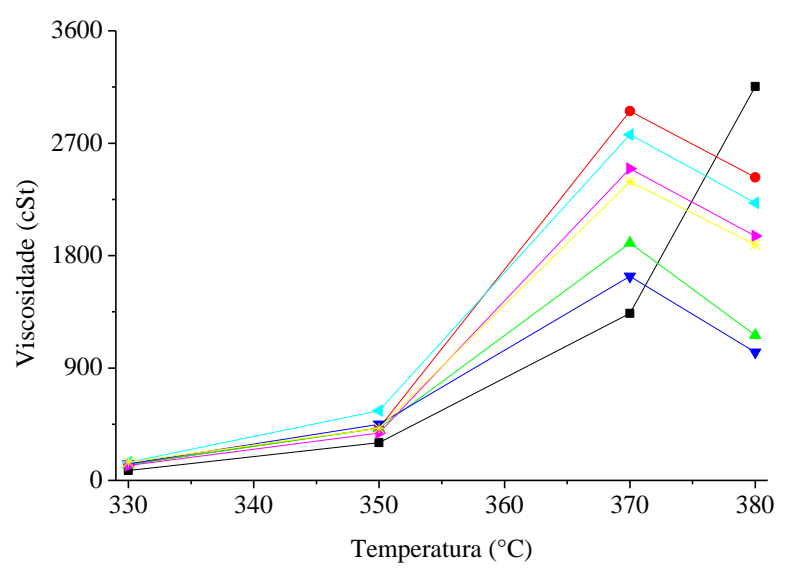

Figura 4.4 - Viscosidade dos polímeros obtidos no balanço de massa: Reação na ausência de catalisador (ロ), na presença de $\mathrm{Pb}(\text { acetato })_{2}(\bullet), \operatorname{Ni}(\text { acetato })_{2}(*), \operatorname{Cu}(\text { acetato })_{2}(\triangleright), \operatorname{Al}(\text { acetato })_{3}(\varangle), \operatorname{Mn}(\text { acetato })_{2}(\triangle)$ e $\mathrm{Zn}(\text { acetato })_{2}(\boldsymbol{\nabla})$.Reações na ausência de agitação. 
Para avaliar melhor o efeito catalítico no processo de polimerização, foi fixada a temperatura de $330{ }^{\circ} \mathrm{C}$ e as reações foram estendidas por até $2 \mathrm{~h}$. Desta forma, foi possível observar de forma mais clara a atividade catalítica durante todo o tempo reacional (ver Figura 4.5). Nota-se que o catalisador de $\mathrm{Pb}$ novamente se destaca por ser o mais eficiente na polimerização, obtendo valores de viscosidade até $46 \%$ superiores aos obtidos sem catalisador. Nota-se também que os demais íons de metais também demonstram atividade catalítica, entretanto com valores de viscosidade moderados.

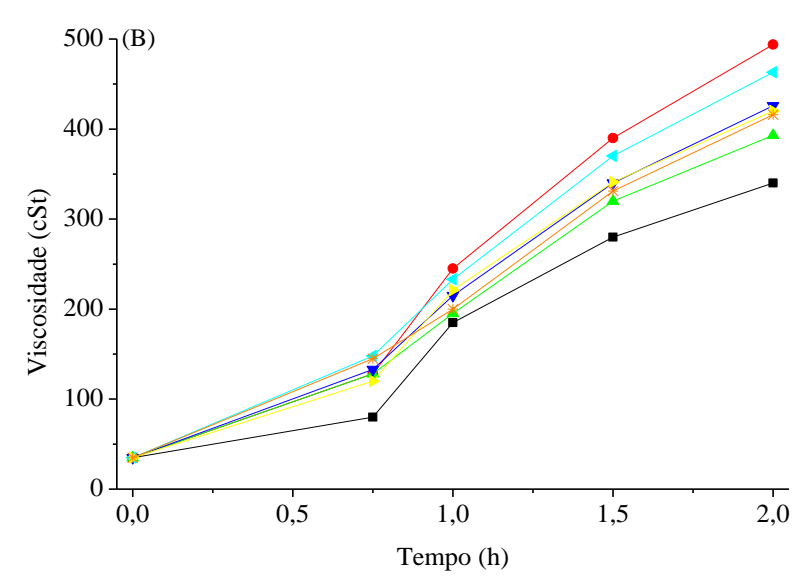

Figura 4.5 - Viscosidade dos polímeros obtidos nas reações de $2 \mathrm{~h}$ a $330{ }^{\circ} \mathrm{C}$ : Reação na ausência de catalisador

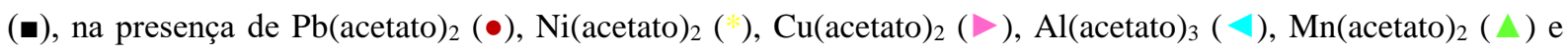
$\mathrm{Zn}(\text { acetato })_{2}(\boldsymbol{\nabla})$.Reações na ausência de agitação.

\subsubsection{Bio-Óleo}

Para avaliar o efeito catalítico dos íons de metais na composição dos bio-óleos formados durante a reação de pirólise, foram realizadas reações em batelada a $370{ }^{\circ} \mathrm{C}$ até a obtenção de determinados valores em massa de bio-óleo. Para isto, as reações ocorreram utilizando $650 \mathrm{~g}$ de TAG até a obtenção das massas de bio-óleo de 50, 100, 200 e 400 g. Para melhor compreensão dos resultados, os valores em massa foram convertidos em porcentagem (conversão) de acordo com a Equação 4.1. Obtendo assim os valores de conversão de 7,5; 15,0; 30 e $63,0 \%$, respectivamente.

Equação 4.1: Conversão em bio-óleo (\%)=(1 - Massa do Bio-Óleo $)$ x 100 
Para avaliar a composição química dos bio-óleos, as amostras foram analisadas por cromatografia gasosa. Nos cromatogramas foram obtidos os valores das áreas relacionadas a cada composto químico encontrado e posteriormente relacionadas com a área total, obtendo assim a porcentagem relativa. Assim, foram encontrados uma diversidade de produtos, principalmente uma série de ácidos carboxílicos com cadeias entre 3 a 18 carbonos e hidrocarbonetos com cadeia variando entre 5 a 17 carbonos. Para se ter uma visão geral dos resultados, os compostos foram divididos em três classes: ácidos carboxílicos (A), hidrocarbonetos saturados (B) e hidrocarbonetos insaturados (C). Foram divididos também em compostos contendo em sua estrutura a quantidade de carbonos entre 5-7 (D), 8-10 (E) e 11-17 (F).

Na Figura 4.6 pode ser observado o perfil de formação em massa de bio-óleo: a quantidade de ácido carboxílico (A) aumenta na medida em que se aproxima de $35 \%$ de conversão e posteriormente ocorre uma redução. Os valores de ácidos carboxílicos obtidos utilizando os íons de metais indicam atividade catalítica, principalmente os íons de $\mathrm{Pb}^{2+} \mathrm{e}^{3+}$. Os hidrocarbonetos saturados (B) possuem uma tendência de aumento na medida em que ocorre a conversão em todas as reações. Os hidrocarbonetos insaturados (C) apresentam uma estabilidade durante toda a formação de bio-óleo.

A atividade catalítica pode ser melhor compreendida ao avaliar o tamanho das cadeias (Figura 4.6 D, E e F). É notado que os catalisadores atuam na produção de compostos com quantidade de carbonos entre $\mathrm{C}_{5}-\mathrm{C}_{7}$. Característica que pode também ser observada na faixa $\mathrm{C}_{8}-\mathrm{C}_{10}$ novamente, destaca-se novamente os catalisadores de $\mathrm{Pb}^{2+}$ e $\mathrm{Al}^{3+}$. Ao avaliar os compostos na faixa $\mathrm{C}_{11}-\mathrm{C}_{17}$, é possível observar que a formação é favorecida na ausência de catalisador, principalmente períodos iniciais de conversão. Na presença de catalisador, a formação de compostos na faixa de C11-C17 ocorre nos períodos finais de conversão.

Os resultados demonstram que os íons de metais, mesmo a baixas concentração, atuam cataliticamente. No geral, os catalisadores demonstram favorecer a produção de grupos ácidos carboxílicos, em detrimento dos hidrocarbonetos. São responsáveis também pela diminuição das cadeias, favorecendo a formação de compostos com a quantidade de carbono entre 5 e 10 . 

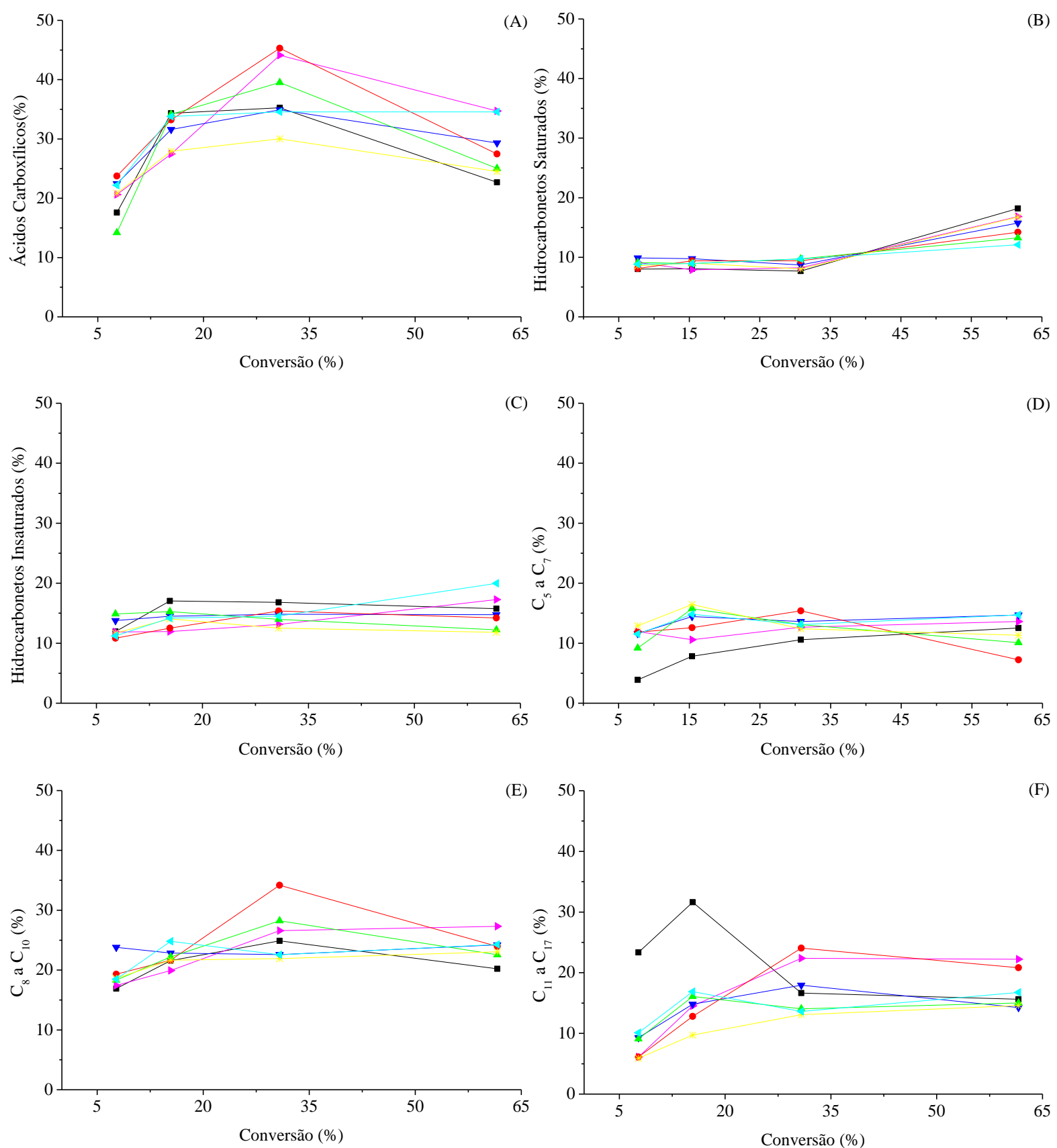

Figura 4.6 - Porcentagem da área total do cromatograma relacionados com (A) Ácidos carboxílicos, (B) hidrocarbonetos saturados, (C) hidrocarbonetos insaturados, compostos contendo em sua estrutura a faixa de carbonos de (D) 5-7, (E) 8-10 e (F) 11-17. Reações sem agitação na ausência de catalisador (ロ) e na presença dos catalisadores: $\mathrm{Pb}(\text { acetato })_{2}(\bullet), \operatorname{Ni}(\text { acetato })_{2}(*), \operatorname{Cu}(\text { acetato })_{2}(\triangleright), \operatorname{Al}(\text { acetato })_{3}(\varangle), \operatorname{Mn}(\text { acetato })_{2}(\Delta)$ e $\mathrm{Zn}(\text { acetato })_{2}(\nabla)$.

Na Figura 4.7 são encontradas as porcentagens dos principais compostos encontrados: ácido heptanóico (A), ácido palmítico (B), ácido decanóico $(\mathbf{C})$ e undeceno (D). Os resultados demonstram que os íons de metais atuam cataliticamente na produção de ácidos de grande cadeia, como os ácidos heptanóicos e palmíticos, assim como na produção de undecenos. Já na 
ausência de catalisador ocorre a formação de ácidos de menor cadeia, como por exemplo o ácido decanóico. Este perfil pode ser explicado de acordo com o tempo das reações, observouse que ao utilizar qualquer um dos catalisadores, houve a formação do bio-óleo em tempos inferiores aos obtidos na reação sem catalisador. Assim, na reação sem catalisador os compostos químicos ficaram um maior tempo no sistema, favorecendo assim a decomposição dos ácidos carboxílicos e de reações de quebra de cadeia.
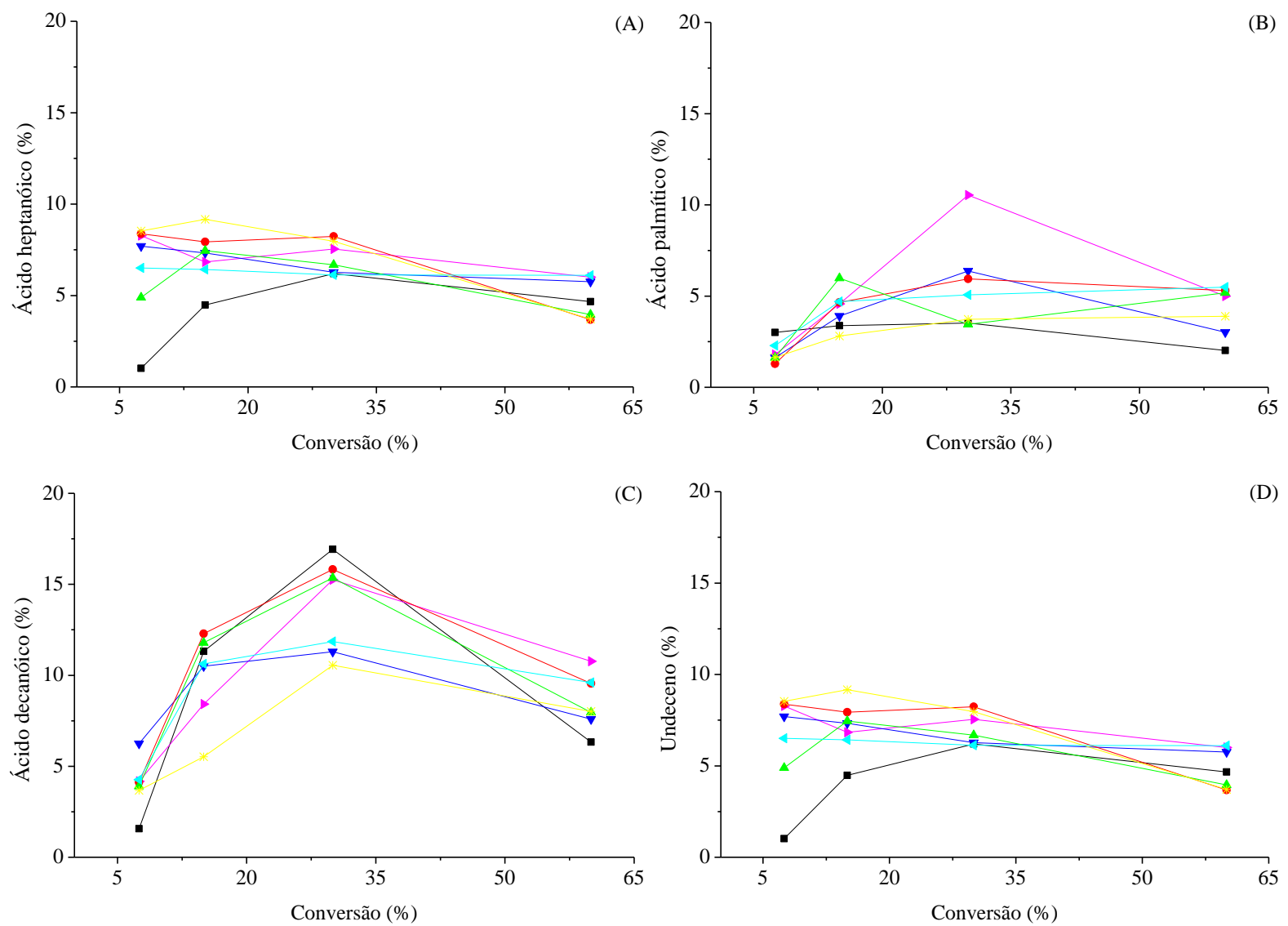

Figura 4.7 - Porcentagem da área total do cromatograma relacionada com os seguintes compostos: (A) Ácido heptanóico, (B) ácido palmítico, (C) ácido decanóico e (D) undeceno. Reações sem agitação na ausência de

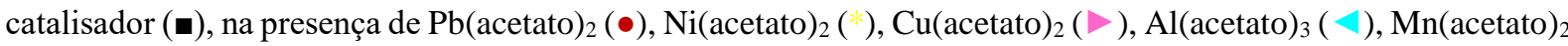
$(\Delta)$ e $\mathrm{Zn}(\text { acetato })_{2}(\boldsymbol{\nabla})$.

Na Figura 4.8, pode ser observado que o IA e viscosidade do bio-óleo na ausência de catalisador são praticamente constantes nos três primeiros pontos, com uma redução em $63 \%$. $\mathrm{Na}$ presença dos complexos de metais, foi possível observar um aumento em todos os pontos analisados, principalmente nas conversões entre 15 e $30 \%$. Os perfis semelhantes das duas propriedades podem ser explicados, pois os ácidos carboxílicos são os principais responsáveis pela viscosidade nos bio-óleos. 

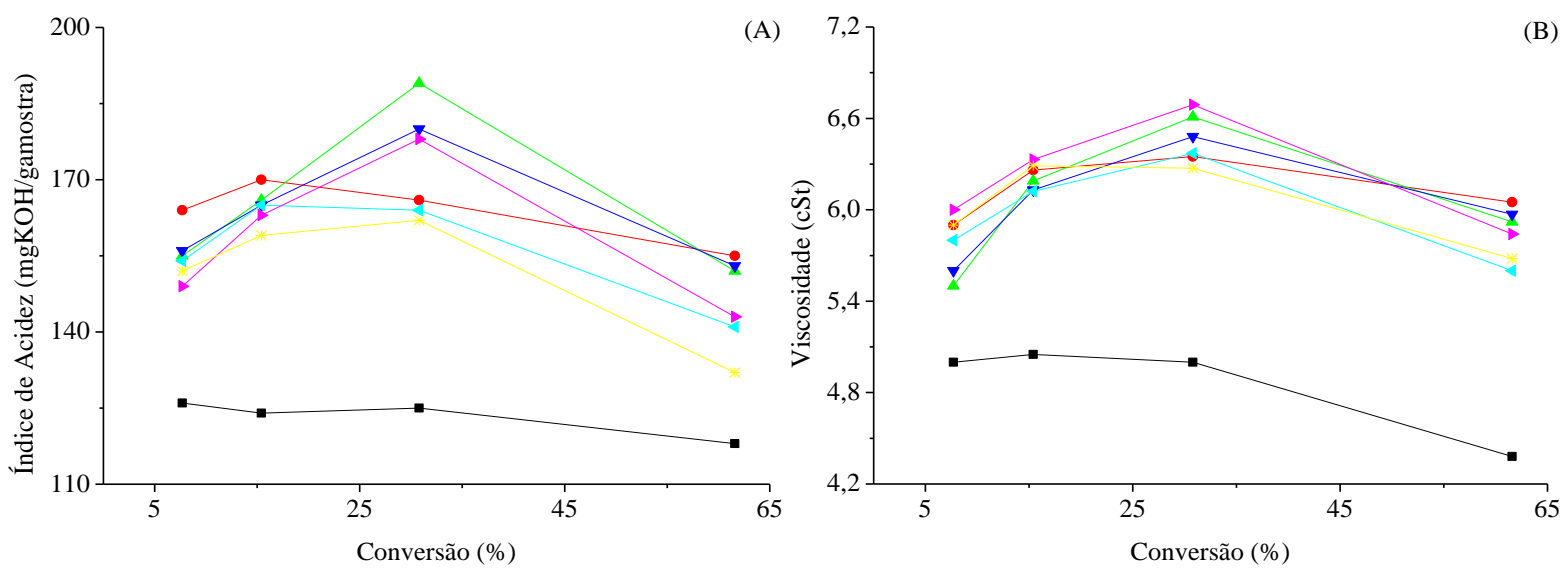

Figura 4.8 - Índice de acidez (A) e viscosidade (B) do bio-óleo: Reação sem agitação na ausência de catalisador $(\bullet)$, na presença de $\mathrm{Pb}(\text { acetato })_{2}(\bullet), \mathrm{Ni}(\text { acetato })_{2}(*), \mathrm{Cu}(\text { acetato })_{2}(\triangleright), \operatorname{Al}(\text { acetato })_{3}(\triangleleft), \operatorname{Mn}(\text { acetato })_{2}(\triangle)$ e $\mathrm{Zn}(\text { acetato })_{2}(\nabla)$.

Assim, conclui-se que os íons de metais, mesmo a baixas concentrações, atuam cataliticamente na decomposição dos TAGs, favorecendo a formação dos compostos ácidos. Entre os catalisadores, destacam-se os íons de $\mathrm{Pb}^{2+}, \mathrm{Mn}^{2+}, \mathrm{Cu}^{2+}$ e $\mathrm{Zn}^{2+}$ como mais os ativos. Entre os que reduzem a acidez, destacam-se os íons de $\mathrm{Al}^{3+} \mathrm{e} \mathrm{Ni}^{2+}$.

\subsubsection{Análise dos Catalisadores Pós-Reação}

Ao final das reações contendo $\mathrm{Al}^{3+}, \mathrm{Pb}^{2+}, \mathrm{Mn}^{2+}$, não foi possível observar a formação de precipitados. Entretanto, ao utilizar os complexos de $\mathrm{Ni}^{2+}, \mathrm{Cu}^{2+}$ e $\mathrm{Zn}^{2+}$, ocorreu a formação de uma fina camada solida na superfície do reator. Assim, os sólidos foram separados, analisados por DRX, e os resultados identificaram a presença de $\mathrm{Cu}^{0}, \mathrm{Ni}^{0}$ e carbetos de $\mathrm{Ni}$ (Figura 4.9 e Figura 4.10). Estes resultados indicam que durante a reação ocorre a redução dos íons divalentes até o estado de oxidação zero. O resíduo de $\mathrm{Zn}$ não apresentou estrutura cristalina identificável por DRX; entretanto, o IV-KBr demonstra vibrações em $1650 \mathrm{~cm}^{-1}$ relacionadas à carbonila de grupo carboxilato, indicando a presença de resíduo do acetato (Figura 4.11).

A formação de compostos insolúveis pode ser responsável pelos valores de viscosidade inferiores utilizando o $\mathrm{Ni}, \mathrm{Cu}$ e $\mathrm{Zn}$, quando comparados com os catalisadores completamente solúveis. Devido à formação de diferentes espécies, torna-se difícil determinar qual o composto ativo na catálise, sendo formado in situ. 


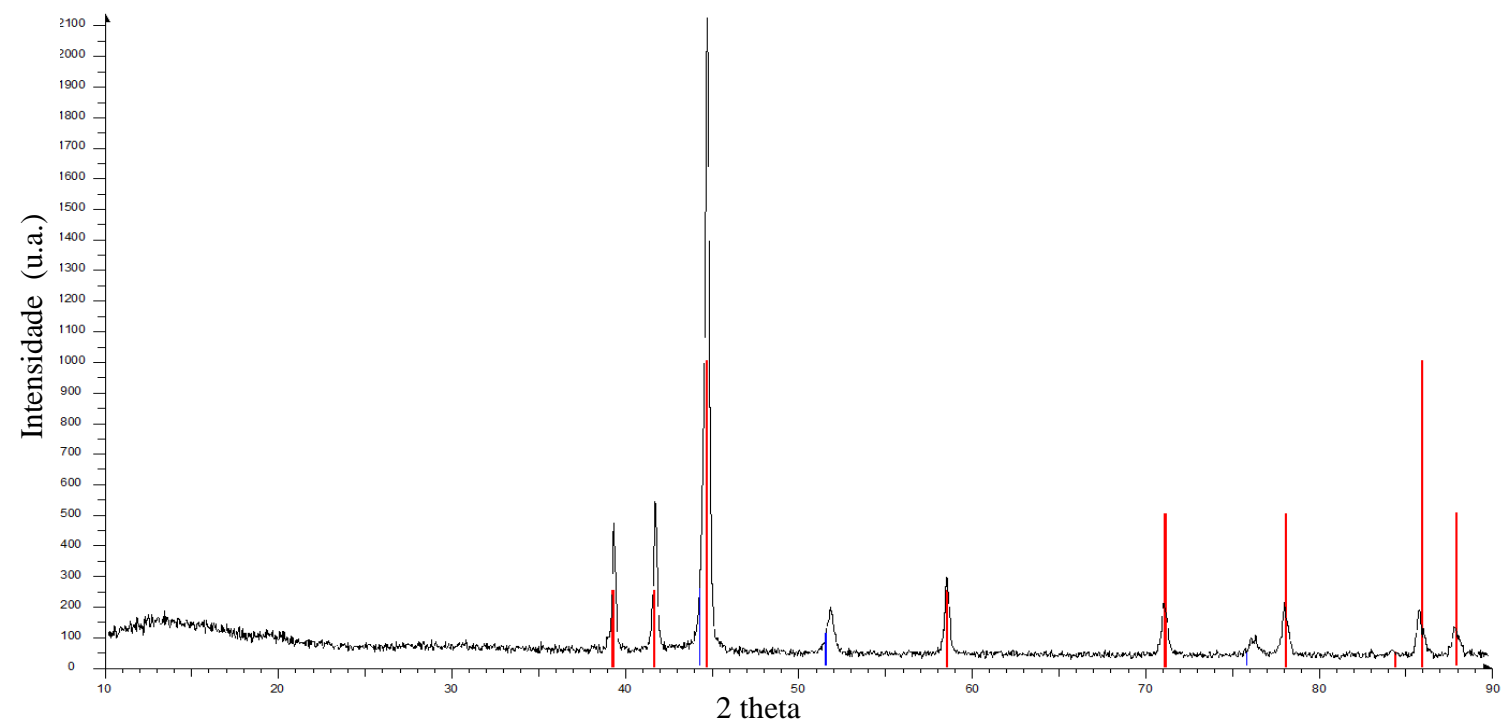

Figura 4.9 - Difratograma de Raios X do precipitado obtido na reação utilizando Ni(acetato) $)_{2}$. Em vermelho os picos característicos de carbeto de $\mathrm{Ni}$ e em azul os característicos de $\mathrm{Ni}^{0}$.

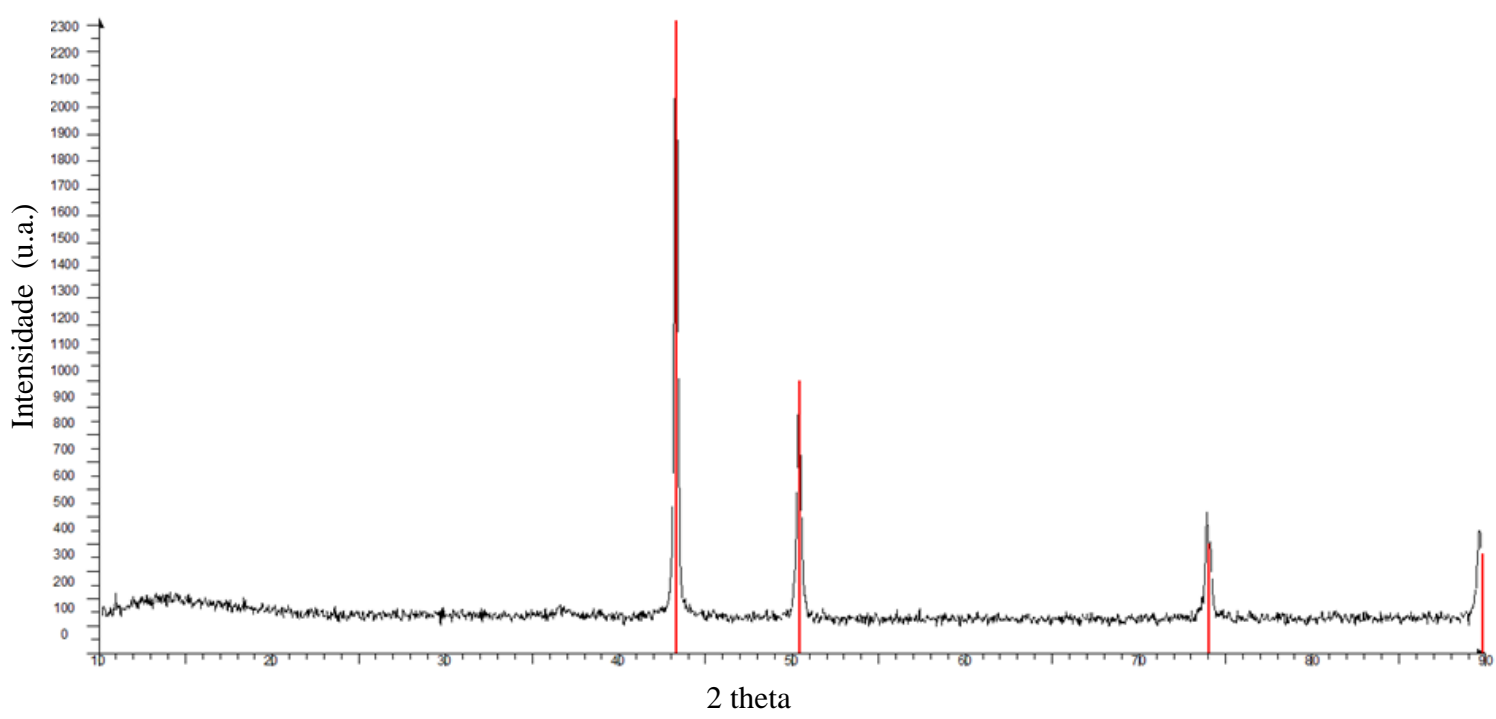

Figura 4.10 - Difratograma de Raios X do precipitado obtido na reação utilizando $\mathrm{Cu}($ acetato)2. Em vermelho os picos característicos do $\mathrm{Cu}^{0}$. 


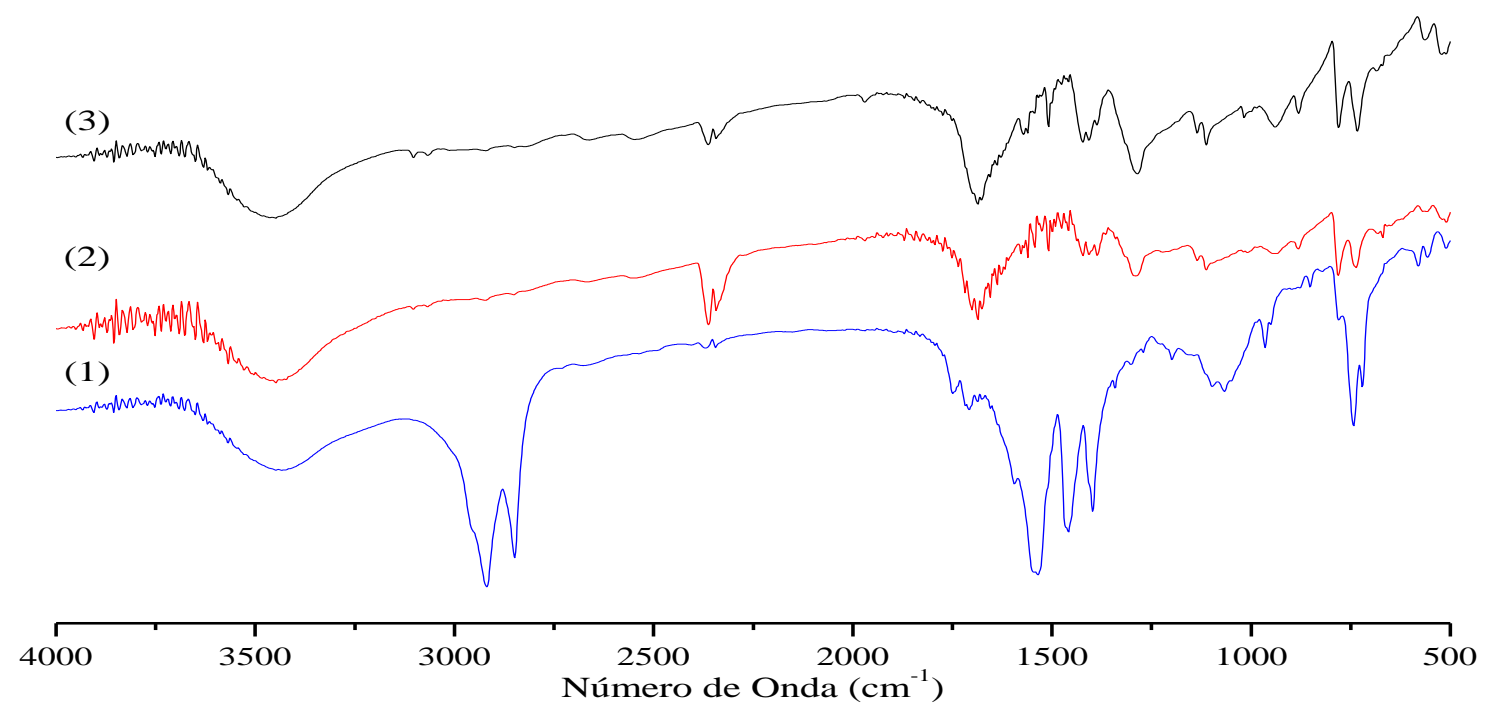

Figura 4.11 - Espectros obtidos por IV-ATR dos precipitados obtidos utilizando os seguintes catalisadores: (1) $\mathrm{Zn}(\text { acetato })_{2},(2) \mathrm{Ni}$ (acetato $)_{2}$ e (1) $\mathrm{Cu}(\text { acetato })_{2}$.

\subsection{Tratamento Térmico do Óleo de Soja: Segunda parte}

A segunda parte do trabalho possui como objetivo avaliar o perfil reacional no decorrer do tempo. O trabalho se encontra dividido em duas partes, a primeira abordando o polímero obtido no interior do reator e a segunda o bio-óleo condensado durante a reação. Foi avaliada também a atividade catalítica do complexo a base de $\mathrm{Ni}^{2+}$ (Item 2.1.5) através da comparação entre os resultados obtidos na ausência e presença de catalisador. $\mathrm{O}$ íon de $\mathrm{Ni}^{2+}$ foi escolhido devido ao fato de já ser descrito na literatura como ativo no processo de polimerização. Assim, o estudo visa aprofundar o entendimento da participação do $\mathrm{Ni}$ (Carboxilato) ${ }_{2}$ nos processos de polimerização e pirólise. Para tal, foi utilizado o sistema descrito no Item 3.2.1B. Isto é, as reações ocorreram na ausência de agitação mecânica.

\subsubsection{Polímeros}

Na Figura 4.12A pode ser observado a viscosidade obtida em diferentes temperaturas na ausência de catalisador. É notado que a $260{ }^{\circ} \mathrm{C}$ não ocorre um aumento da viscosidade durante o tempo de $12 \mathrm{~h}$, já a $300{ }^{\circ} \mathrm{C}$, ocorre um incremento de forma exponencial com a obtenção de altas viscosidades no tempo de $12 \mathrm{~h}$. Nas reações com temperaturas entre 330 e $370^{\circ} \mathrm{C}$, é notado inicialmente um aumento de viscosidade seguido por uma redução dos valores. É importante mencionar que a reação a $370{ }^{\circ} \mathrm{C}$ termina em aproximadamente $2 \mathrm{~h}$ devido à 
pronunciada formação de produtos leves, gerando uma importante perda de massa dentro do sistema reacional. Estes dados demonstram que tanto o efeito da polimerização como da pirólise, são dependentes da temperatura e que a redução da viscosidade observada pode ser um indício no polímero do efeito de pirólise, acarretando na quebra das cadeias poliméricas para a formação de compostos de baixa massa molar.

Ao comparar os resultados na ausência e presença do complexo de níquel (Figura 4.12B), foi observado que ao utilizar o catalisador há um aumento de viscosidade em menores períodos de tempo e também a redução de viscosidade ocorre em tempos inferiores. Outro fator que pode ser observado é que a $300^{\circ} \mathrm{C}$ na presença de catalisador ocorre o incremento e redução da viscosidade, perfil que não se observa na reação sem catalisador. Já nas reações a $370{ }^{\circ} \mathrm{C}$, foi observado que o catalisador conseguiu reduzir o tempo reacional de $2 \mathrm{~h}$ para $0,5 \mathrm{~h}$, demonstrando atividade catalítica na pirólise que proporcionou uma redução de aproximadamente $75 \%$ do tempo reacional. Estes dados demonstram que o catalisador pode ser ativo tanto para o processo de polimerização como o de pirólise.
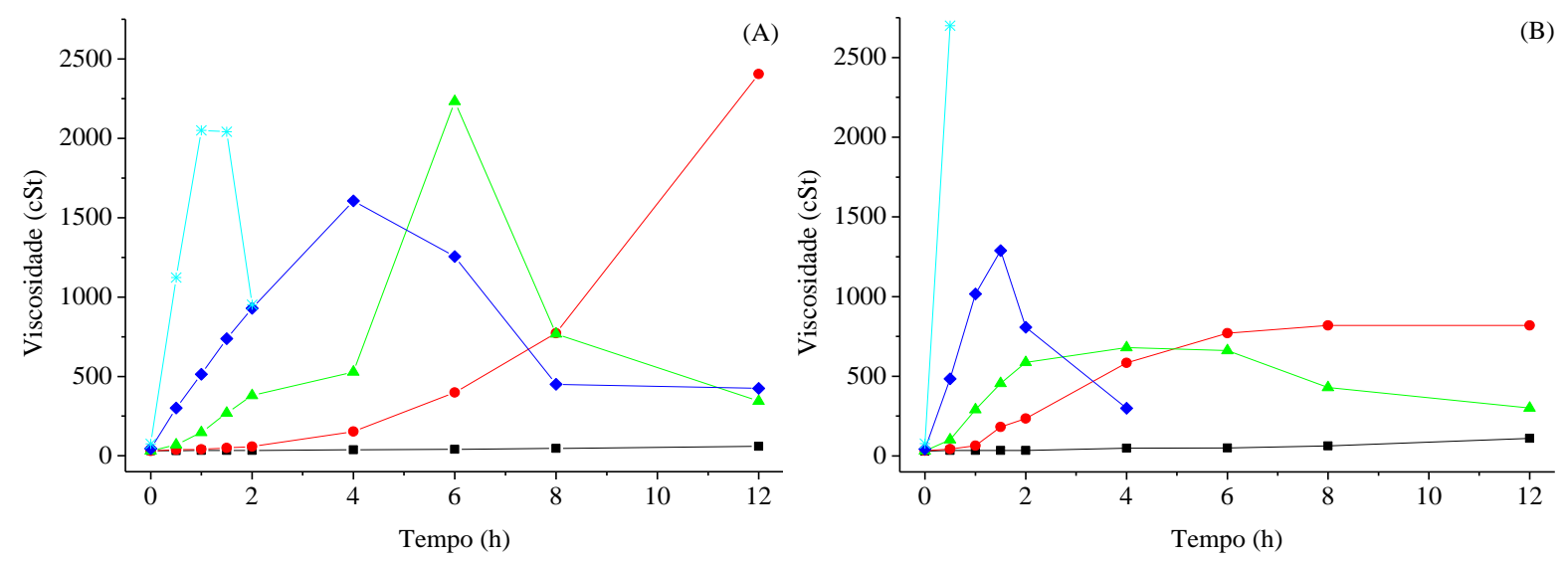

Figura 4.12 - Viscosidade dos polímeros obtidos em reações sem agitação na ausência (A) e na presença (B) de

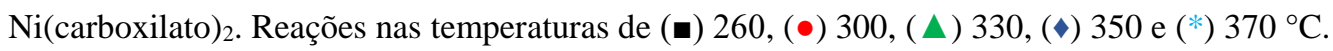

$\mathrm{Na}$ sequência, foi avaliado o IA das amostras do polímero. Foi observado que na ausência de catalisador (Figura 4.13A) a acidez é crescente durante as reações nas temperaturas de 260,300 e $330{ }^{\circ} \mathrm{C}$. Nás reações a 350 e $370{ }^{\circ} \mathrm{C}$ os valores de acidez decresceram após um máximo, o que indica a desoxigenação dos ácidos carboxílicos formados durante a decomposição térmica dos ésteres. Na presença do complexo de níquel, pode ser observado um comportamento similar à reação sem catalisador (Figura 4.13B). Entretanto, é observado que a presença do íon de metal favorece inicialmente a formação de grupos ácidos, assim como 
valores inferiores no final da reação. Assim, pode-se observar atividade catalítica na decomposição do grupo éster e na desoxigenação dos grupos ácidos.
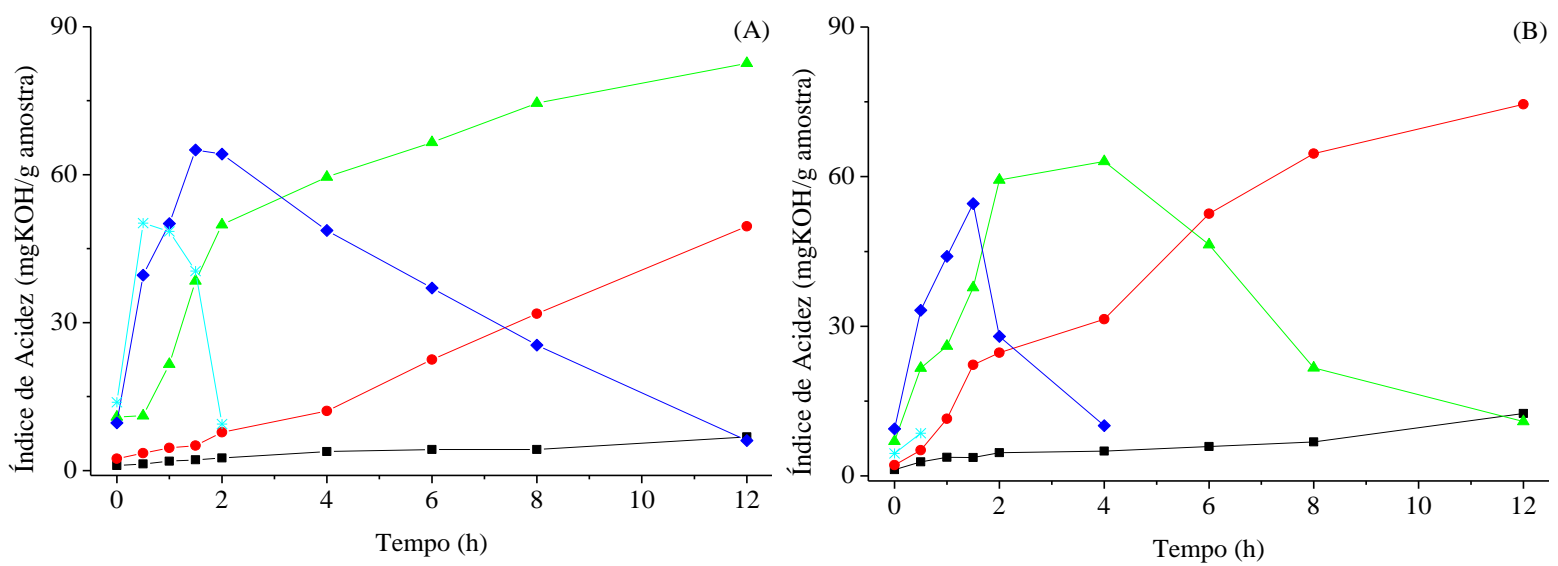

Figura 4.13 - Índice de acidez dos polímeros obtidos em reações sem agitação na ausência (A) e na presença (B)

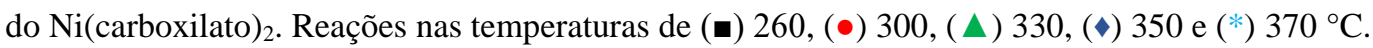

Para obter informação sobre o mecanismo reacional, as amostras foram analisadas por IV-ATR. Os números de onda selecionados estão relacionados com duplas ligações conjugadas na conformação trans-trans $\left(987 \mathrm{~cm}^{-1}\right)$, carbonila do grupo éster $\left(1741 \mathrm{~cm}^{-1}\right)$ e carbonila do grupo ácido carboxílico $\left(1708 \mathrm{~cm}^{-1}\right)$. Os resultados são demonstrados na Figura 4.14 e Figura 4.15. Inicialmente, é observada a isomerização e formação de dienos conjugados na conformação trans-trans (Figura 4.14). O crescimento ocorre de forma constante a $260{ }^{\circ} \mathrm{C}$. Entretanto, a $300{ }^{\circ} \mathrm{C}$ há uma rápida formação e uma estabilização durante determinado tempo, posteriormente ocorre a redução da absorção, demonstrando que o consumo passa a ser mais intenso que a produção. Já a $330^{\circ} \mathrm{C}$, este perfil passa a ocorrer em menores períodos de tempo. Nas temperaturas de 350 e $370{ }^{\circ} \mathrm{C}$ é observado um alto valor no período inicial com redução durante o tempo reacional. Na presença do íon de metal o perfil ocorre em tempos inferiores, o que sugere atividade catalítica neste processo. Relacionando o perfil de isomerização/conjugação das duplas com o da viscosidade, sugere que reações com duplas ligações (Diels-Alder e/ou radicalar) possam ser as mais importantes no aumento da viscosidade e, consequentemente, nas reações de polimerização.

Os resultados obtidos ao avaliar as cabonilas demonstram que os grupos ésteres (Figura 4.15A e 4.15B) são decompostos para a formação dos ácidos carboxílicos (Figura 4.15C e Figura 4.15D), sendo ente processo favorecido pela temperatura. Na presença do catalisador de $\mathrm{Ni}^{2+}$ a decomposição dos grupos ésteres são sempre mais pronunciadas que nas reações sem 
catalisador, ocorrendo até mesmo na temperatura de $260{ }^{\circ} \mathrm{C}$. Pode também ser observado que a desoxigenação dos ácidos carboxílicos é favorecida pela presença do íon metálico.
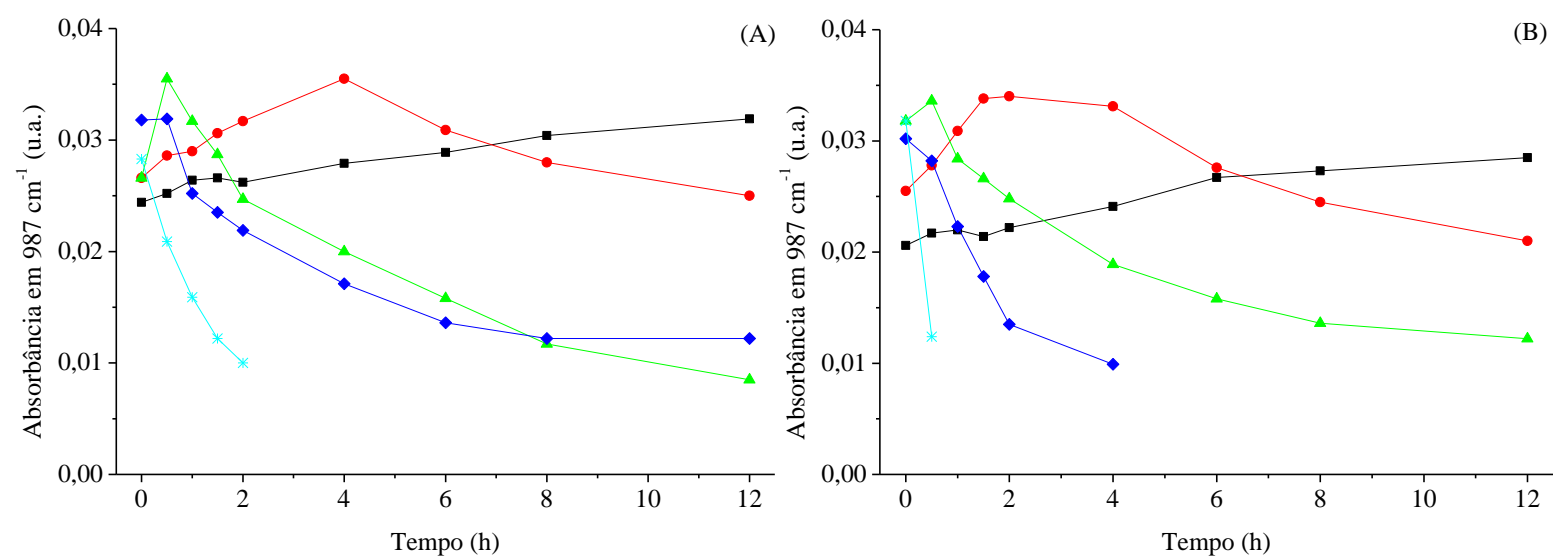

Figura 4.14 - Absorbâncias relacionadas às duplas ligações conjugadas na conformação trans-trans em $987 \mathrm{~cm}^{-1}$ na ausência (A) e na presença (B) do Ni(carboxilato) 2. Reações sem agitação nas temperaturas de (•) 260, (•) 300 , ( $\Delta$ ) $330,(\diamond) 350$ e $(*) 370{ }^{\circ} \mathrm{C}$.
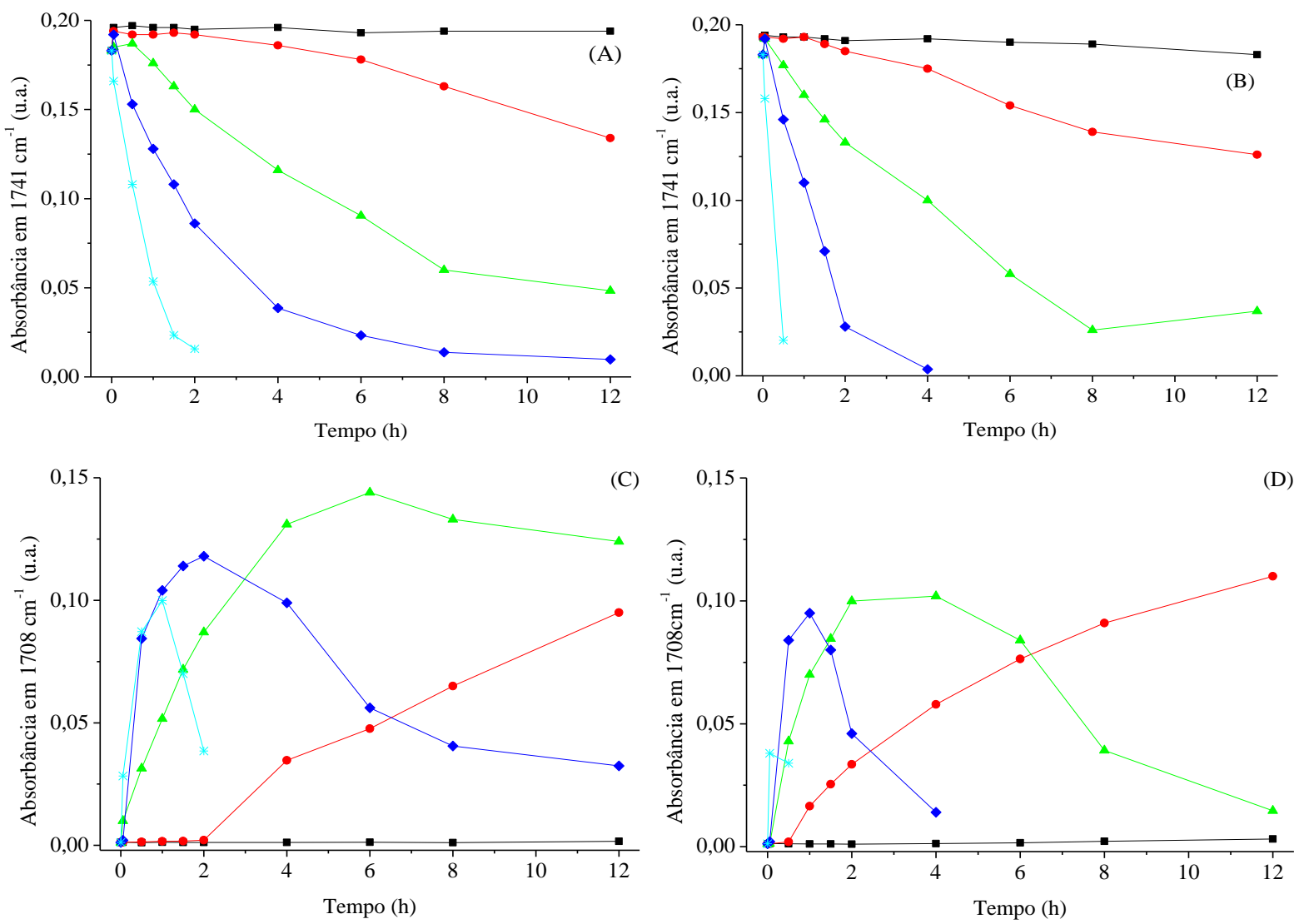

Figura 4.15 - Absorbância em $1741 \mathrm{~cm}^{-1}$ relacionada a carbonila de grupo éster (A, B) e absorbância em 1708 $\mathrm{cm}^{-1}$ relacionada a carbonila de ácido carboxílico $(C, D)$. Na ausência $(A, C)$ e na presença $(B, D)$ de

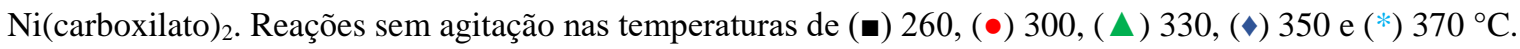


Nas reações entre 300 a $370{ }^{\circ} \mathrm{C}$ utilizando catalisador foi observada a precipitação de sólido, que foi isolado e caracterizado por DRX (Figura 4.16). Os resultados indicam que neste ambiente químico possibilita a formação de carbetos de níquel e níquel no estado de oxidação zero.

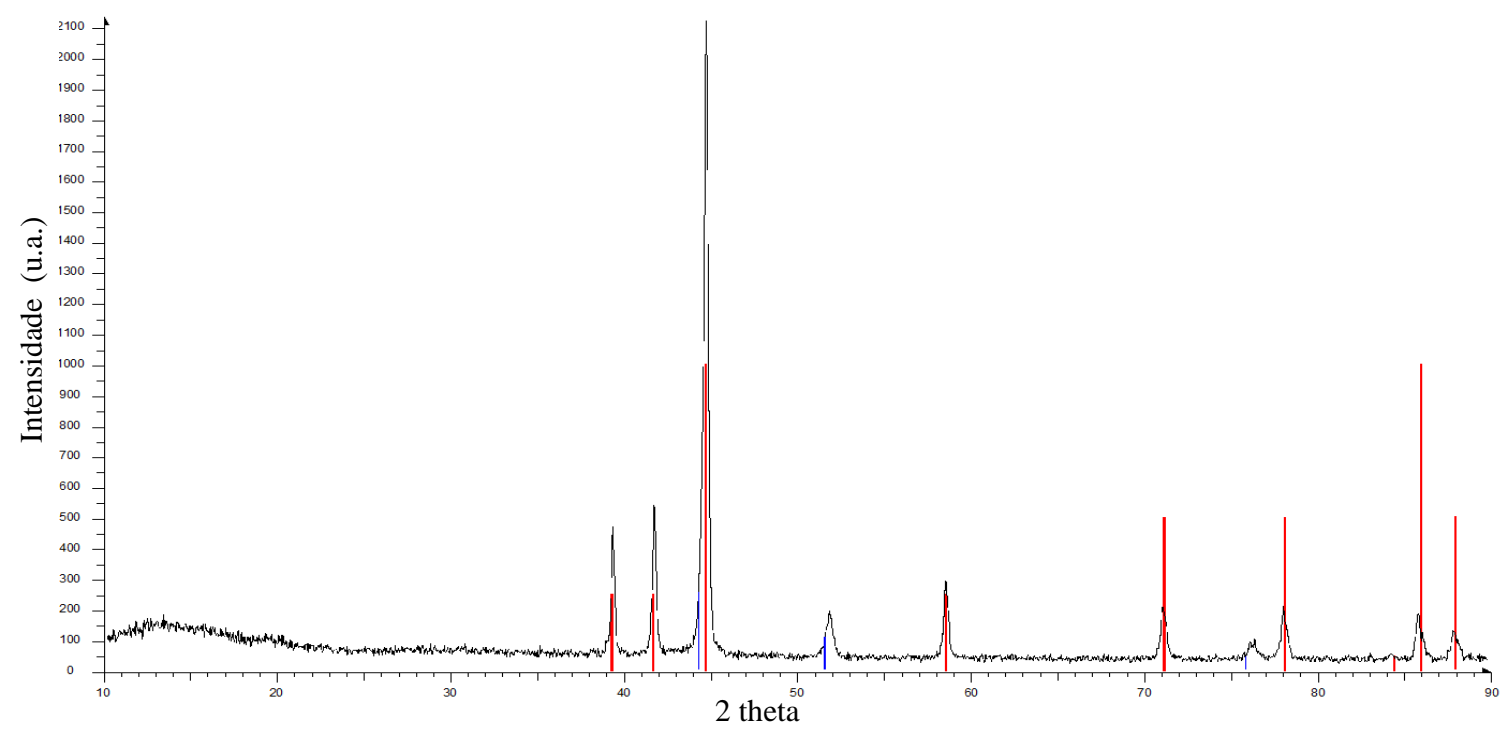

Figura 4.16 - Difratograma de Raios X do precipitado obtido na reação utilizando Ni(acetato) 2 . Em vermelho os picos característicos de carbeto de $\mathrm{Ni}$ e em azul os característicos de $\mathrm{Ni}^{0}$.

\subsubsection{Bio-Óleo}

As análises por CG-MS demonstraram uma grande quantidade de picos que estão relacionados com os variados compostos encontrados no bio-óleo. Para ilustrar este perfil, um típico cromatograma de bio-óleo obtido do tratamento térmico dos TAGs pode ser observado na Figura 4.17. 


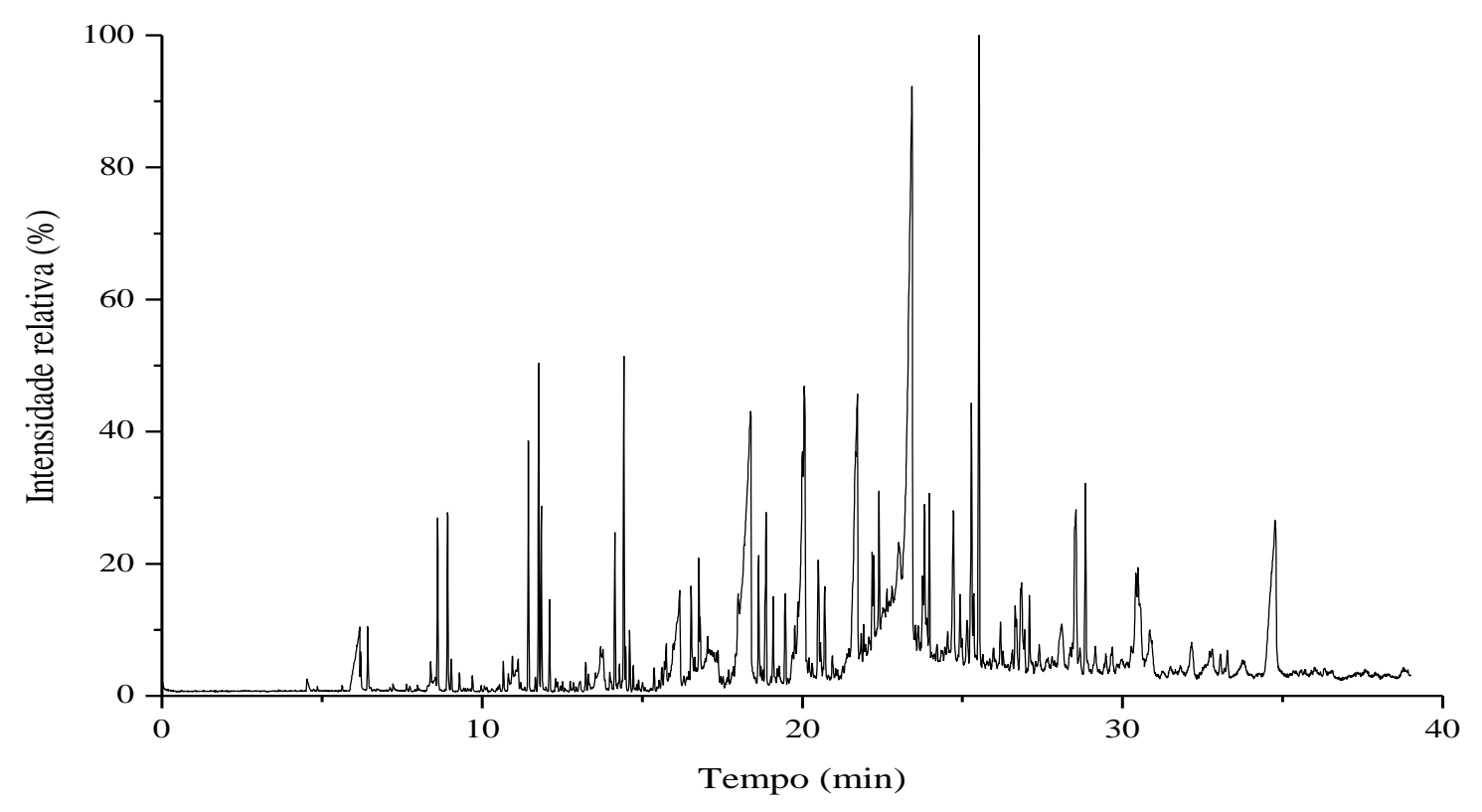

Figura 4.17 - Exemplo de um cromatograma obtido do bio-óleo de óleo de soja.

Os resultados da análise por cromatografia são demonstrados na Figura 4.18, Figura 4.19 e Figura 4.20. Assim, pode-se comprovar a formação de ácidos carboxílicos de baixa cadeia carbônica (6 a 8 carbonos) e a formação de ácidos carboxílicos com grande cadeia carbônica (15 a 17 carbonos). É importante mencionar que as composições das amostras são fortemente influenciadas pelo tempo, pela presença do complexo de $\mathrm{Ni}^{2+}$ e pela temperatura. Por exemplo, nas Figura 4.18, Figura 4.19 e Figura 4.20, demonstram-se, respectivamente, a porcentagem do ácido heptadecanóico, pentadecano, e heptadecano na amostra. Torna-se claro nestas figuras que o aumento da temperatura e a presença do complexo de $\mathrm{Ni}^{2+}$ aumenta a formação de hidrocarbonetos de cadeia longa, reduzindo assim a presença de ácidos carboxílicos nos bio-óleos formados. Deve-se destacar que o IA nas amostras (Figura 4.21) corrobora estes resultados. 

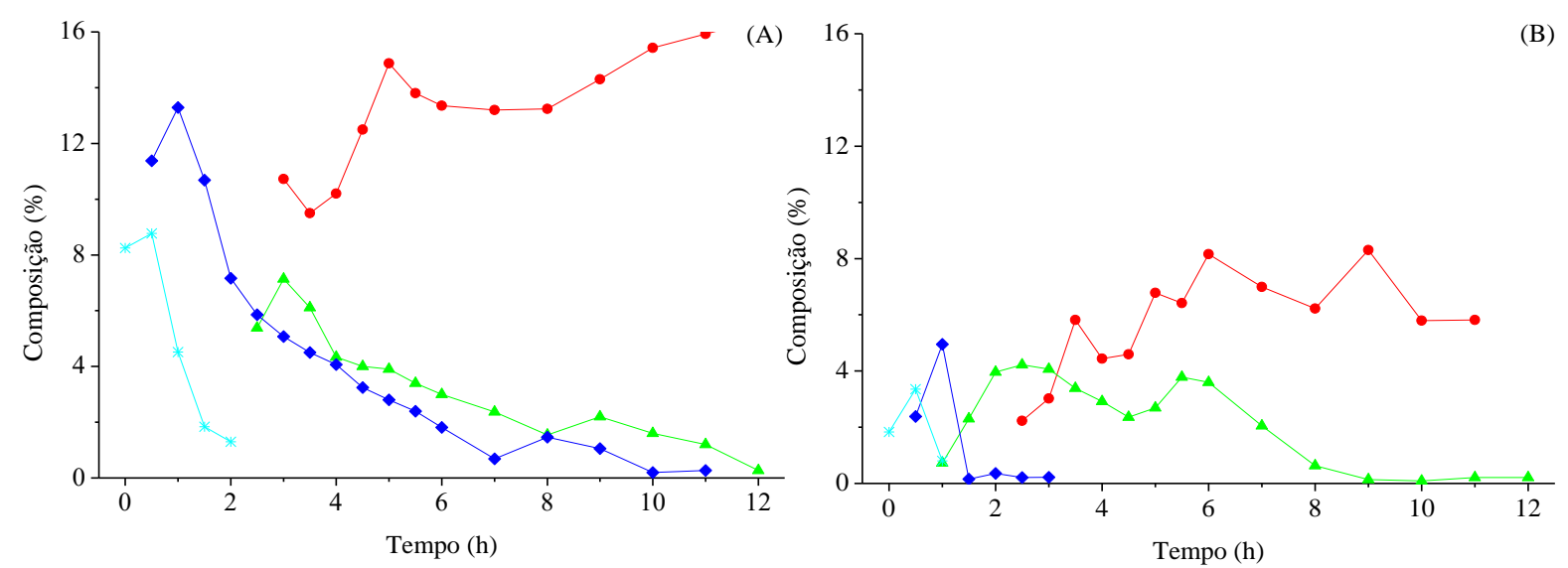

Figura 4.18 - Presença do ácido heptadecanóico nas amostras de bio-óleo na ausência (A) e presença (B) de

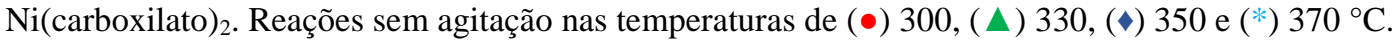
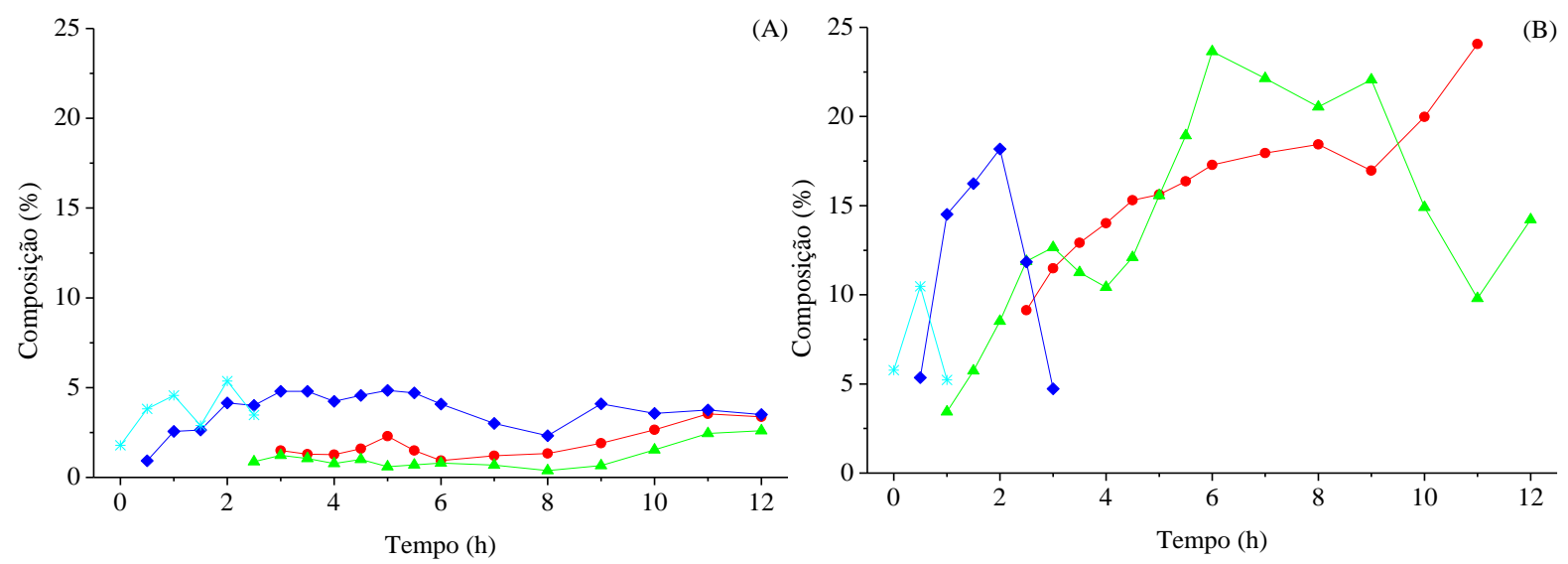

Figura 4.19 - Porcentagem de pentadecano nas amostras de bio-óleo na ausência (A) e presença (B) de

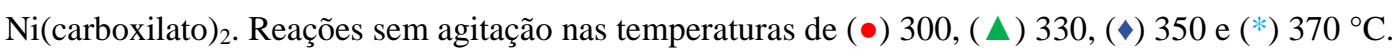
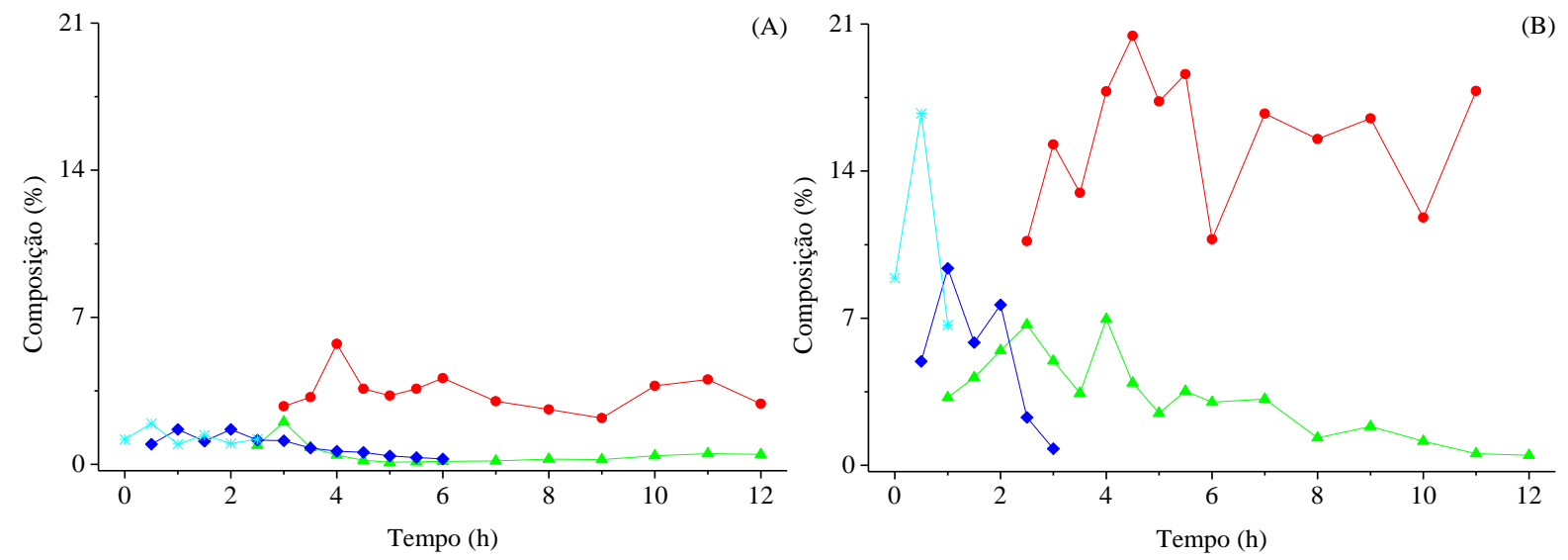

Figura 4.20 - Porcentagem de heptadecano nas amostras de bio-óleo na ausência (A) e presença (B) de

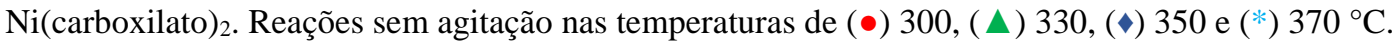



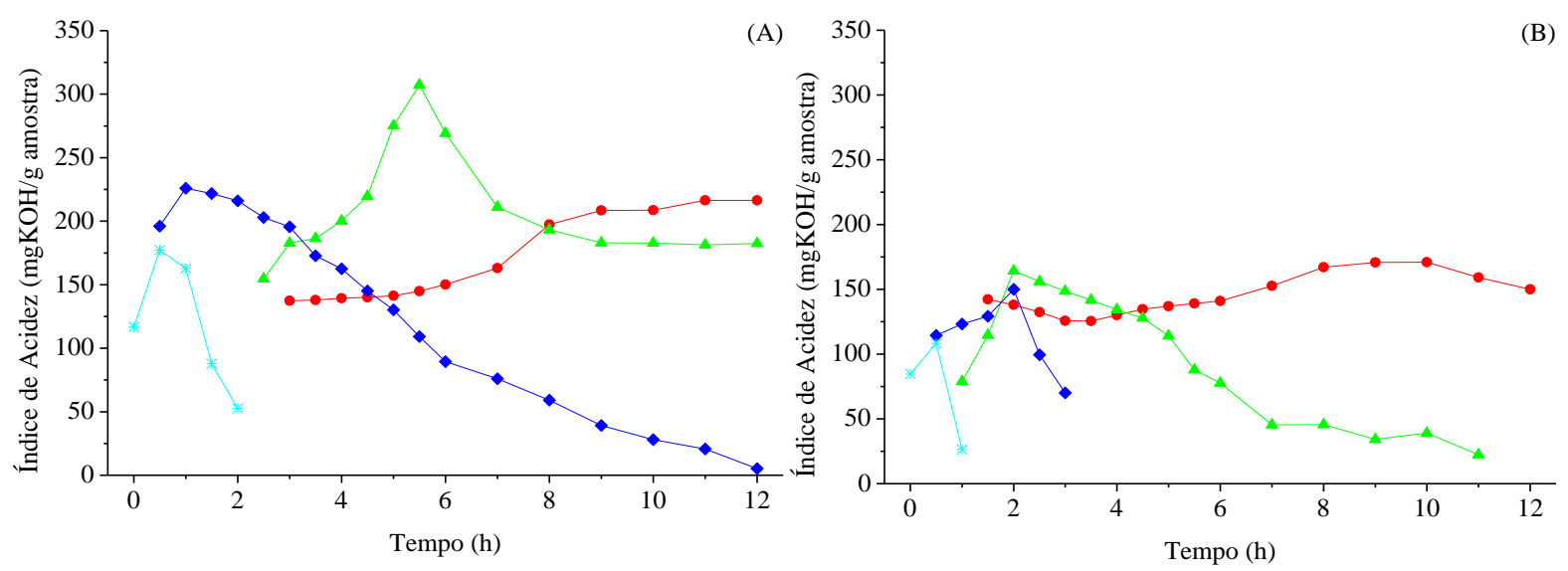

Figura 4.21 - Índice de acidez das amostras de bio-óleo obtidas na ausência (A) e presença (B) de Ni(carboxilato) 2 . Reações sem agitação a (•) $300{ }^{\circ} \mathrm{C}$; ( $\Delta$ ) $330{ }^{\circ} \mathrm{C}$; (•) $350{ }^{\circ} \mathrm{C}$ e (*) $370{ }^{\circ} \mathrm{C}$.

\subsection{Considerações do Capítulo}

Neste capítulo, foi possível demonstrar que é possível selecionar a formação de polímero ou bio-óleo através da escolha adequada de tempo, temperatura e a presença de catalisador. Na primeira parte foi observado que íons de diferentes metais podem ser utilizados como catalisadores nas reações de polimerização e pirólise dos TAGs. Podendo obter tanto polímeros com maior viscosidade em menores períodos de tempo, assim como uma maior quantidade de bio-óleo em um mesmo período de tempo. Dentre eles, se destacam os íons de $\mathrm{Pb}^{2+}, \mathrm{Ni}^{2+}$ e $\mathrm{Al}^{3+}$ por auxiliar a formação de bio-óleo e na obtenção de polímeros de alta viscosidade em curtos períodos de tempo. Ao avaliar o bio-óleo formado nos mesmos valores de conversão, foi possível observar que ao utilizar os íons de metais foi possível obter uma maior quantidade de compostos ácidos formados, assim como compostos com baixa quantidade de carbonos em suas cadeias. Ao utilizar os íons de $\mathrm{Ni}^{2+}, \mathrm{Cu}^{2+}$ e $\mathrm{Zn}^{2+}$, foi possível observar a produção de precipitados baseados em carbetos e metais no estado de oxidação zero, demonstrando que os catalisadores estão atuando como agentes oxidantes durante as reações de polimerização/pirólise dos TAGs.

Na segunda parte foi observado que a decomposição térmica dos TAGs ocorre em duas etapas: Na primeira etapa ocorre a formação de dienos na conformação trans-trans conjugadas seguido por seu consumo. Este perfil de produção e consumo pode ser relacionado com o aumento da viscosidade, sugerindo que é um processo determinante para a polimerização dos TAGs. A segunda etapa ocorre através da redução da viscosidade do material, sendo um indício da quebra de ligações e formação de compostos leves, associada ao processo de pirólise. 
Estudando a composição do bio-óleo com relação ao tempo, foi observado que as reações sem catalisador produzem grandes quantidades de ácidos carboxílicos e pequenas quantidades de hidrocarbonetos saturados e insaturados. Ao utilizar catalisador de níquel, foi observado uma redução na presença dos compostos ácidos carboxílicos e um aumento na presença de hidrocarbonetos saturados e insaturados. Evidenciando a atividade catalítica do íon de metal na descarboxilação e descarbonilação dos grupos carboxilas.

Vale mencionar que o tempo de residência dos compostos voláteis no sistema reacional é determinante para a composição dos bio-óleos. Na primeira parte do trabalho foi utilizado sistema com agitação interna, o que favoreceu a saída dos ácidos carboxílicos antes de sua decomposição. A segunda parte foi realizada na ausência de agitação interna, o que aumentou o tempo de residência dos ácidos no reator e, por consequência, sua decomposição e aumento na presença de hidrocarbonetos. 


\section{Capítulo 5}

Tratamento Térmico dos Ácidos Graxos de Soja 
No presente capítulo, é avaliado o perfil das reações envolvendo o tratamento térmico dos AGs no decorrer do tempo. O trabalho é dividido em duas partes, a primeira abordando o material obtido no interior do reator e a segunda o bio-óleo condensado durante a reação. Avalia-se também possibilidade do uso de complexos a base de $\mathrm{Ni}^{2+}$ (Item 2.1.4) como possível catalisador para as reações de polimerização e pirólise. Para tal, foi utilizado o sistema descrito no Item 3.2.1B, na ausência de agitação mecânica.

\subsection{Polímeros}

Inicialmente, os polímeros foram submetidos à análise por viscosidade. Na Figura $\mathbf{5 . 1}$ é possível observar que viscosidade a $260{ }^{\circ} \mathrm{C}$ não varia de forma perceptível, já a partir de 300 ${ }^{\circ} \mathrm{C}$ é notado pequeno incremento e nas temperaturas de 330 e $350{ }^{\circ} \mathrm{C}$ o aumento torna-se vigoroso, chegando a valores próximos a 5000 cSt. Estes dados demonstram que a polimerização dos AG ocorre durante todo tempo reacional e é influenciada pelo aumento da temperatura. Ao utilizar catalisador, foram observados valores de viscosidade sempre inferiores aos obtidos nas reações com somente AG, o que sugere que o complexo esteja atuando em reações secundárias que reduzam o efeito de polimerização. Uma provável explicação para esse perfil é que o complexo de íon de metal esteja atuando na desoxigenação e formação de hidrocarbonetos de baixa massa molar. ${ }^{62}$
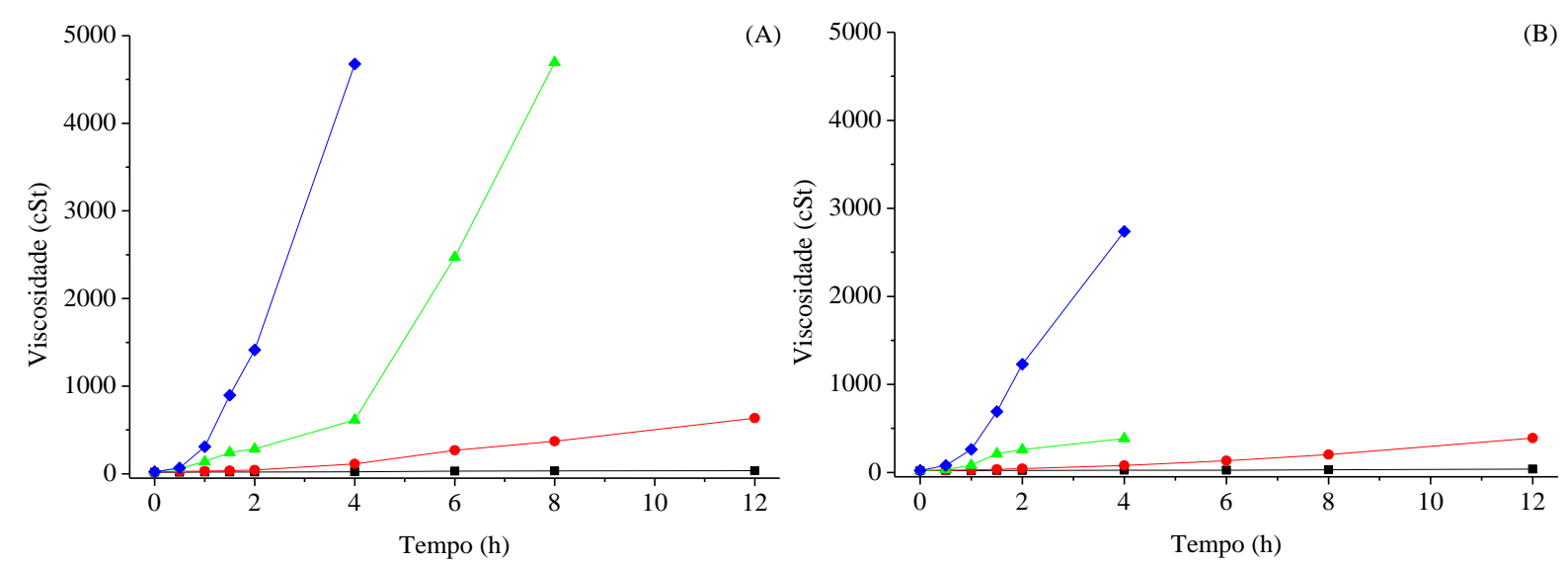

Figura 5.1 - Viscosidade do AG na ausência (A) e na presença (B) de Ni(carboxilato) ${ }_{2}$. Reações sem agitação a (•) $260{ }^{\circ} \mathrm{C},(\bullet) 300{ }^{\circ} \mathrm{C},(\Delta) 330{ }^{\circ} \mathrm{Ce}(\bullet) 350{ }^{\circ} \mathrm{C}$.

Nas temperaturas de 260 e $300{ }^{\circ} \mathrm{C}$ a redução do IA com relação ao tempo é baixa, entretanto, passa a ser pronunciada nas temperaturas de 330 e $350{ }^{\circ} \mathrm{C}$. Este resultado se encontra de acordo com os observados na literatura, ${ }^{62}$ em que maiores temperaturas favorecem a 
decomposição dos AGs. Ao comparar o perfil de queda dos valores de IA com o crescimento da viscosidade, é possível inferir que existe uma correlação entre a decomposição dos grupos ácidos carboxílicos e o aumento da viscosidade. Ao comparar os resultados na ausência e presença de catalisador é observado que no primeiro caso são obtidos valores tanto de viscosidade como de acidez superiores aos encontrados nas reações na presença do íon de $\mathrm{Ni}^{2+}$.

Utilizando esta base de análise, pode-se inferir que no tratamento térmico dos AGs ocorre inicialmente a decomposição dos grupos ácidos carboxílicos, posteriormente podem ocorrer reações de polimerização, favorecendo composto da alta massa molar e consequentemente de alta viscosidade, e de formação de compostos de baixa viscosidade, podendo estar relacionados com compostos de baixa massa molar. O primeiro caso ocorre majoritariamente utilizando os AGs puros. Já ao utilizar o catalisador, o segundo caso é favorecido, o que sugere que o complexo de $\mathrm{Ni}^{2+}$ atua cataliticamente na formação de composto de massa molar inferiores aos obtidos na ausência de catalisador.
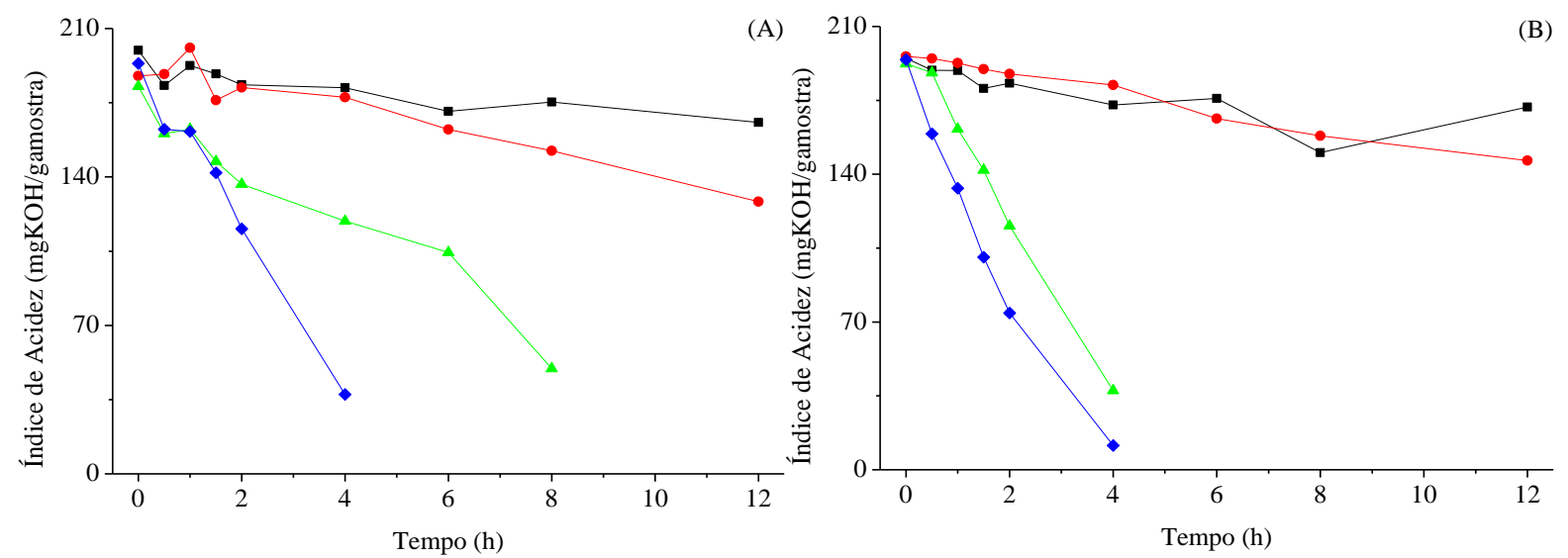

Figura 5.2 - Índice de acidez dos AGs obtidos em reações sem agitação nas temperaturas de (•) $260^{\circ} \mathrm{C},(\bullet) 300$ $\left.{ }^{\circ} \mathrm{C},(\Delta) 330{ }^{\circ} \mathrm{C} \mathrm{e} \mathrm{(}\right) 350{ }^{\circ} \mathrm{C}$, na ausência (A) e na presença (B) de Ni(carboxilato) 2 .

O perfil reacional do AG foi melhor estudado utilizando IV-ATR. Para isso, foram avaliadas as bandas de absorção relacionada com duplas ligações conjugadas na conformação trans-trans $\left(987 \mathrm{~cm}^{-1}\right)$, com carbonila de grupo ácido carboxílico $\left(1708 \mathrm{~cm}^{-1}\right)$, com carbonila de anidrido $\left(1818 \mathrm{~cm}^{-1}\right)$ e com $\mathrm{CH}_{2} \mathrm{sp}^{3}\left(2922 \mathrm{~cm}^{-1}\right)$.

A primeira reação é a conjugação e isomerização de duplas ligações para conformação trans-trans, podendo ser observadas já na temperatura de $260^{\circ} \mathrm{C}$. A partir de $300{ }^{\circ} \mathrm{C}$ as duplas ligações são formadas e ao longo do tempo passam a ser consumidas, diminuindo assim a intensidade. Este perfil torna-se mais intenso ao aumentar a temperatura para 330 e $350{ }^{\circ} \mathrm{C}$, com rápida formação e consumo. A Figura 5.3 ressalta que a formação e decomposição é a 
mesma na presença e na ausência de catalisador, com picos de intensidade em períodos de tempo próximos, o que sugere pouca ou nenhuma influência neste processo.
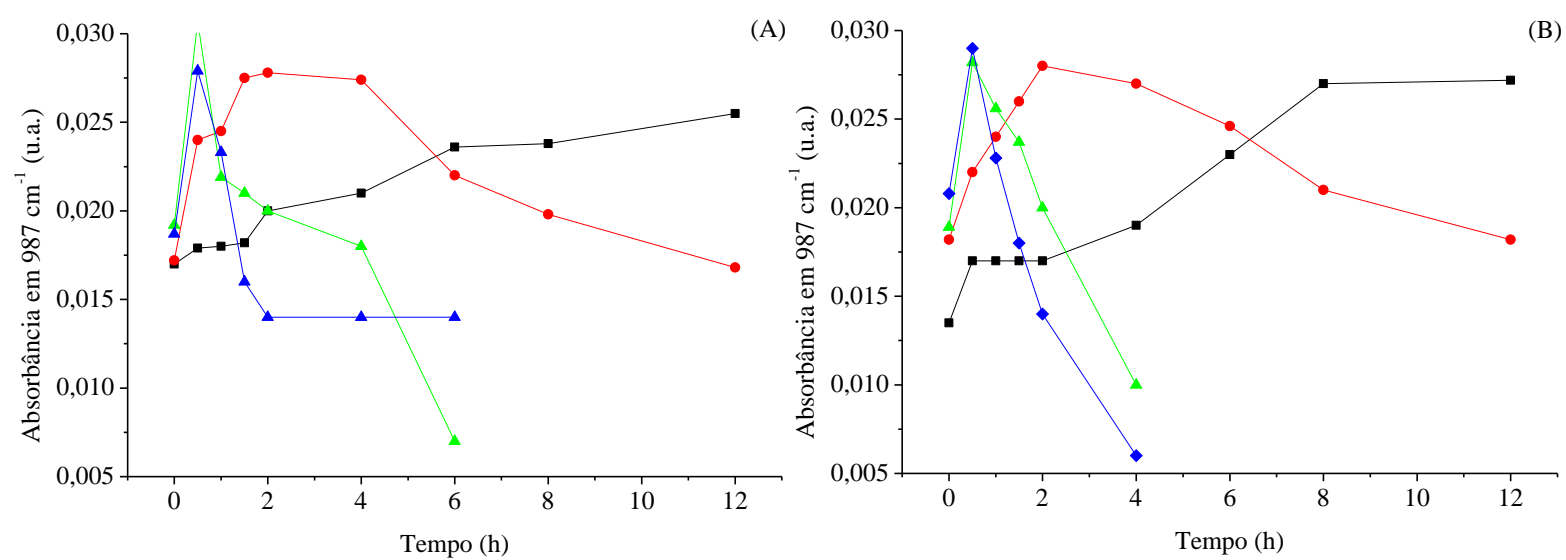

Figura 5.3 - Absorbâncias relacionadas às duplas ligações conjugadas na conformação trans-trans em 987 cm$^{-1}$. Reações sem agitação na ausência (A) e na presença (B) do Ni(carboxilato) 2 . Reações a (•) $260{ }^{\circ} \mathrm{C},(\bullet) 300{ }^{\circ} \mathrm{C}$, (४) $330{ }^{\circ} \mathrm{Ce}(\diamond) 350{ }^{\circ} \mathrm{C}$.

A variação de absorção da carbonila (Figura 5.5A e B) relacionada ao grupo ácido carboxílico possui o mesmo perfil que o demonstrando no IA, com maior redução nas temperaturas de 330 e $350{ }^{\circ} \mathrm{C}$, tanto na presença como na ausência de catalisador. As analises utilizando IV-ATR também demonstram vibrações características de anidrido (ver Figura 5.5C e D), tanto na ausência (a partir de $300{ }^{\circ} \mathrm{C}$ ) como na presença de catalisador (a partir de 260 ${ }^{\circ} \mathrm{C}$ ). Ao aumentar a temperatura, sua formação e consumo ocorre em tempos reduzidos. Estes resultados são um indício que a decomposição dos AGs a altas concentrações pode envolver também a reação de condensação, tendo o anidrido como intermediário.

O IV-ATR indica também que conforme ocorre a decomposição do grupo ácido carboxílico, há um incremento nas absorções dos grupos $\mathrm{CH}_{2}$ e $\mathrm{CH}_{3}$ nas cadeias (Figura 5.6). É importante mencionar que a alíquota obtida na reação á $350{ }^{\circ} \mathrm{C}$ após $12 \mathrm{~h}$, tanto na presença como na ausência de catalisador, demonstram a basicamente presença de hidrocarbonetos saturados e uma pequena quantidade de ácidos carboxílicos, como demonstrado na Figura 5.7. 

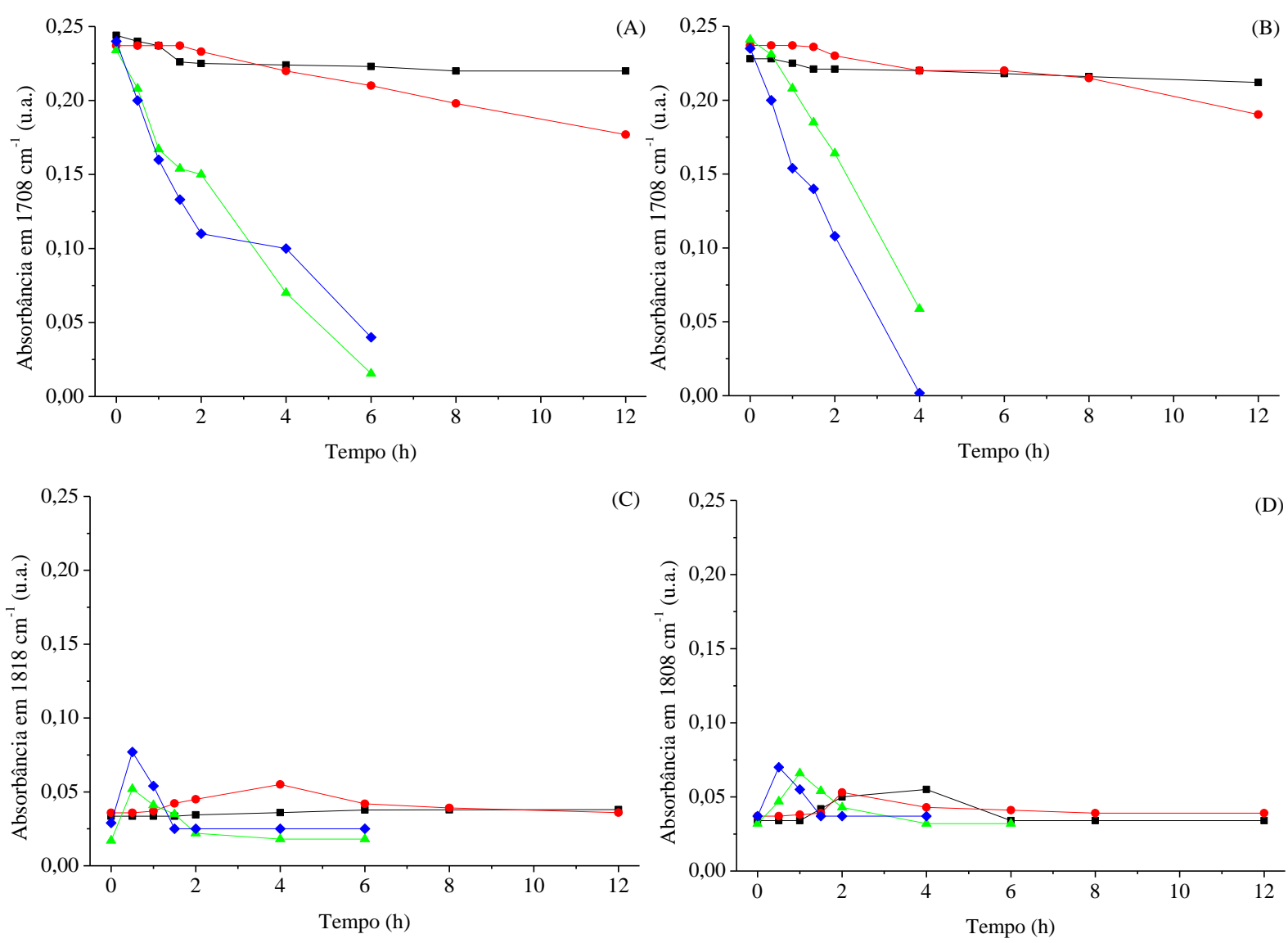

Figura 5.5 - Absorbância em $1708 \mathrm{~cm}^{-1}$ (A e B) relacionada a carbonila de grupo ácido carboxílico e em 1818 $\mathrm{cm}^{-1}(\mathrm{C}, \mathrm{D})$ relacionada a carbonila de anidrido. Reações na ausência de agitação, na ausência (A, C) e na presença (B, D) de Ni(carboxilato) $)_{2}$ e nas temperaturas de $(\bullet) 260{ }^{\circ} \mathrm{C},(\bullet) 300{ }^{\circ} \mathrm{C},(\Delta) 330{ }^{\circ} \mathrm{C} \mathrm{e} \mathrm{( \triangleleft )} 350{ }^{\circ} \mathrm{C}$.
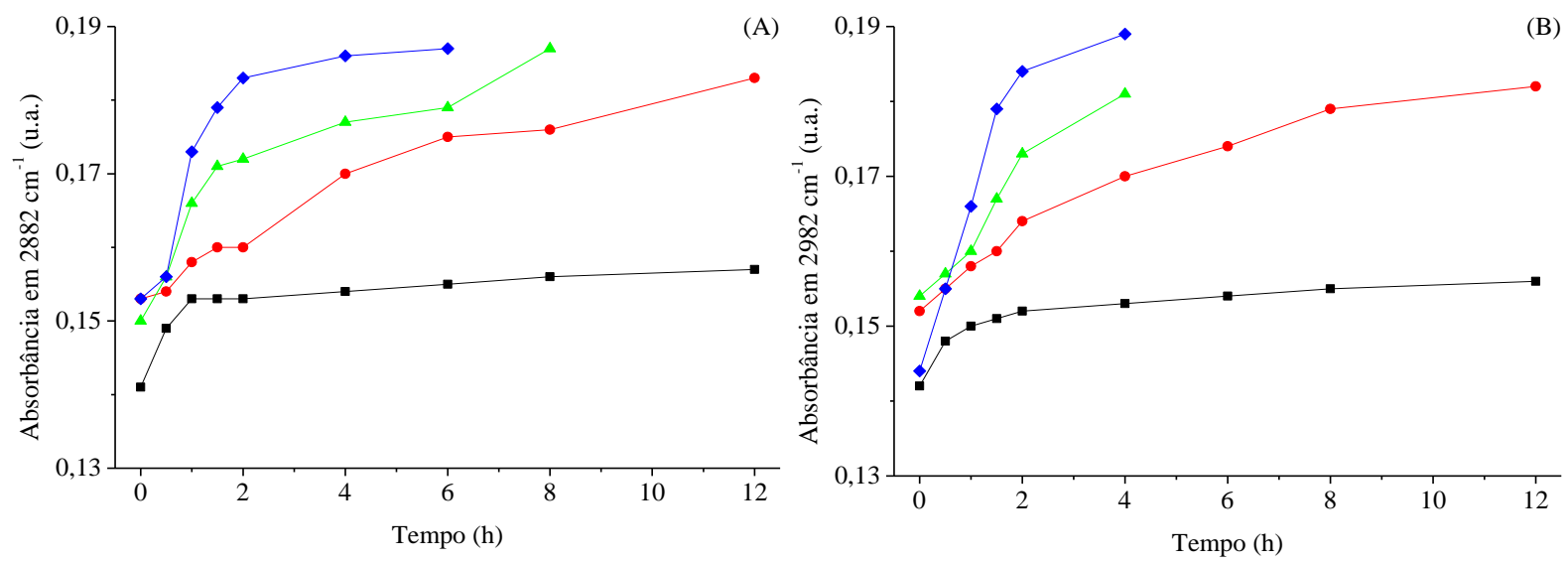

Figura 5.6 - Absorbância em $2982 \mathrm{~cm}^{-1}$ relacionada $\mathrm{CH}_{2} \mathrm{sp}^{3}$ na ausência (A) e na presença (B) do $\mathrm{Ni}$ (carboxilato) 2 . Reações a (•) $260{ }^{\circ} \mathrm{C} ;(\bullet) 300{ }^{\circ} \mathrm{C} ;(\Delta) 330^{\circ} \mathrm{C}$ e (•) $350{ }^{\circ} \mathrm{C}$. 


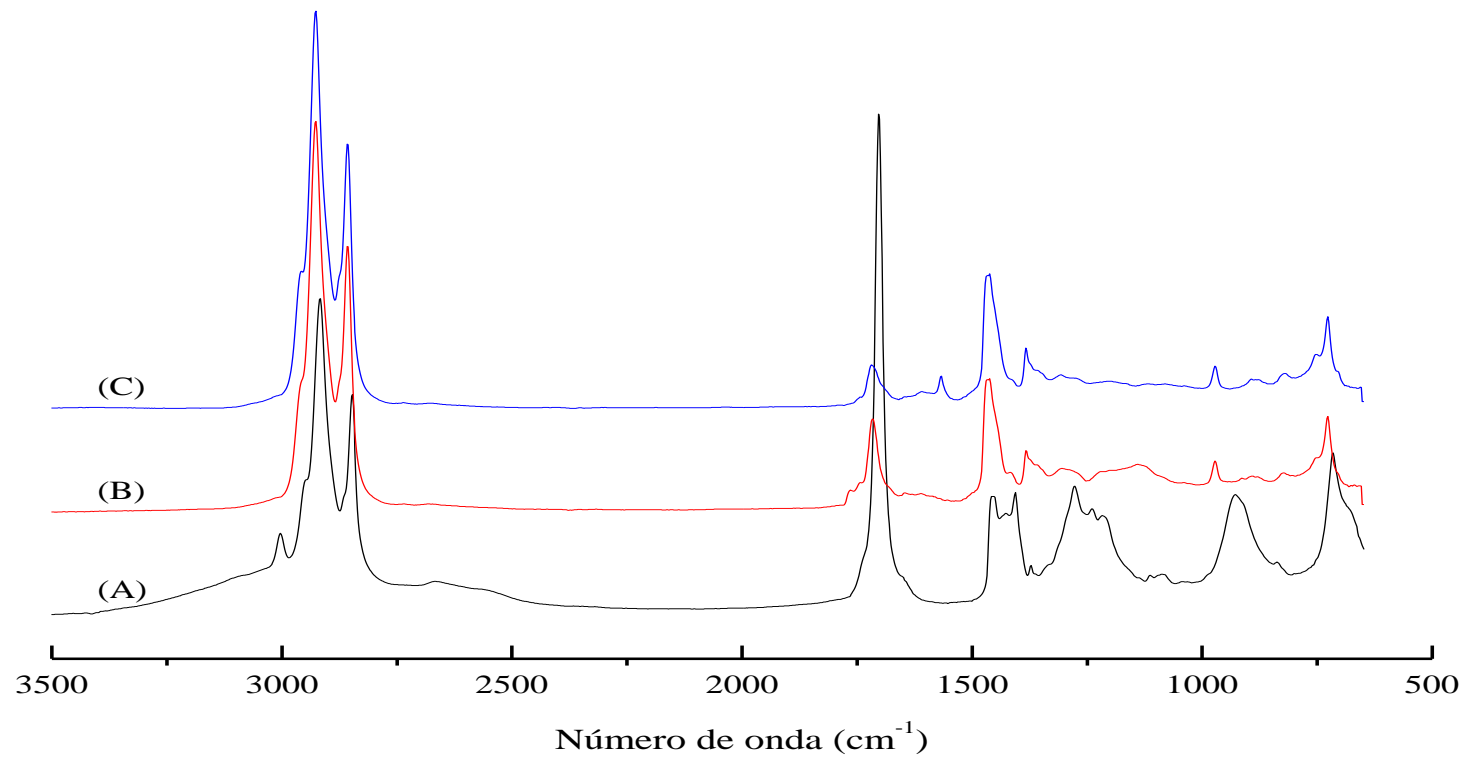

Figura 5.7 - IV-ATR do ácido carboxílico (A) utilizado como matéria prima e das amostras obtidas a $350{ }^{\circ} \mathrm{C}$ no tempo de 4 h na ausência (B) e presença de $\mathrm{Ni}$ (carboxilato) ${ }_{2}(\mathrm{C})$.

\subsection{Bio-Óleo}

As análises por cromatografia demonstraram que os voláteis são constituídos por diferentes tipos de hidrocarbonetos e ácidos carboxílicos, variando basicamente o tamanho da cadeia e a presença de instaurações. É necessário mencionar que os volumes produzidos de bioóleo em todos os tempos foram pequenos, demonstrando que o processo de formação de compostos voláteis é pouco favorecido ao aquecer o $\mathrm{AG}$, mesmo a temperatura de $350{ }^{\circ} \mathrm{C}$. Esta baixa quantidade em volume possibilitou somente a análise por CG nas amostras entre os tempos de 0,5 e $5 \mathrm{~h}$.

Inicialmente, é possível observar que os valores de composição dos AGs e hidrocarbonetos variam com a temperatura, tempo reacionais e presença de catalisador. Um perfil geral é que no decorrer do tempo ocorre uma redução da porcentagem de ácido carboxílico e um aumento da composição de hidrocarbonetos totais, principalmente os hidrocarbonetos saturados, demonstrando que o tempo auxilia as reações de decomposição dos ácidos. Ao variar a temperatura de $330{ }^{\circ} \mathrm{C}$ para $350{ }^{\circ} \mathrm{C}$ é notado valores menores de ácidos e maiores de hidrocarbonetos totais em todos os pontos analisados, demonstrando assim que maiores temperaturas favorecem a decomposição dos grupos ácidos carboxílicos. Ao avaliar a influência do catalisador, é possível uma redução de acidez e formação de hidrocarbonetos de até $50 \%$ da composição percentual. Assim, pode-se concluir que o complexo de $\mathrm{Ni}^{2+}$ atua na desoxigenação dos ácidos e formação de hidrocarbonetos tanto a 330 como a $350{ }^{\circ} \mathrm{C}$. 

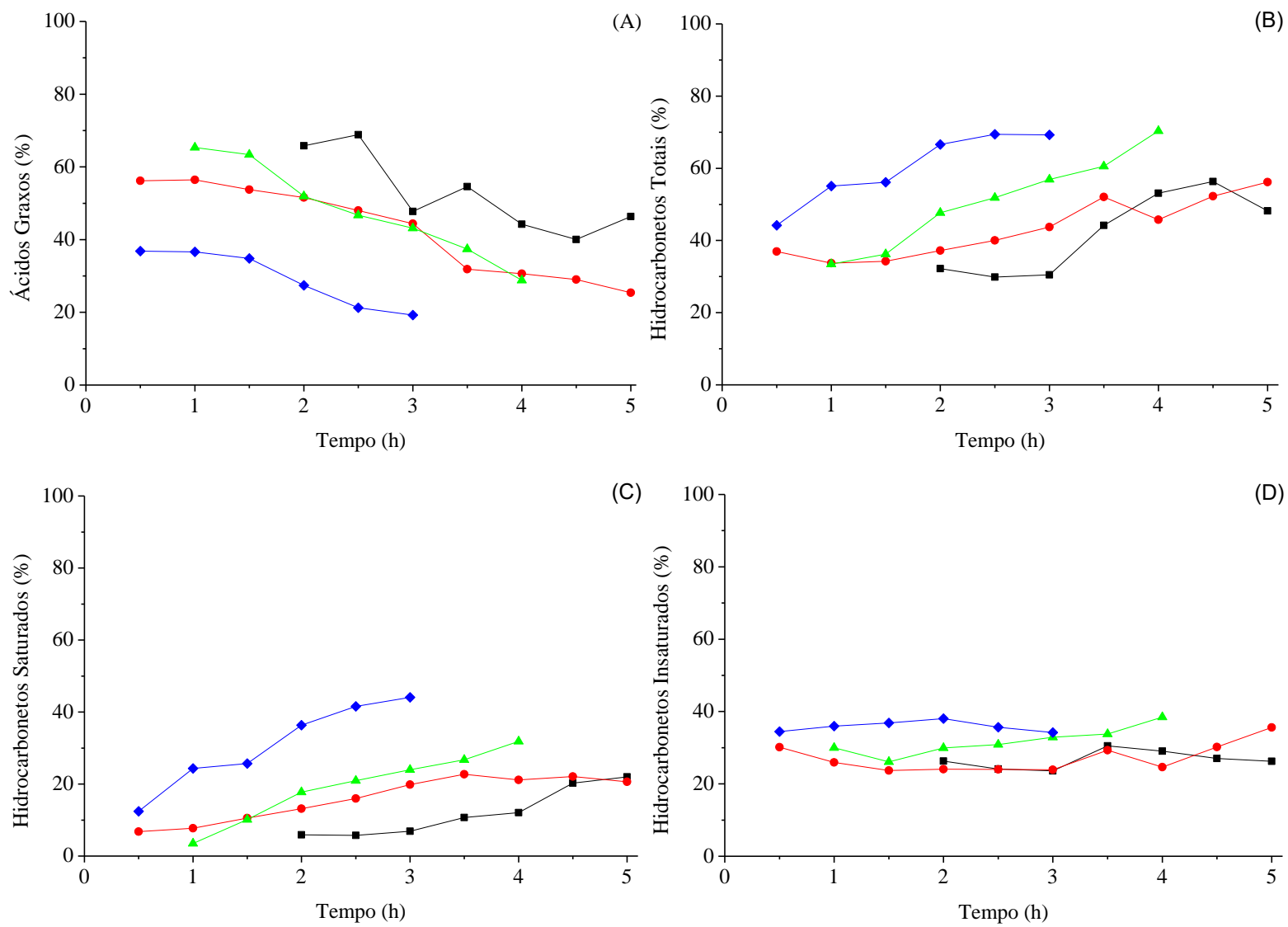

Figura 5.8 - Composição em porcentagem relativa dos bio-óleos obtidos a partir dos AGs de soja: (A) Ácidos carboxílicos totais; (B) hidrocarbonetos totais; (C) hidrocarbonetos saturados; (D) hidrocarbonetos insaturados. Reações sem agitação, na temperatura de $330{ }^{\circ} \mathrm{C}$ na ausência $(\bullet)$ e presença de catalisador $(\bullet)$, e reações a $350{ }^{\circ} \mathrm{C}$ na ausência $(\Delta)$ e presença de catalisador $(\diamond)$.

Para demonstrar a variação observada de ácidos e hidrocarbonetos, foram selecionados os compostos com maior concentração relativa de cada classe, assim as concentrações do ácido decanóico e do hidrocarboneto pentadeceno podem ser vistos na Figura 5.9.

Ao avaliar o índice de acidez (Figura 5.10), foi possível observar para todas as reações analisadas altos valores iniciais, com redução no decorrer do tempo. Note que o íon de $\mathrm{Ni}^{2+}$ reduz a acidez em aproximadamente um terço nas duas temperaturas avaliadas, demonstrando novamente atividade catalítica desoxigenação dos AGs. 

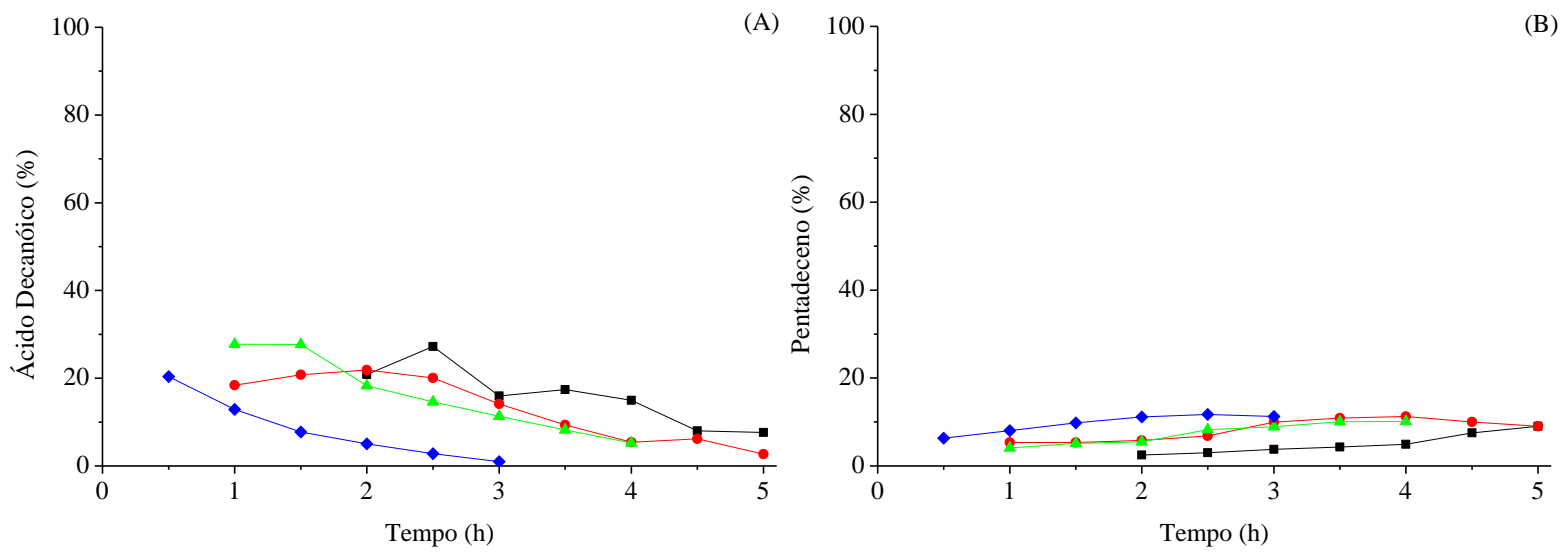

Figura 5.9 - Concentrações relativas dos ácidos decanóicos (A) e pentadeceno (B) presentes nos bio-óleos obtidos dos AGs de soja. Reações sem gitação na temperatura de $330^{\circ} \mathrm{C}$ na ausência $(\boldsymbol{\bullet})$ e presença de catalisador $(\bullet)$, e reações a $350{ }^{\circ} \mathrm{C}$ na ausência $(\Delta)$ e presença de catalisador $(\diamond)$.

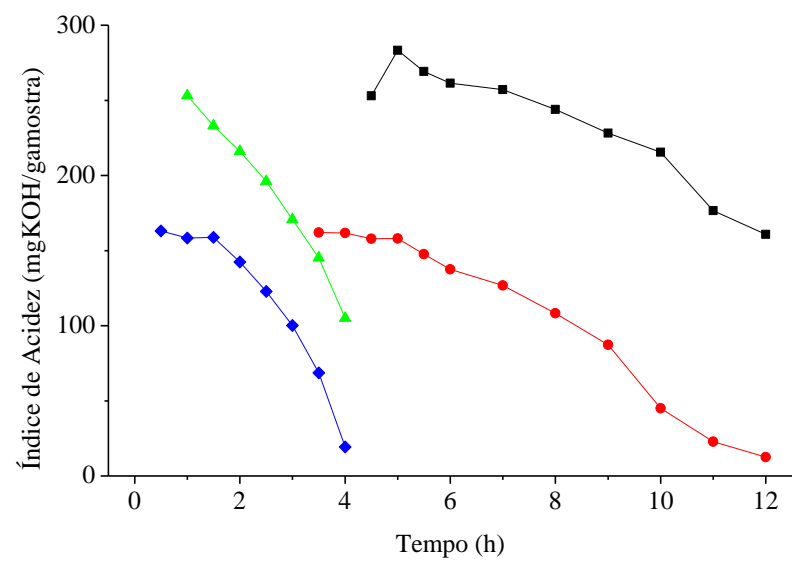

Figura 5.10 - Índice de acidez dos bio-óleos obtidos nas reações sem agitação na ausência (•) e presença (•) de catalisador na temperatura de $330{ }^{\circ} \mathrm{C}$ e bio-óleos obtidos na ausência $(\Delta)$ e presença $(\diamond)$ de catalisador a $350{ }^{\circ} \mathrm{C}$.

\subsection{Considerações do Capítulo}

No processo de polimerização ocorre a desoxigenação dos ácidos carboxílicos, gerando material de alta viscosidade e baixos valores de acidez, sendo esse efeito mais evidente nas temperaturas próximas a $350{ }^{\circ} \mathrm{C}$ e longos períodos de tempo reacional. Deve-se salientar que as duplas foram modificadas para a conformação conjugada trans-trans e trans-cis e, posteriormente, consumidas. Ao avaliar a influência do $\mathrm{Ni}$ (carboxilato) $)_{2}$, foi possível observar atividade catalítica tanto na redução da viscosidade como nos valores de índice de acidez. Este perfil pode ser atribuído ao efeito catalítico que favorece a desoxigenação, reduzindo a presença de grupos ácidos carboxílicos e formando compostos de baixa massa molar. As análises por IV- 
ATR demonstraram uma pequena quantidade de anidrido como intermediário, tanto na presença como na ausência de catalisador.

Ao avaliar a formação de bio-óleos, pode-se observar que o processo de formação de voláteis é limitado, gerando baixas quantidades de material e sua composição é baseada em ácidos carboxílicos nos tempos iniciais, a baixas temperaturas e na ausência de catalisador. Por outro lado, os hidrocarbonetos são favorecidos pelo maior tempo, altas temperaturas e catalisador. 


\section{Capítulo 6}

Tratamento Térmico do Éster Metílico de Soja 
O Capítulo 6 possui como objetivo avaliar o perfil reacional no decorrer do tempo utilizando o Éster Metílico de Soja (EM) como matéria-prima. O trabalho se encontra dividido em duas partes, a primeira abordando o polímero obtido no interior do reator e a segunda o bioóleo condensado durante a reação. Foi avaliada também a atividade catalítica do complexo a base de $\mathrm{Ni}^{2+}$ (Item 2.1.5) através da comparação entre os resultados obtidos na ausência e presença de catalisador. Para tal, foi utilizado o sistema descrito no Item 3.2.1B, na ausência de agitação mecânica.

\subsection{Polímeros}

Na Figura 6.1 pode ser observado o perfil de viscosidade das reações na ausência e presença de catalisador em diferentes temperaturas. A $260{ }^{\circ} \mathrm{C}$, a variação é imperceptível para ambas as reações. A partir de $300{ }^{\circ} \mathrm{C}$, é notado um aumento linear na viscosidade que se torna mais evidente a temperaturas mais altas. Observe que, ao utilizar catalisador, a inclinação da reta torna-se maior e ao comparar os valores com os obtidos na ausência de catalisador, é possível observar também um incremento de viscosidade de aproximadamente $60 \%$ nas reações a $350{ }^{\circ} \mathrm{C}$. Assim, é possível sugerir que o complexo de $\mathrm{Ni}$ atua como catalisador na polimerização dos EM.
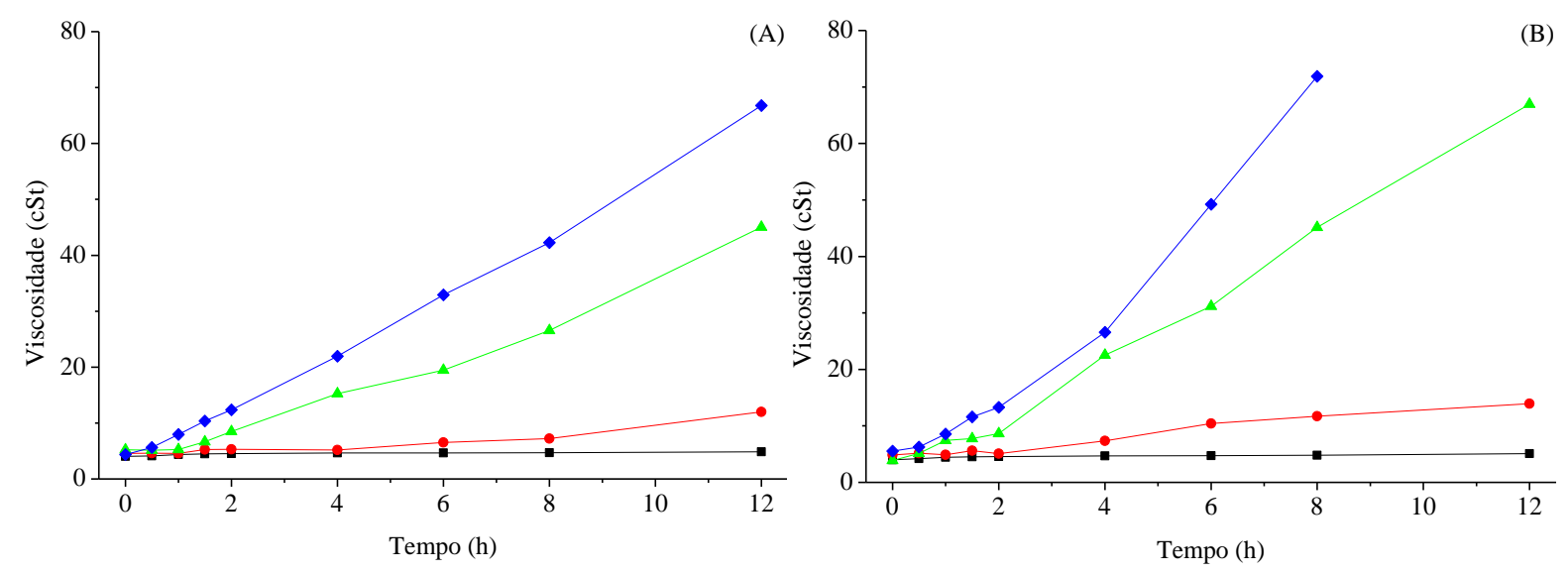

Figura 6.1 - Viscosidade dos EMs obtidos na ausência (A) e na presença (B) de Ni(carboxilato) ${ }_{2}$. Reações na ausência de agitação nas temperaturas de (•) $260{ }^{\circ} \mathrm{C},(\bullet) 300{ }^{\circ} \mathrm{C},(\Delta) 330{ }^{\circ} \mathrm{C}$ e (•) $350{ }^{\circ} \mathrm{C}$.

Os valores de índices de acidez demonstram pequeno incremento inicial com posterior estabilização no decorrer do tempo (ver Figura 6.2). Este perfil pode ser um indício de que a rota de decomposição dos EM e formação de compostos ácidos é pouco favorecida, tanto na presença como na ausência de catalisador. 

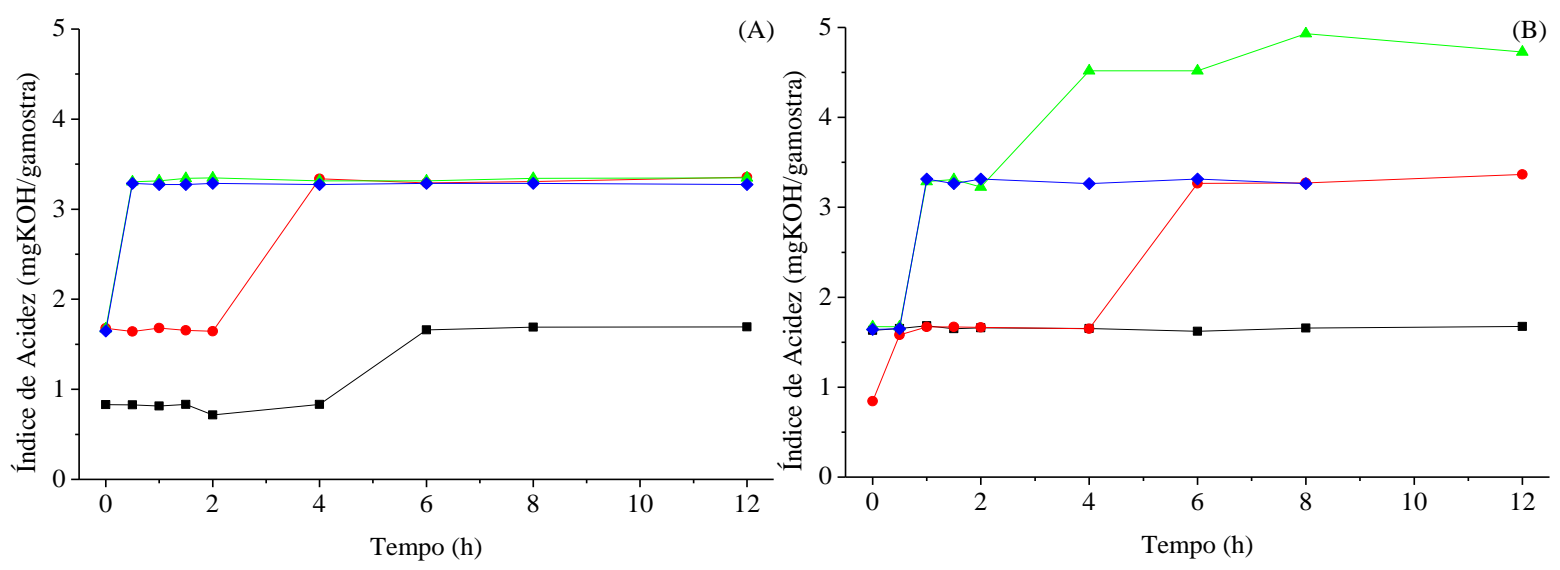

Figura 6.2 - Índice de acidez das reações com os EMs, sem agitação, nas temperaturas de (•) $260^{\circ} \mathrm{C},(\bullet) 300^{\circ} \mathrm{C}$,

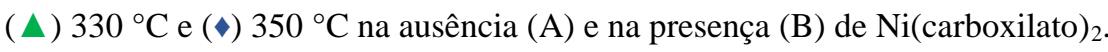

As amostras posteriormente foram analisadas por IV-ATR e monitoradas as bandas nos números de ondas relacionadas com duplas ligações conjugadas na conformação trans-trans $\left(987 \mathrm{~cm}^{-1}\right)$, carbonila de grupo ácido carboxílico $\left(1708 \mathrm{~cm}^{-1}\right)$, carbonila do grupo éster (1741 $\left.\mathrm{cm}^{-1}\right)$ e $\mathrm{CH}_{2} \mathrm{sp}^{3}\left(2922 \mathrm{~cm}^{-1}\right)$.

Na Figura 6.3 é observada que a primeira modificação que ocorre nos ésteres é a isomerização e conjugação das duplas, o que ocorre mesmo a $260{ }^{\circ} \mathrm{C}$. Ao aumentar a temperatura é observada uma rápida formação com posterior consumo da dupla na conformação trans-trans, sendo mais evidente a 330 e $350{ }^{\circ} \mathrm{C}$. AO comparar as absorções na ausência e presença de catalisador é observado perfil similar, sugerindo pouca ou nenhuma atividade do íon de metal nas reações que envolvem conjugação e isomerização das duplas.
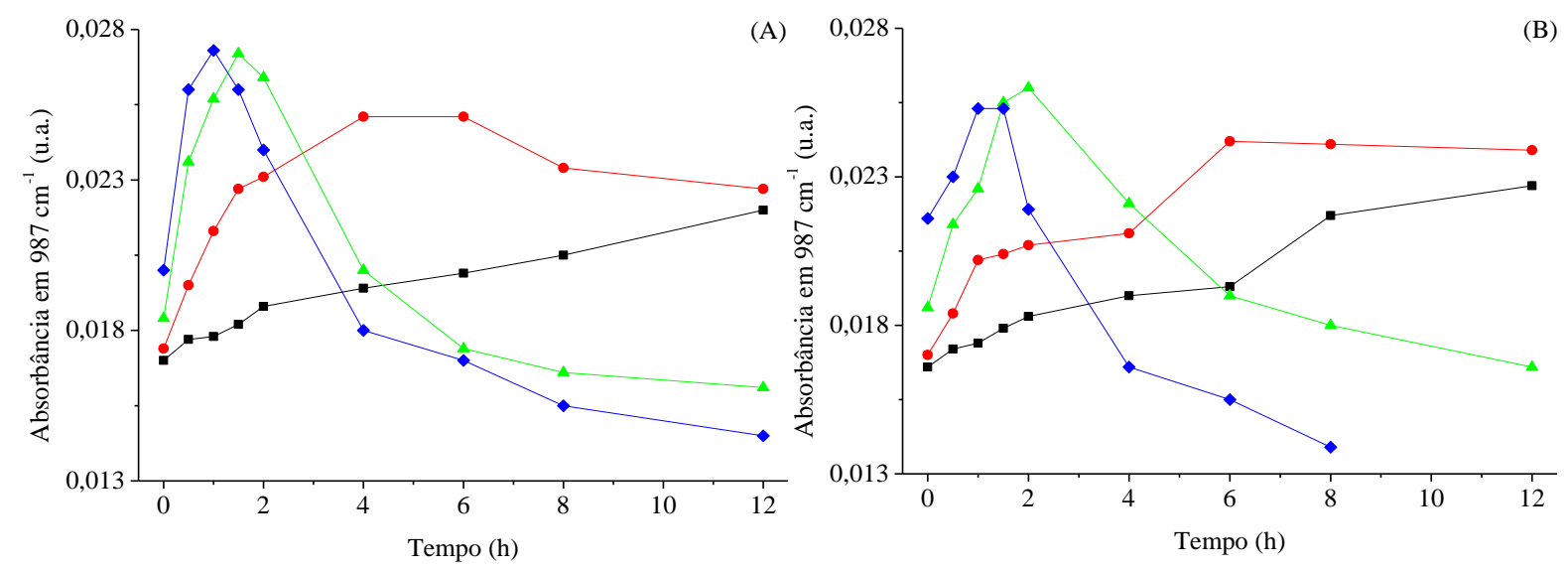

Figura 6.3 - Absorbâncias relacionadas às duplas ligações conjugadas na conformação trans-trans em $987 \mathrm{~cm}^{-1}$ na ausência (A) e na presença (B) do Ni(carboxilato) 2 . Reações sem agitação nas temperaturas de $(\bullet) 260^{\circ} \mathrm{C} ;(\bullet)$ $300{ }^{\circ} \mathrm{C} ;(\Delta) 330{ }^{\circ} \mathrm{C}$ e (४) $350{ }^{\circ} \mathrm{C}$. 
Na Figura 6.4 (A e B) se encontram os valores de absorbância da carbonila do grupo éster. Assim, é possível observar que tanto a temperatura de 260 como a $300{ }^{\circ} \mathrm{C}$, não se observa variação no decorrer do tempo. Já a $330{ }^{\circ} \mathrm{C}$ ocorre pequena variação no tempo de $12 \mathrm{~h}$ e a 350 ${ }^{\circ} \mathrm{C}$, a redução começa no tempo de $2 \mathrm{~h}$. É possível observar uma maior redução da absorbância ao utilizar catalisador na temperatura de $350{ }^{\circ} \mathrm{C}$, o que sugere atividade catalítica. As absorbâncias relacionadas com a carbonila do grupo ácido carboxílico se encontram na Figura 6.4 (C e D), o que demonstram que durante a reação praticamente não ocorre a formação de compostos contendo em suas estruturas esta função.
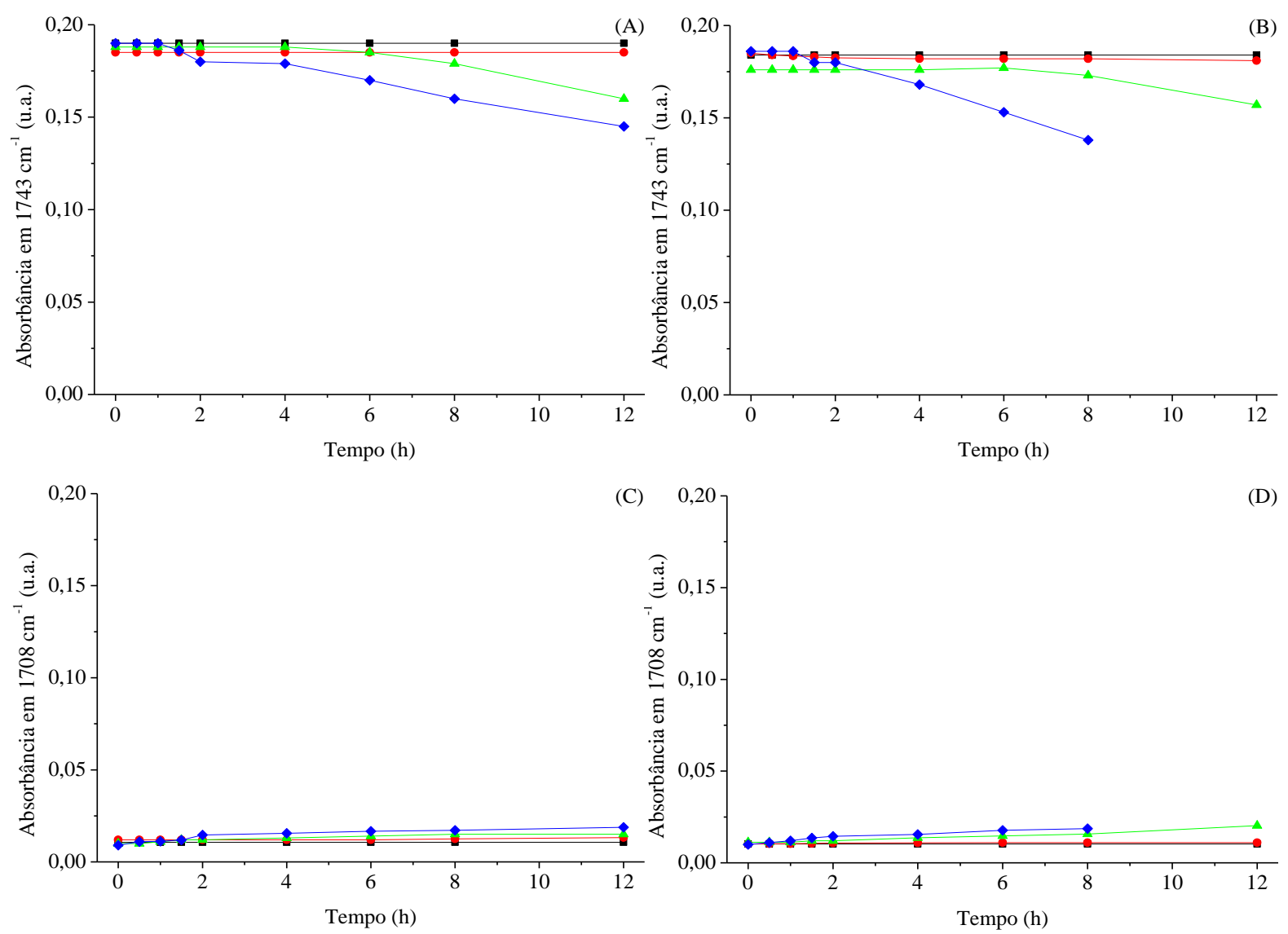

Figura 6.4 - Absorbância em $1743 \mathrm{~cm}^{-1}$ relacionada a carbonila de grupo éster (A, B) e absorbância em $1708 \mathrm{~cm}^{-}$ ${ }^{1}$ relacionada a carbonila de ácido carboxílico (C, D). Na ausência (A, C) e na presença (B, D) de Ni(carboxilato) 2 . Reações sem agitação nas temperaturas de $(\boldsymbol{\bullet}) 260^{\circ} \mathrm{C},(\bullet) 300{ }^{\circ} \mathrm{C},(\Delta) 330{ }^{\circ} \mathrm{C}$ e (») $350{ }^{\circ} \mathrm{C}$.

Ao avaliar a absorção dos grupos $\mathrm{CH}_{2}$ (Figura 6.5) foi observado um incremento em suas absorções, principalmente nas temperaturas de 330 e $350{ }^{\circ} \mathrm{C}$. Demonstrando assim que a tendência do tratamento térmico do EM tende a formar ligações carbono-carbono. 

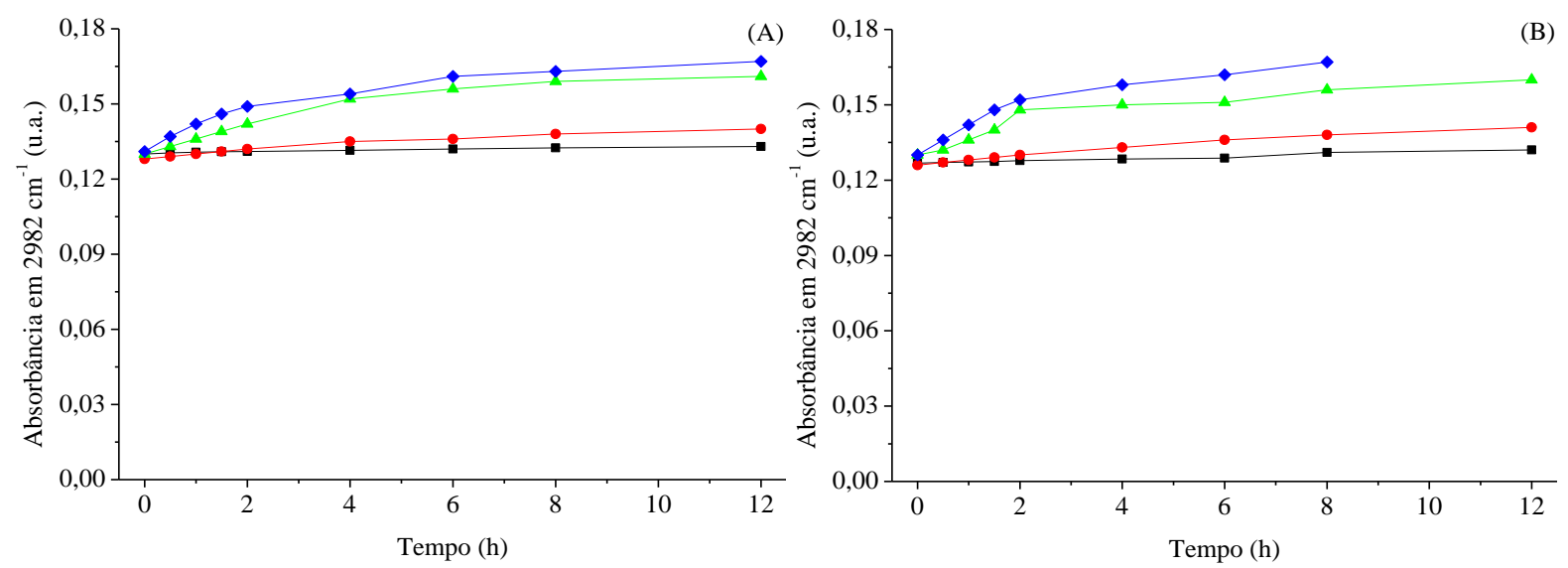

Figura 6.5 - Absorbância em $2982 \mathrm{~cm}^{-1}$ relacionada $\mathrm{CH}_{2} \mathrm{sp}^{3}$ na ausência (A) e na presença (B) do Ni(carboxilato) 2 . Reações sem agitação nas temperaturas de $(\bullet) 260{ }^{\circ} \mathrm{C},(\bullet) 300^{\circ} \mathrm{C},(\Delta) 330{ }^{\circ} \mathrm{C}$ e (४) $350{ }^{\circ} \mathrm{C}$.

\subsection{Bio-Óleo}

Inicialmente, é necessário mencionar que somente foi possível a obtenção de bio-óleo com volume suficiente para as análises por cromatografia em fase gasosa em poucos intervalos de tempo, na temperatura de $350{ }^{\circ} \mathrm{C}$ e principalmente ao utilizar catalisador. As análises por cromatografia demonstraram que os voláteis são constituídos por diferentes EMs, ácidos carboxílicos e hidrocarbonetos saturados e insaturados, variando o tamanho da cadeia e a presença ou não de instaurações. Para facilitar a análise dos resultados, os compostos foram aglutinados nestes grupos e os resultados de composições relativas podem ser observados na Figura 6.6.

A baixa formação de voláteis limitou a análise do perfil de composição dos bio-óleos durante o tempo devido a quantidade de pontos. Na reação na ausência de catalisador foram analisados somente os tempos de 4 e 4,5 h. Os resultados demonstram concentrações predominantes de ésteres de metila e hidrocarbonetos, assim como uma pequena formação de ácidos carboxílicos. Na reação contendo catalisador de $\mathrm{Ni}^{2+}$ houve uma maior formação de bioóleo, possibilitando análise por CG-MS nos tempos entre 1,5 e 4,5 h. Assim como na ausência de catalisador, o bio-óleo obtido foi formado por diferentes ésteres e hidrocarbonetos saturados e insaturados. Ao avaliar durante o tempo, não foi possível observar modificações substanciais consideráveis, com um pequeno aumento na produção de hidrocarbonetos saturados e diminuição dos insaturados nos tempos próximos a 4,5h. 

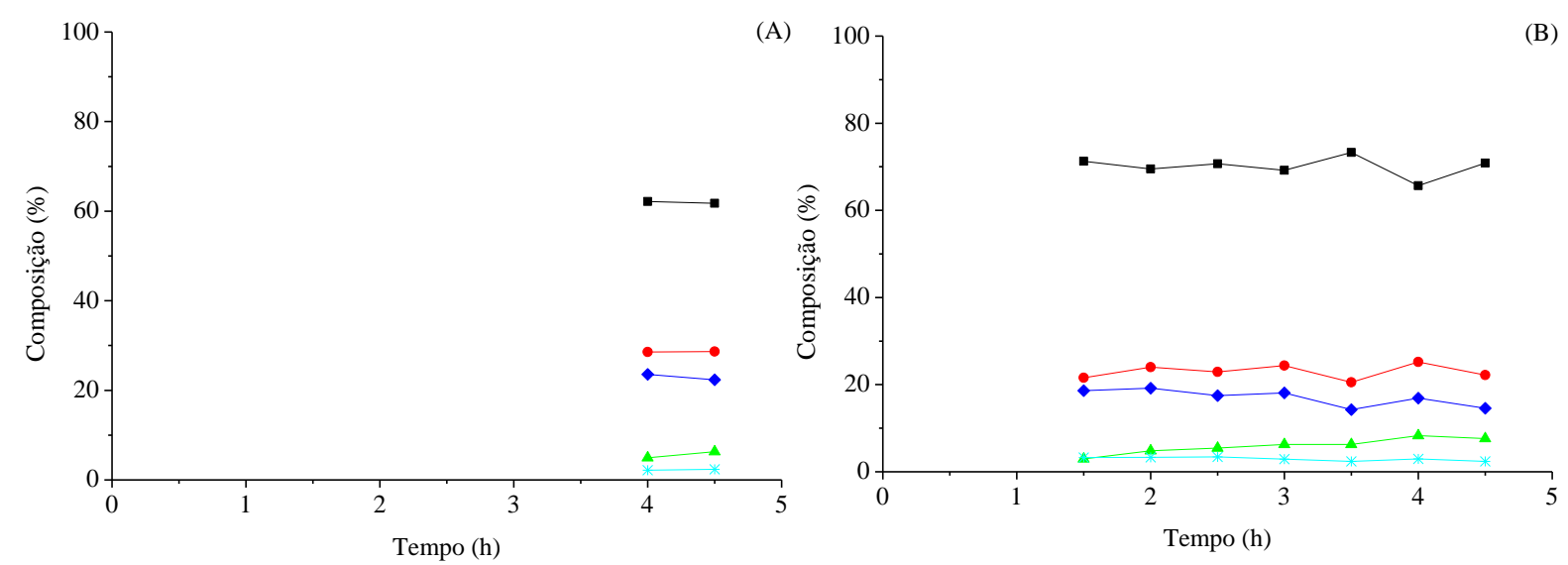

Figura 6.6 - Composição em porcentagem relativa dos principais grupos de compostos observados: (ロ) Ésteres metílicos, $(\bullet)$ hidrocarbonetos totais, $(\Delta)$ hidrocarbonetos saturados, $(\diamond)$ hidrocarbonetos insaturados e $\left(^{*}\right)$ ácidos carboxílicos. Reações sem agitação na (A) ausência e (B) presença de Catalisador na temperatura de $350{ }^{\circ} \mathrm{C}$.

Ao avaliar os diferentes ésteres (Figura 6.7), foi possível observar que, inicialmente, o octadecenoato de metila representa aproximadamente $25 \%$ da composição total, reduzindo na medida em que o tempo aumenta. Foi possível observar também uma estabilidade nas concentrações dos undecenoato de metila, decadienoato de metila, nonoato de metila e heptanoato de metila. Ao avaliar os hidrocarbonetos formados, foi possível observar uma tendência de aumento para o octano, nonano, undeceno, hexadeceno, e tetradeceno, como demonstrado na Figura 6.8. Assim, as análises por cromatografia sugerem que os bio-óleos são formados por ésteres de diferentes tamanhos de cadeia e hidrocarbonetos de cadeia curta. É possível observar também que a formação de grupos ácidos carboxílicos via desmetilação dos ésteres é limitada a valores próximos a $2 \%$.

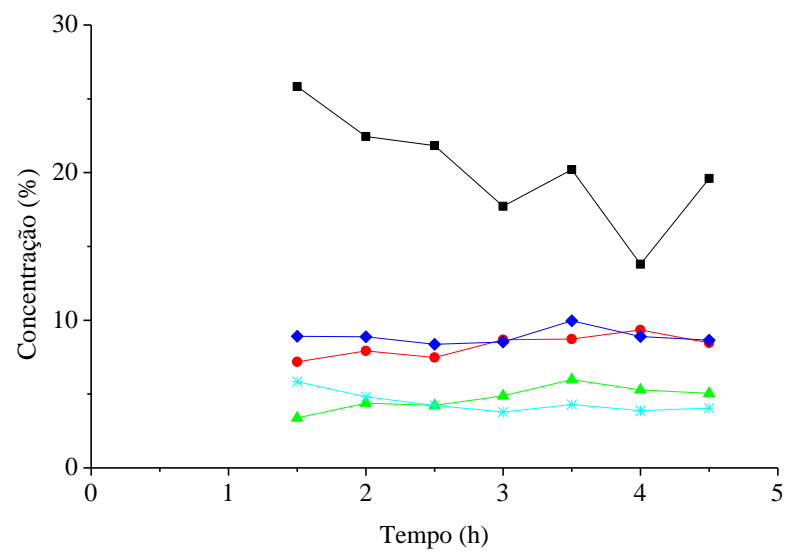

Figura 6.7 - Concentração dos principais ésteres de metila obtidos na reação sem agitação a $350{ }^{\circ} \mathrm{C}$ na presença de catalisador: $(\boldsymbol{\bullet})$ octadecenoato de metila, $(\bullet)$ undecenoato de metila, $(\boldsymbol{\Delta})$ decadienoato de metila, $(\diamond)$ nonoato de metila e $\left(^{*}\right)$ heptanoato de metila. 


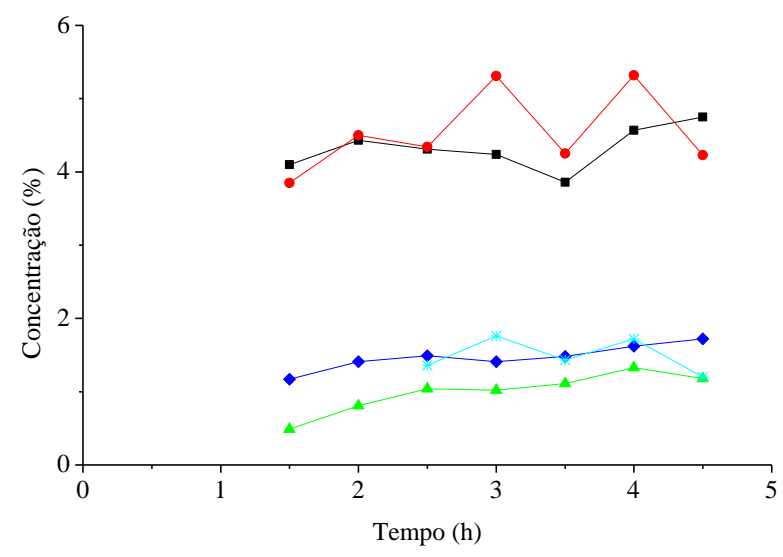

Figura 6.8 - Concentração dos principais hidrocarbonetos obtidos na reação sem agitação, a temperatura de 350 ${ }^{\circ} \mathrm{C}$ e presença de catalisador: $(\mathbf{\square})$ undeceno, $(\bullet)$ hexadeceno, $(\Delta)$ octano, $(\diamond)$ nonano e $\left(^{*}\right)$ tetradeceno.

As análises por índice de acidez demonstraram perfil decrescente no decorrer da reação, tanto na ausência como na presença de catalisador, não sendo possível determinar se ocorre atividade catalítica na redução da acidez, pois ocorre grande oscilação nos valores no decorrer do tempo (Figura 6.9).

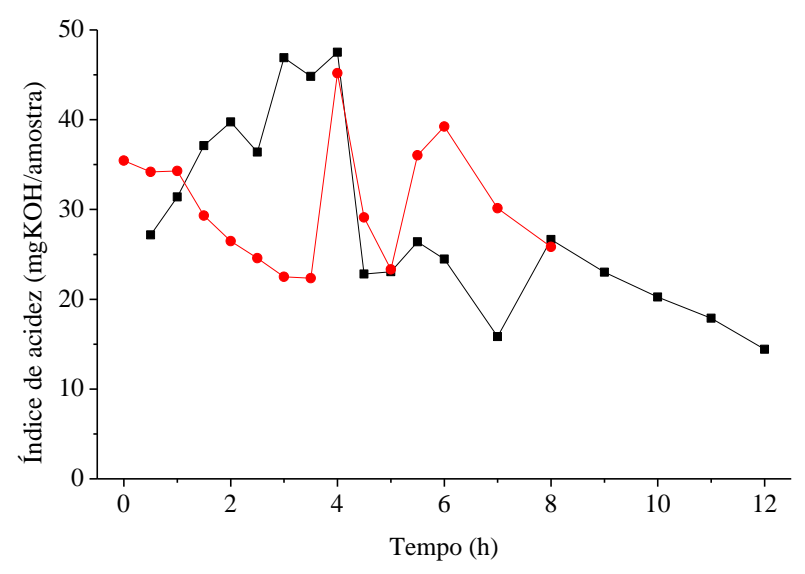

Figura 6.9 - Índice de acidez dos bio-óleos obtidos nas reações sem agitação na temperatura de $350{ }^{\circ} \mathrm{C}$ na ausência e $(\bullet)$ presença de catalisador de $\mathrm{Ni}^{2+}$.

\subsection{Considerações do Capítulo}

No presente capítulo foram observadas as seguintes características para o polímero obtido do tratamento térmico dos EMs: (1) as duplas ligações são isomerizadas, levando a formação de duplas ligações conformação trans-trans conjugadas, que são rapidamente consumidas; (2) o grupo éster é relativamente estável; (3) ao comparar os resultados na ausência 
na ausência e presença de $\mathrm{Ni}^{2+}$, foi possível observar a atividade catalítica do íon de metal na polimerização, com consequente obtenção de materiais com maiores viscosidades.

Ao avaliar os bio-óleos, foi possível observar que o processo de decomposição dos ésteres pouco favorece a formação de voláteis, sendo formandos em pequena quantidade somente na temperatura de $350{ }^{\circ} \mathrm{C}$ e principalmente na presença de catalisador. As análises por cromatografia sugerem que os bio-óleos são produtos da destilação da própria matéria-prima e por ésteres e hidrocarbonetos produzidos pela ruptura das cadeias. Devido a impossibilidade de comparação das reações na ausência e presença de catalisador, não foi possível concluir se houve ou não atividade catalítica do íon de $\mathrm{Ni}^{2+}$. 


\section{Capítulo 7}

Polimerização dos Triacilglicerídeos e Ésteres Metílicos na Presença de aditivos 


\subsection{Polimerização dos EMs e TAGs na presença de AGs}

Para avaliar a influência dos AGs na polimerização dos EMs e dos TAGs, foram realizadas reações contendo blendas de AGs nas porcentagens de 0,0;0,1;1,0;10,0 e 25,0\%. Foi selecionada a temperatura de $300{ }^{\circ} \mathrm{C}$ como devido a estabilidade da carbonila dos EMs, minimizando assim a variavel relacionada a decomposição da carbonila e possibilitando compreender isoladamente as reações nas duplas ligações. Os polímeros foram analisados por viscosidade e índice de acidez e alíquotas foram retiradas a cada $0,25 \mathrm{~h}$ para analise por IVATR. Durante o capítulo, serão relatados inicialmente os resultados obtidos com EMs, posteriormente com os TAGs e por fim a analise entre ambos.

Inicialmente os dados de viscosidade (Figura 7.1A) demonstram que a polimerização dos EMs é influenciada pela presença de AGs. Note que com apenas $0,1 \%$ já ocorre incremento de viscosidade, chegando no tempo de $12 \mathrm{~h}$ de reação com valor 2,5 vezes superior ao obtido com EM puro. É possível observar também que o perfil do crescimento de viscosidade versus tempo passa de linear para exponencial nos valores de 10 e $25 \%$ devido a alta atividade catalítica. Ao avaliar o IA (Figura 7.1B), observou-se um pequeno aumento de valor nas reações 0,0 e 0,1 , nos demais ocorreu redução. Este perfil sugere que o tratamento térmico dos EMs gera pequenas quantidades de AGs de forma espontânea, e quando na presença de altas concentrações de AGs ocorre predominantemente a decomposição dos compostos ácidos. Ao comparar os resultados obtidos de viscosidade e IA, pode-se inferir que os AGs ou os produtos de sua decomposição atuam como catalisadores no processo de polimerização dos EM, favorecendo maiores viscosidades em menores tempos.
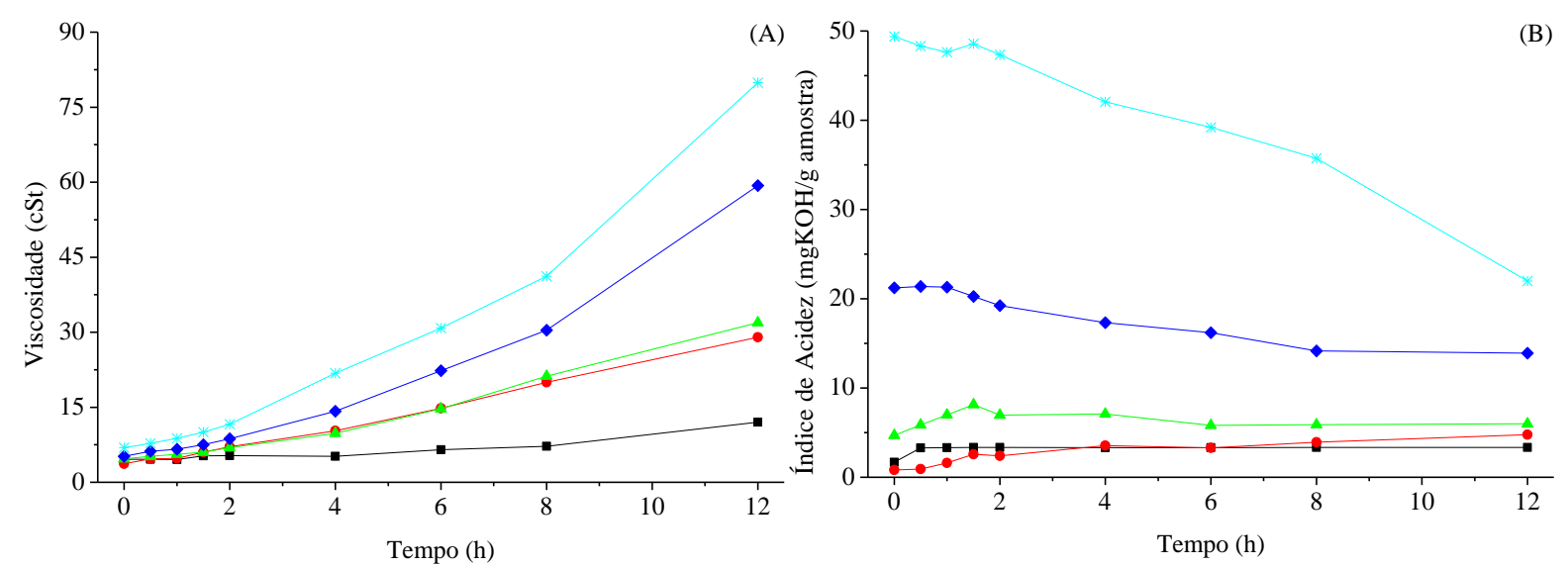

Figura 7.1 - Análises de viscosidade (A) e índice de acidez (B) nas reações sem agitação a $300{ }^{\circ} \mathrm{C}$ utilizando mistura de EM e AG nas proporções em massa de (•) 0,$0 ;(\bullet) 0,1 ;(\Delta) 1,0 ;(\bullet) 10,0$ e (*) $25 \%$. 
A partir dos IV-ATR obtidos foi possível obter importantes informações sobre o tratamento térmico por meio do monitoramento dos os números de ondas relacionados com as vibrações dos seguintes grupos funcionais (ver Figura 7.2): carbonilas dos EMs (A) e dos AGs (B); duplas ligações totais (relacionadas com a vibração axial) (C), conformação cis (D); conformação trans $(\mathbf{E})$ e conformação trans-trans conjugadas $(\mathbf{F})$.
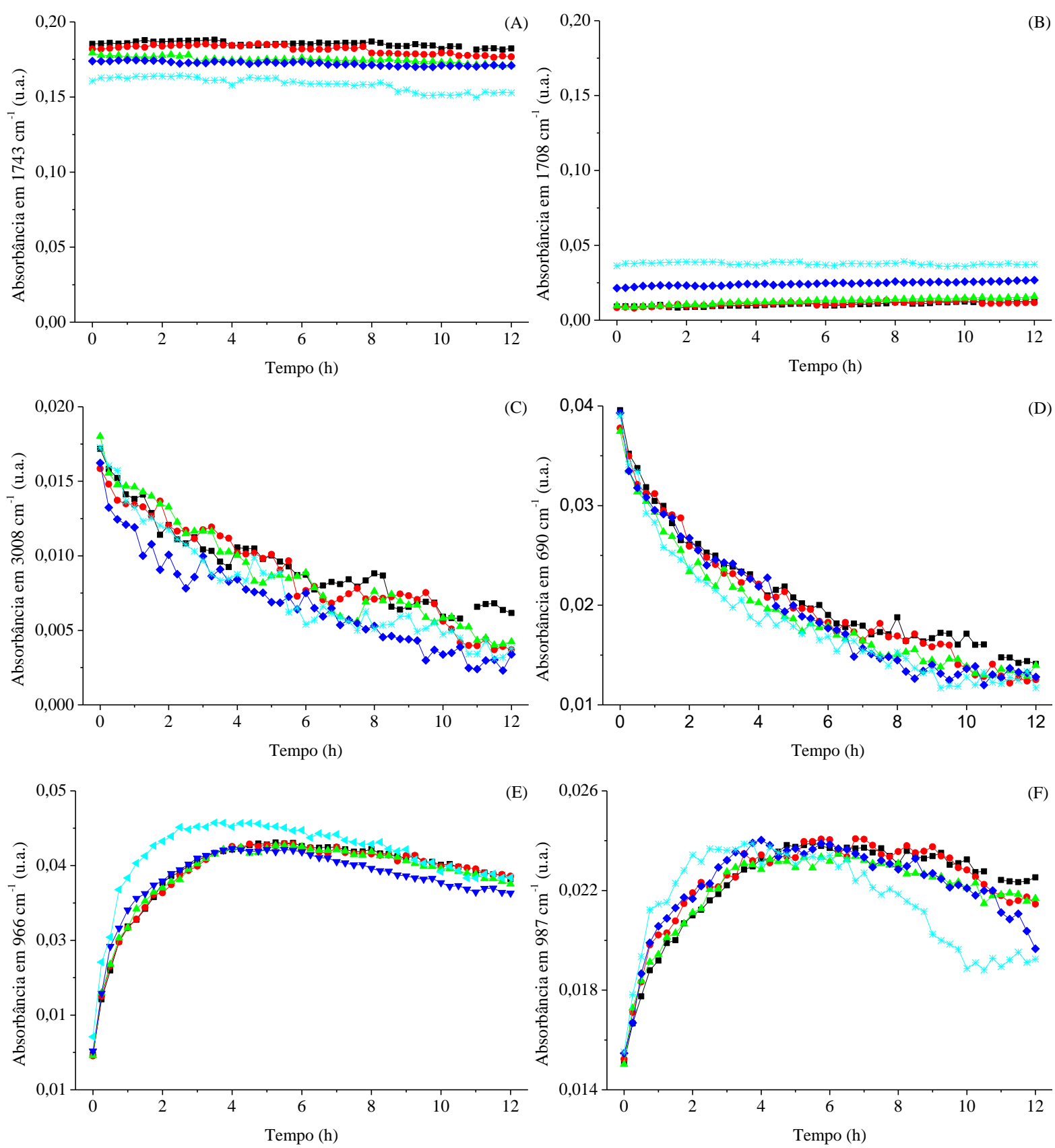

Figura 7.2 - Absorbâncias nos números de onda relacionados com carbonilas dos grupos éster (A) e ácidos carboxílicos (B), assim como duplas ligações totais (C), na conformação cis não conjugada (D), conformação trans (E) e trans-trans conjugadas (F). Reações sem agitação, na temperatura de $300{ }^{\circ} \mathrm{C}$ contento misturas de TAGs e AGs nas proporções em massa de (ロ) 0,$0 ;(\bullet) 0,1 ;(\Delta) 1,0 ;(\diamond) 10,0$ e (*) $25 \%$. 
Ao analisar os dados, é possível observar que as carbonilas presentes nos EMs são de grande estabilidade durante todo o tempo reacional devido a baixa variação na absorção, mesmo na presença dos AGs (A). Quando se observa o número de onda relacionado com a carbonila dos AGs, ocorre um pequeno aumento de intensidade nas reações 0,0 e $0,1 \%$, valores são estáveis nas porcentagens de 1,0 e 10\% e uma redução a 25\% (B). Assim, os dados de IV-ATR vão de acordo com o índice de acidez e sugerem que a formação dos grupos ácidos ocorre espontaneamente até atingir pequenos valores, que posteriormente se estabilizam. Quando na presença de grandes proporções de AGs, as reações de decomposição prevalecem e reduzem a presença destes compostos.

Ao avaliar as absorções relacionadas as duplas ligações, observa-se o seu consumo em todas as reações, entretanto, nas contendo AGs o consumo passa a ser mais intenso (C). É necessário mencionar que em $3008 \mathrm{~cm}^{-1}$ ocorre também vibrações relacionadas com $\mathrm{OH}$ de ácidos carboxílicos, sendo assim, a presença dos AGs pode ser o principal motivo da elevação das absorções na reação de $25 \%$. As reações relacionadas com as duplas ligações podem ser descritas da seguinte forma: Inicialmente, as duplas se encontram na conformação cis não conjugadas (D) e no decorrer da reação são consumidas. O seu consumo gera duplas ligações nas conformações trans (E) e trans-trans conjugadas, que posteriormente são consumidas $(\mathbf{F})$. Ao comparar os resultados na ausência e presença de AGs, é notado que quanto maior a concentração de AGs mais rápido a formação e o consumo ocorrem. Assim é possível concluir que os AGs ou o produto de sua decomposição atuam nas reações relacionadas as duplas ligações, favorecendo a polimerização dos EMs. Um esquema destas reações pode ser visualizado na Figura 7.3.

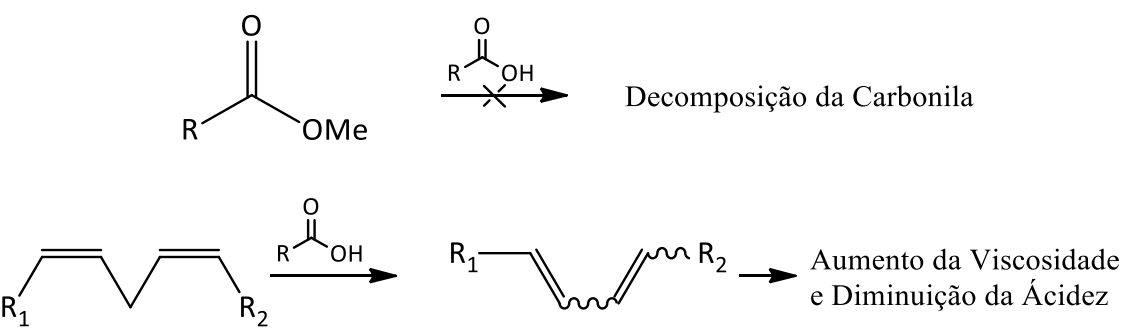

Figura 7.3 - Possíveis reações na polimerização dos EMs na presença de AGs.

Este mesmo estudo foi realizado com os TAGs e os resultados de viscosidade com relação ao tempo podem ser observados na Figura 7.4A. Ao utilizar somente o TAG, o incremento possui forma exponencial. Nas reações contendo contaminação por AG, foi possível 
observar incremento no início da reação superior ao obtido na ausência de AGs e com posterior estabilização dos valores nos tempos finais. Note que na faixa entre 0,1 e $10 \%$ o aumento da viscosidade é maior na medida em que se aumenta a proporção de AGs. Assim, estes resultados demonstram que mesmo em baixas concentrações de AGs, ocorre a polimerização. Na reação contendo $25 \%$, os valores de viscosidade passam a ser inferiores aos obtidos com 10\%, demonstrando que o excesso proporciona valores de viscosidade próximos aos obtidos na reação contendo somente os AGs (100\%).

Os valores de IA (ver Figura 7.4B) das reações com até de 10\% demonstram perfil linear crescente, com maior inclinação da curva na medida em que se aumenta a quantidade de AGs, sugerindo assim estes favorecem a decomposição dos TAGs. Na reação contendo $25 \%$ ocorre uma estabilização da acidez durante o tempo, indicando que o IA passa a ser influenciado tanto pela decomposição como pela produção dos compostos ácidos.
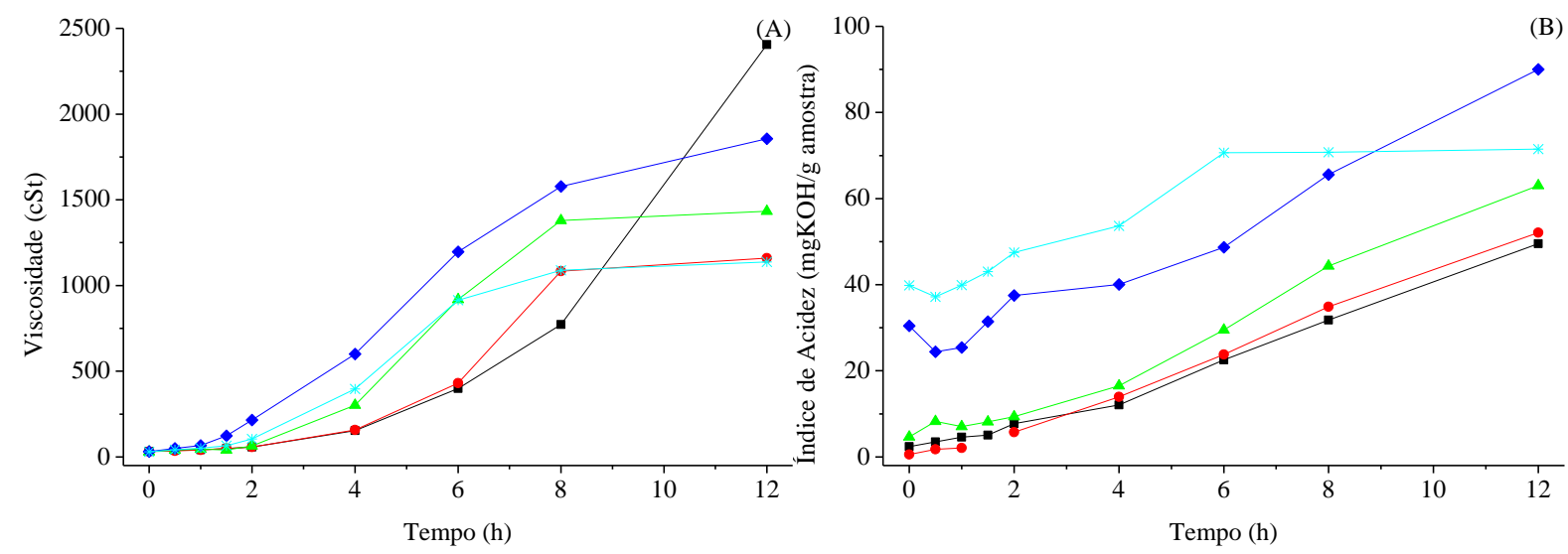

Figura 7.4 - Analises de viscosidade (A) e índice de acidez (B) das reações sem agitação a temperatura de $300{ }^{\circ} \mathrm{C}$ contendo TAGs e AGs nas proporções em massa de (•) 0,$0 ;(\bullet) 0,1 ;(\boldsymbol{\Delta}) 1,0 ;(\bullet) 10,0$ e $\left(^{*}\right) 25 \%$.

Ao avaliar as mudanças observadas por IV-ATR, é possível inicialmente observar redução na absorbância do grupo éster (A) e um crescimento no grupo ácido carboxílico (B), indicando que a decomposição do primeiro gera o segundo produto. Este perfil torna-se mais intenso na medida em que se aumenta a quantidade de AGs presentes inicialmente nos TAGs, indicando assim atividade catalítica dos AGs ou dos produtos de sua decomposição. É possível observar também um desvio nas absorções obtidas da carbonila dos grupos ácido carboxílico na reação de $25 \%$ o que pode ser explicado devido ao fato de haver duas reações ocorrendo ao mesmo tempo, a produção de ácidos carboxílicos e a decomposição tanto dos AGs presentes inicialmente como dos formados durante o tempo. 
Ao avaliar as duplas ligações (ver Figura 7.5), nota-se que ocorre consumo durante a reação $(\mathbf{C})$, entretanto, não é possível observar a influência dos AGs devido a absorções dos OH de ácidos carboxílicos produzidos/consumidos no processo. Ressalta-se que esta influência já foi demonstrada nas reações contendo EMs. Durante o consumo, as duplas ligações sofrem as seguintes modificações: duplas na conformação cis não conjugadas (D) são consumidas, sendo favorecida pela maior presença de AGs. O seu consumo gera duplas ligações nas conformações trans $(\mathbf{E})$ e trans-trans conjugadas $(\mathbf{F})$. Ambas as absorções possuem o mesmo perfil de aumento nos tempos iniciais e posterior consumo. Ao comparar os resultados na ausência e presença de AGs, é notado que maior concentração de AGs favorece a sua formação e posterior consumo. Note também que na medida em que aumenta a concentração dos AGs, o ápice de absorção ocorre em tempos cada vez menores. Assim, é possível concluir que os AGs, ou os produtos de sua decomposição, atuam nas reações relacionadas com as duplas ligações e, assim como no caso dos EMs, favorecem a polimerização dos TAGs. 

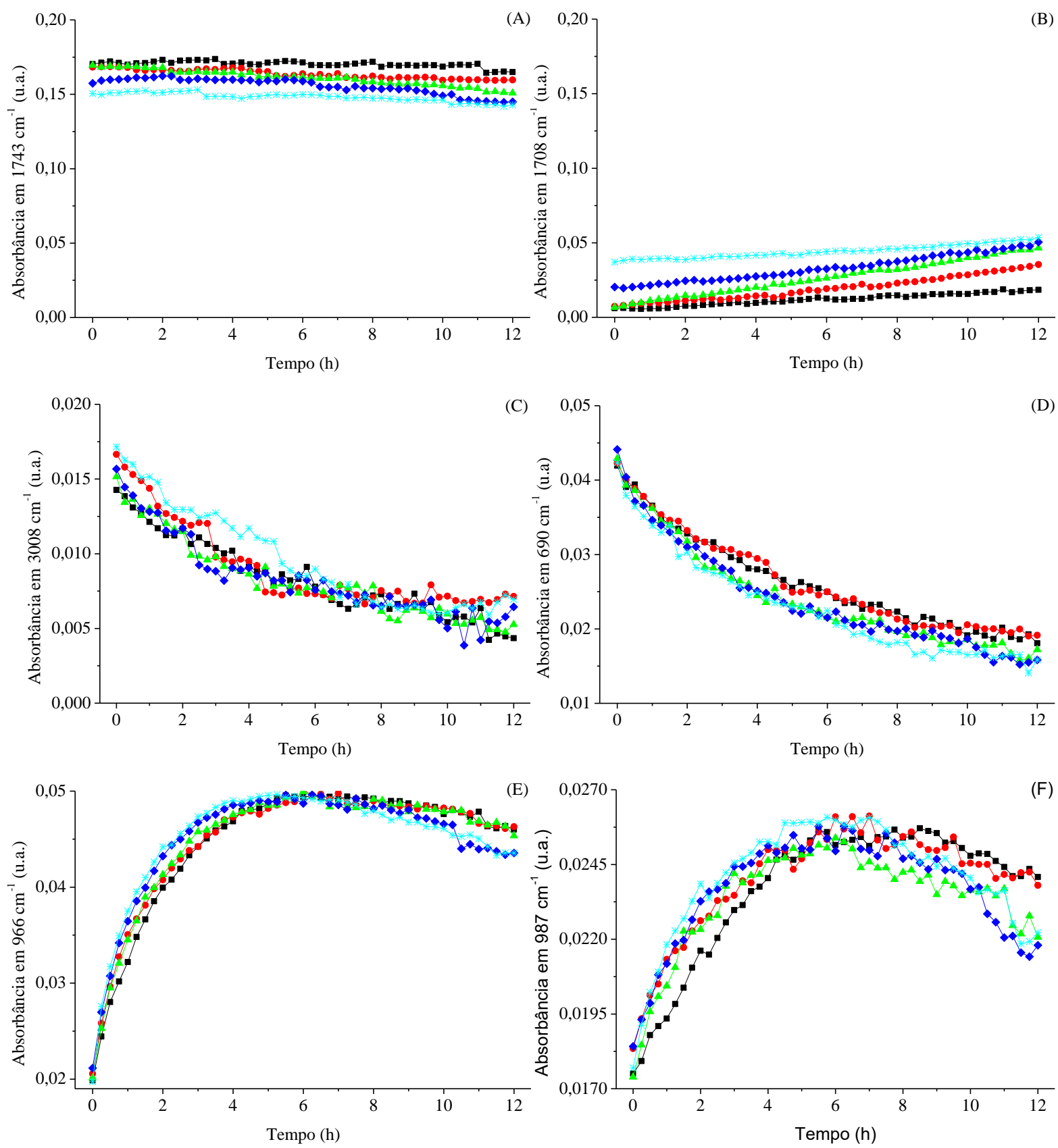

Figura 7.5 - Absorbâncias nos números de onda relacionados com carbonilas dos grupos éster (A) e ácidos carboxílicos (B), assim como duplas ligações totais (C), na conformação cis não conjugada (D), conformação trans (E) e trans-trans conjugadas (F). Reações sem agitação na temperatura de $300{ }^{\circ} \mathrm{C}$ contento TAGs e AGs nas relações em massa de (•) 0,$0 ;(\bullet) 0,1 ;(\Delta) 1,0 ;(\bullet) 10,0$ e (*) $25 \%$.

Assim, Na Figura 7.6 podem ser visualizadas as principais reações na polimerização dos TAGs. Ela ocorre pela decomposição do grupo éster (1), com consequente formação de compostos oxigenados, principalmente ácidos carboxílicos. Esta reação acarreta na diminuição da viscosidade e aumento da acidez. Em paralelo, ocorre o processo de isomerização/conjugação, proporcionando aumento da viscosidade e diminuição da acidez (2). 
Em ambas as reações se observou que pequenas quantidades de AGs podem atuar como catalisadores em ambas as reações.

(1)

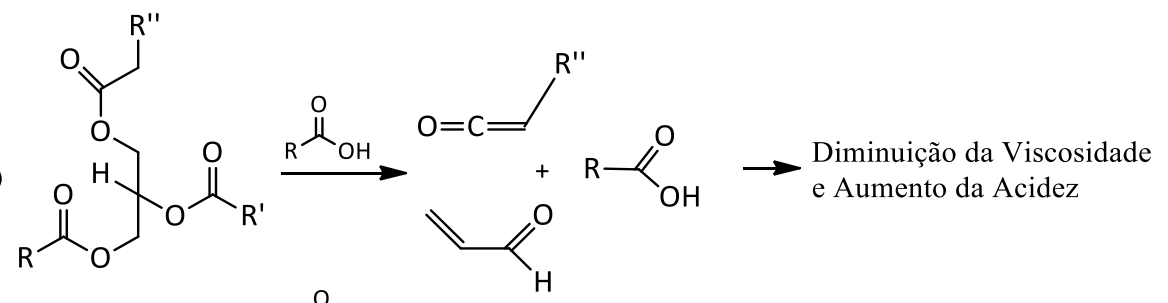

(2)

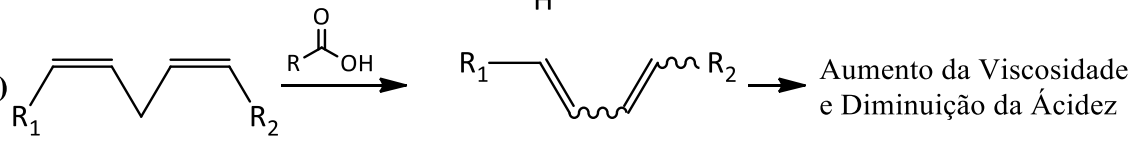

Figura 7.6 - Reações de polimerização/pirólise dos TAGs na presença de AGs.

\subsection{Polimerização dos EM e TAGs na presença de $\mathrm{H}_{3} \mathrm{PO}_{4}$ e $\mathrm{Ni}$ (carboxilato)2}

Para se obter melhores informações dos processos reacionais e das atividades catalíticas, o mesmo estudo demonstrando anteriormente foi realizado utilizando $\mathrm{Ni}$ (Carboxilato) 2 e $\mathrm{H}_{3} \mathrm{PO}_{4}$. É necessário mencionar que o complexo de níquel possui como característica atuar como um ácido de Lewis e o $\mathrm{H}_{3} \mathrm{PO}_{4}$ atuar como ácido de Brønsted.

Para facilitar a análise de viscosidade (Figura 7.7A) e índice de acidez (Figura7.7B) foram adicionados aos gráficos os dados obtidos das blendas de 0,0 a 25\% de EM/AG. Desta forma, observa-se que tanto a presença de $\mathrm{Ni}^{2+}$ como a presença de $\mathrm{H}_{3} \mathrm{PO}_{4}$ pouco influenciam no aumento da viscosidade e no índice de acidez quando comparados com a reação contendo EM puro e são inferiores aos dados obtidos com $0,1 \%$ de AG.
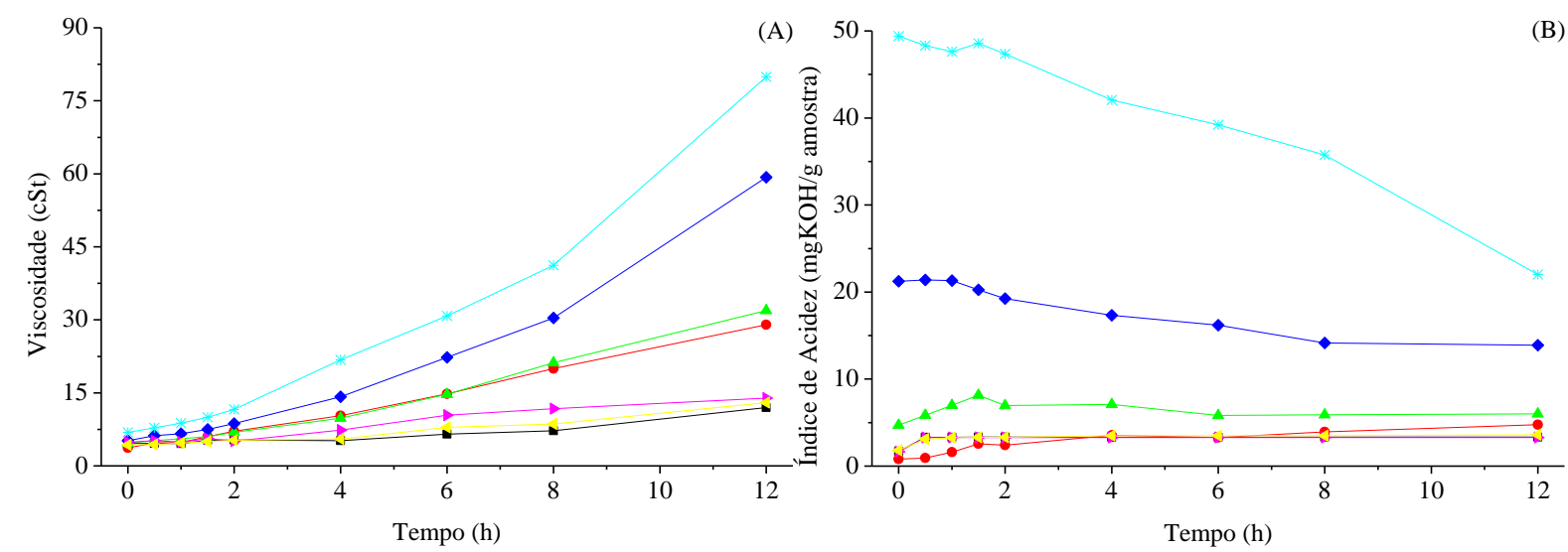

Figura 7.7 - Análises de viscosidade (A) e índice de acidez (B) nas reações sem agitação, a $300{ }^{\circ} \mathrm{C}$ contendo

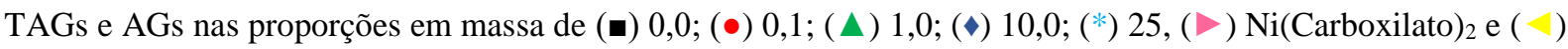
$\mathrm{H}_{3} \mathrm{PO}_{4}$. 
Ao avaliar os IV-ATR das amostras (ver Figura 7.8), não foi possível observar grandes variações nas reações contendo $\mathrm{Ni}^{2+} \mathrm{e}_{3} \mathrm{PO}_{4}$ frente aos dados obtidos no $\mathrm{EM}$ puro (ver Figura 7.8): As carbonilas dos EMs se mantém estáveis (A), a formação de ácidos carboxílicos é pouco relevante (B); não se observa grandes variações nas duplas totais (C); assim como no consumo das duplas cis $(\mathbf{D})$ e consequente formação trans $(\mathbf{E})$ e trans-trans $(\mathbf{F})$. Desta forma, é possível inferir que os íons de $\mathrm{Ni}^{2+}$ e de $\mathrm{H}^{+}$pouco interferem nas reações que envolvem a isomerização e conjugação de duplas, assim como nas reações posteriores de polimerização.
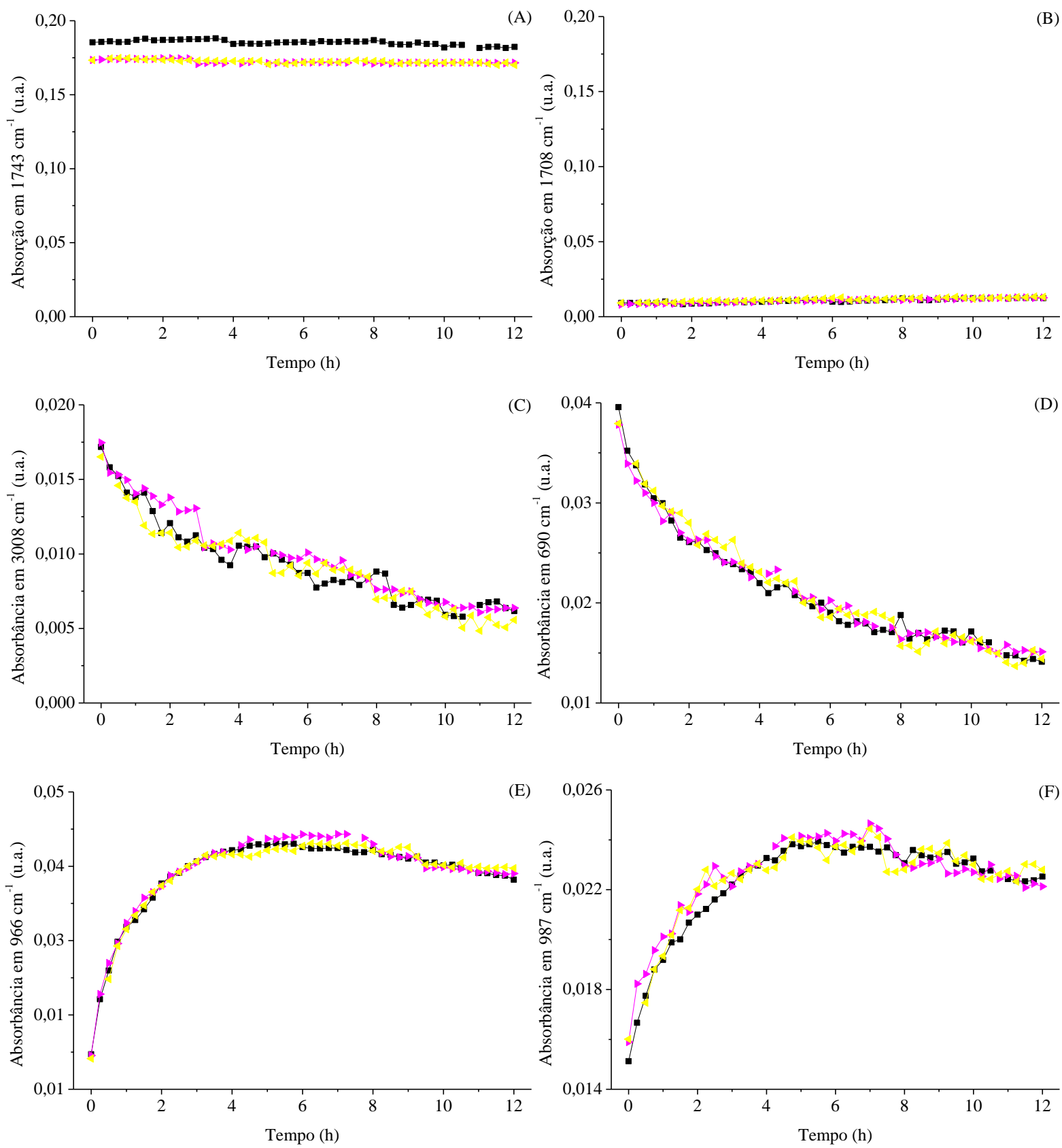

Figura 7.8 - Absorbâncias nos números de onda relacionados com carbonilas dos grupos éster (A) e ácidos carboxílicos (B), assim como duplas ligações totais (C), na conformação cis não conjugada (D), conformação trans 
(E) e trans-trans conjugadas (F). Reações sem agitação, a $300{ }^{\circ} \mathrm{C}$ contento EM puro (ロ) e na presença de $\mathrm{Ni}(\text { Carboxilato })_{2}(\triangleright)$ e $\mathrm{H}_{3} \mathrm{PO}_{4}(\hookrightarrow)$.

Ao avaliar a influência do $\mathrm{H}_{3} \mathrm{PO}_{4}$ e do $\mathrm{Ni}$ (Carboxilato) $)_{2}$ na polimerização dos TAGs, foi possível observar um aumento de viscosidade inicial e, nos tempos finais, uma redução frente a reação contendo somente os TAGs (ver Figura 7.9). Indicando assim, atividade catalítica, tanto na polimerização, como na decomposição do material. Os valores de IA aumentam no decorrer da reação, sendo sempre superiores aos obtidos na ausência dos catalisadores.
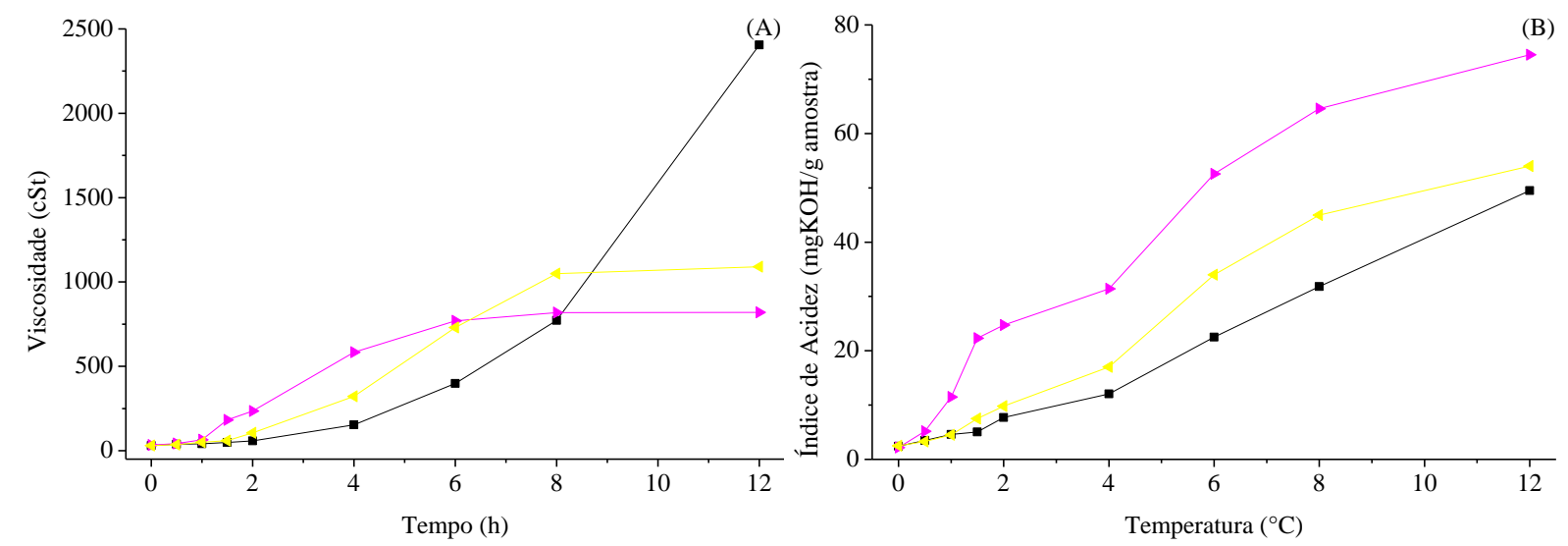

Figura 7.9 - Análises de viscosidade (A) e índice de acidez (B) das reações sem agitação a $300{ }^{\circ} \mathrm{C}$ utilizando TAGs puro (匹), na presença de $\mathrm{Ni}(\text { Carboxilato) })_{2}(\triangleright)$ e $\mathrm{H}_{3} \mathrm{PO}_{4}(\triangleleft)$.

Quando se observa as absorções no IV-ATR (ver Figura 7.10), é demonstrado que o $\mathrm{H}_{3} \mathrm{PO}_{4}$ e o Ni(Carboxilato) $)_{2}$ atuam de forma similar. Assim, o uso destes compostos favorece a decomposição das carbonilas dos triacilglicerídedos (A) e provocam aumento dos ácidos carboxílicos (B). Já no caso das duplas ligações, ocorre um favorecimento do consumo das duplas cis, assim como na formação das duplas trans e trans-trans. As absorções se tornam mais intensas principalmente ao se utilizar o catalisador de $\mathrm{Ni}$. 

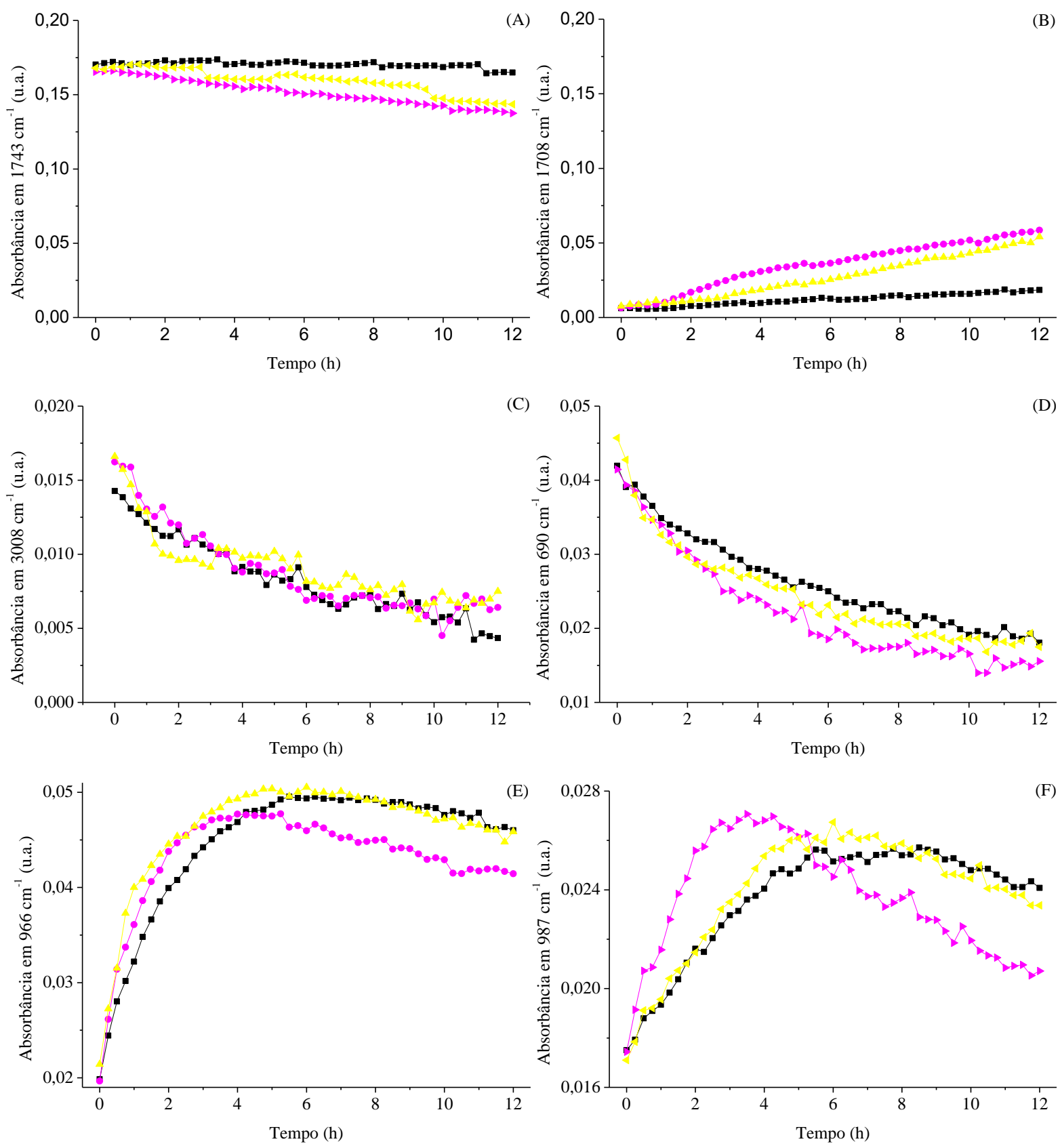

Figura 7.10 - Absorbâncias nos números de onda relacionados com carbonilas dos grupos éster (A) e ácidos carboxílicos (B), assim como duplas ligações totais (C), na conformação cis não conjugada (D), conformação trans (E) e trans-trans conjugadas (F). Reações sem agitação a $300{ }^{\circ} \mathrm{C}$ contento EM puro (घ) e na presença de $\mathrm{Ni}(\text { Carboxilato })_{2}(\triangleright)$ e $\mathrm{H}_{3} \mathrm{PO}_{4}(\triangleleft)$.

Para melhor compreensão da forma como os $\mathrm{Ni}$ (Carboxilato) ${ }_{2} \mathrm{e}_{3} \mathrm{HO}_{4}$ atuam na polimerização dos TAGs é necessário levar em consideração as seguintes informações: a presença de $\mathrm{Ni}^{2+}$ e $\mathrm{H}_{3} \mathrm{PO}_{4}$ favorecem consideravelmente a formação de ácidos carboxílicos derivados da quebra dos TAGs e atuam de forma limitada nas reações envolvendo as duplas ligações. Como demonstrado anteriormente, os ácidos carboxílicos são muito ativos nas reações 
que envolvem as duplas. Assim, pode-se inferir que durante a polimerização os catalisadores de $\mathrm{Ni}$ (Carboxilato) $)_{2}$ e $\mathrm{H}_{3} \mathrm{PO}_{4}$ atuam na quebra dos TAGs, formando rapidamente grandes quantidades de ácidos carboxílicos que atuam nas reações com as duplas ligações. Por fim, a viscosidade e a acidez são reflexos da disputa entre estas duas reações que ocorrem em paralelo. A primeira favorece a diminuição da viscosidade e aumento da acidez, a segunda, o aumento da viscosidade e diminuição da acidez. Um esquema reacional pode ser visualizado na Figura

\subsection{1.}

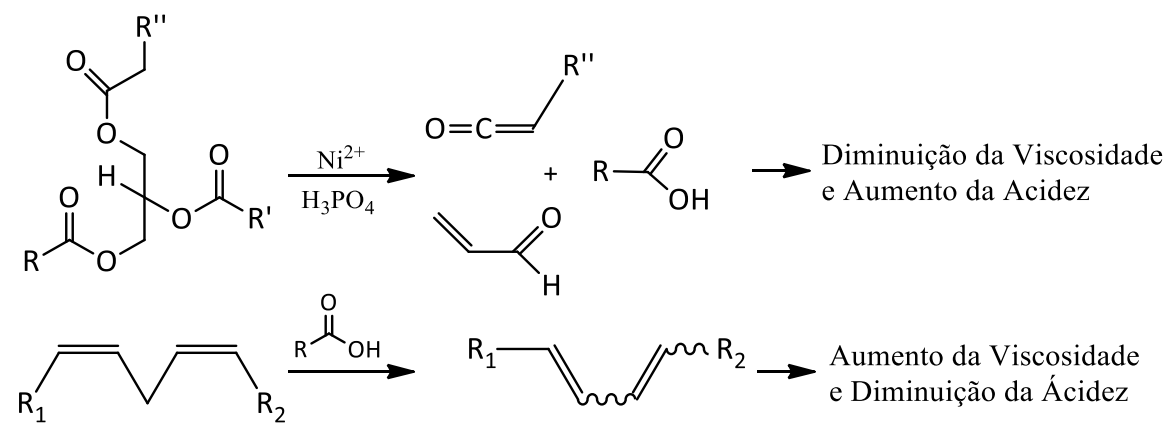

Figura 7.11 - Reações de polimerização/pirólise dos TAGs na presença de $\mathrm{Ni}\left(\right.$ Carboxilato) ${ }_{2}$ e $\mathrm{H}_{3} \mathrm{PO}_{4}$.

\subsection{Polimerização dos TAGs na presença de $\mathrm{Ca}(\mathrm{OH})_{2}$ e $\mathrm{Na}_{2} \mathrm{CO}_{3}$}

A polimerização dos TAGs na presença de $\mathrm{Ca}(\mathrm{OH})_{2}(0,1$ e $1 \%)$ e $\mathrm{Na}_{2} \mathrm{CO}_{3}$ anidro $(5 \%)$ foi proposta para se observar como as reações ocorrem na presença de uma base, com o foco na neutralização dos ácidos carboxílicos produzidos durante a reação. É necessário mencionar que nas temperaturas próximas a $200{ }^{\circ} \mathrm{C}$ já se observa a formação de espumas, indicando assim tanto a presença de sais de ácidos carboxílicos como a presença de água no sistema. Outro fator a ser mencionado é que durante o estudo foi observado a formação um material de altíssima viscosidade, o que impossibilitou a análise por viscosidade. Assim, o estudo procedeu somente com os dados obtidos por IV-ATR.

Os dados de IV-ATR da Figura 7.12 demonstram que ao comparar a reação sem aditivo com as contendo $\mathrm{Ca}(\mathrm{OH})_{2}$ e $\mathrm{Na}_{2} \mathrm{CO}_{3}$, foi possível observar que as bases favorecem a decomposição dos TAGs (A), a formação de ácidos carboxílicos $(\mathbf{B})$ e carboxilatos $(\mathbf{C})$. Notase que as duplas ligações totais (D) são consumidas e produzem duplas trans $(\mathbf{E})$ e trans-trans conjugadas $(\mathbf{F})$ mais rapidamente que na reação contendo somente TAGs. Assim, os dados demonstraram que as reações envolvendo bases são mais complexas do que se esperado, já que era previsto que a presença delas neutralizaria os ácidos carboxílicos formados na reação e 
consequentemente reduziria seus os efeitos nas reações presentes nas duplas, entretanto, os dados obtidos demonstram o oposto.
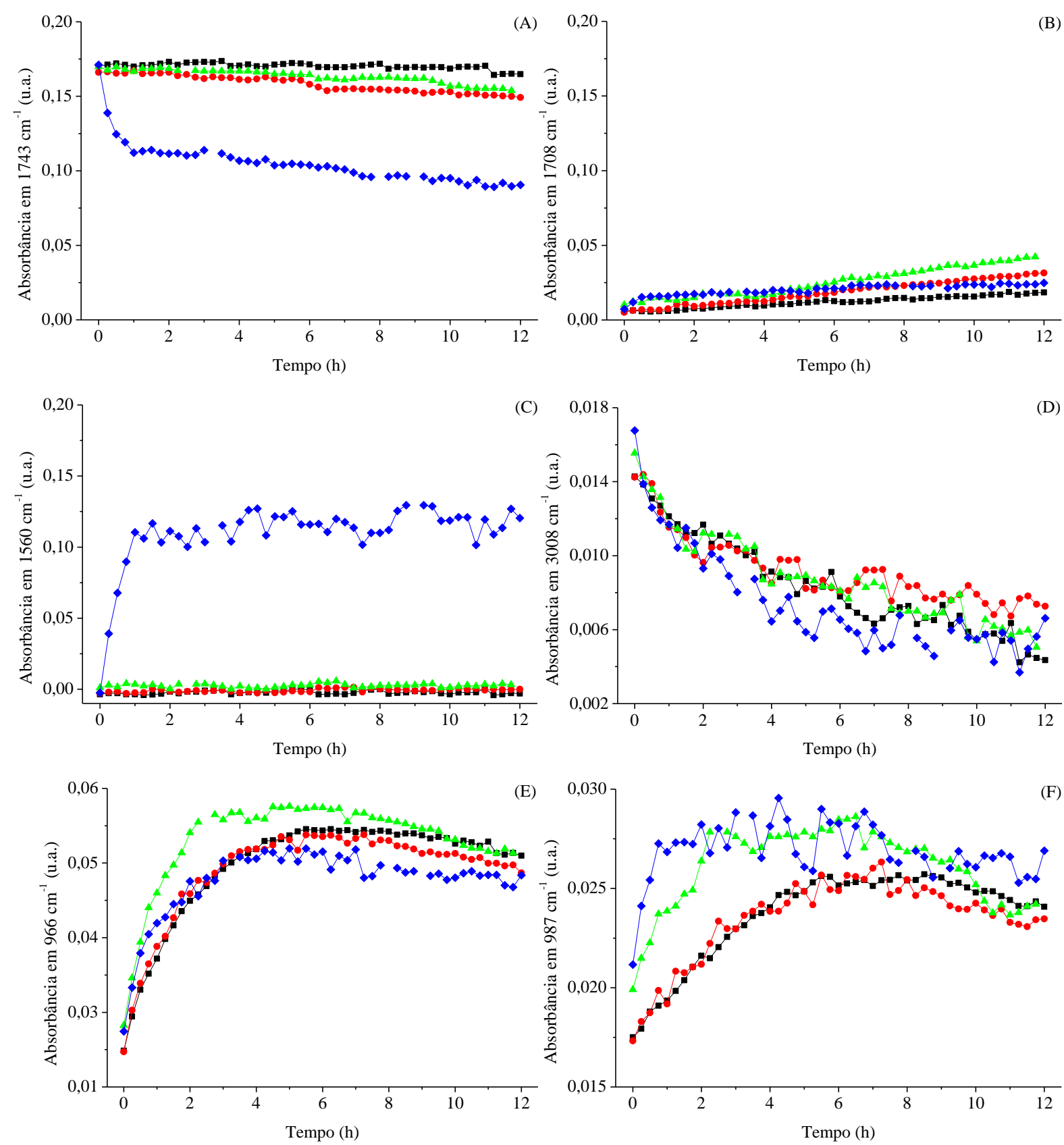

Figura 7.12 - Absorbâncias nos números de onda relacionados com carbonilas dos grupos éster (A), de ácidos carboxílicos (B) e carboxilatos (C), assim como duplas ligações totais (D), na conformação trans (E) e trans-trans conjugadas (F). Reações sem agitação a $300{ }^{\circ} \mathrm{C}$ com TAG puro (•), $\mathrm{Ca}(\mathrm{OH})_{2} 0,1 \%(\bullet) ; \mathrm{Ca}(\mathrm{OH})_{2} 1,0 \%(\Delta)$ ) $\mathrm{CaCO}_{3}$ $5 \%(\diamond)$.

Assim, as reações na presença de bases demonstraram ser mais complexas do que as reações na presença de ácidos carboxílicos e íons de metais. Os resultados podem ser explicados 
levando em consideração as reações de hidrólise dos TAGs e consequente formação de glicerol e AGs. Pois quando na presença de $\mathrm{OH}^{-}$ocorre a reação de neutralização dos ácidos e formação de $\mathrm{H}_{2} \mathrm{O}$. Ao se adicionar $\mathrm{Na}_{2} \mathrm{CO}_{3}$, ocorre a formação de $\mathrm{H}_{2} \mathrm{CO}_{3}$ que posteriormente, se decompõe formando $\mathrm{CO}_{2}$ e $\mathrm{H}_{2} \mathrm{O}$. Desta forma, é necessário um estudo mais específico para se avaliar este novo ambiente químico e avaliar as novas possibilidades reacionais.

\subsection{Considerações do Capítulo}

Inicialmente, foi possível avaliar a influência dos AGs, na polimerização dos TAGs e EMs. Assim, observou-se atividade catalítica na decomposição dos grupos ésteres, assim como na isomerização/conjugação das duplas ligações. Foi possível determinar que a polimerização, com consequente o aumento da viscosidade, está diretamente relacionada com as reações nas duplas ligações.

Ao avaliar as influências do complexo de $\mathrm{Ni}$ e do $\mathrm{H}_{3} \mathrm{PO}_{4}$ nas reações, foi observada baixa atividade nas reações com EMs, indicando baixa atividade nas reações de duplas ligações. Entretanto, utilizando os TAGs foi possível obter informações que sugerem que o íon de metal atua principalmente na decomposição dos grupos ésteres, favorecendo a formação de compostos ácidos. Consequentemente, são estes ácidos carboxílicos que atuam cataliticamente nas reações de isomerização/conjugação das duplas ligações, favorecendo assim as reações de polimerização e aumento da viscosidade. Os resultados obtidos com TAGs e $\mathrm{Ca}(\mathrm{OH})_{2}$ e $\mathrm{Na}_{2} \mathrm{CO}_{3}$, indicam que utilizando estes aditivos, podem estar ocorrendo reações relacionadas à hidrólise dos ésteres. 


\section{Capítulo 8}

Tratamento Térmico dos Óleos e Gorduras Residuais 


\subsection{Balanço de Massa}

Os OGRs são formados a partir da utilização dos TAGs refinados no processamento de alimentos, normalmente em altas temperaturas e em contato com o oxigênio do ar. A composição química dos OGRs pode variar de acordo com a forma em que foi produzido, pois este complexo ambiente químico produz modificações na composição dos TAGs através da isomerização e conjugação das duplas ligações, assim como a formação de diferentes compostos, destacando os ácidos carboxílicos, aldeídos, cetonas e hidrocarbonetos.

Para avaliar o OGR como potencial matéria-prima nos os processos de polimerização e pirólise, foram realizadas reações em temperaturas entre 260 a $370{ }^{\circ} \mathrm{C}$ por período de $1 \mathrm{~h}$, visando à obtenção do balanço de massa entre o polímero e o bio-óleo formado. Para efeito de comparação, foram realizadas reações utilizando óleo de soja refinado. Em paralelo, utilizouse catalisador a base de íon de $\mathrm{Ni}^{2+}$ para avaliar uma possível atividade catalítica no processo. No final de cada reação, foram obtidas as massas de bio-óleo e polímero formados, assim como alíquotas para posterior análise.

$\mathrm{Na}$ Figura 8.1A pode ser observado que a formação do bio-óleo ocorre após $350{ }^{\circ} \mathrm{C}$ na ausência de catalisador e, na presença do catalisador de Níquel, o bio-óleo passa a ser produzido a partir de $330{ }^{\circ} \mathrm{C}$. Este perfil pode visualizado tanto utilizando os OGRs, como o óleo de soja, o que demonstra atividade catalítica na formação de bio-óleo utilizando ambas as matérias primas.
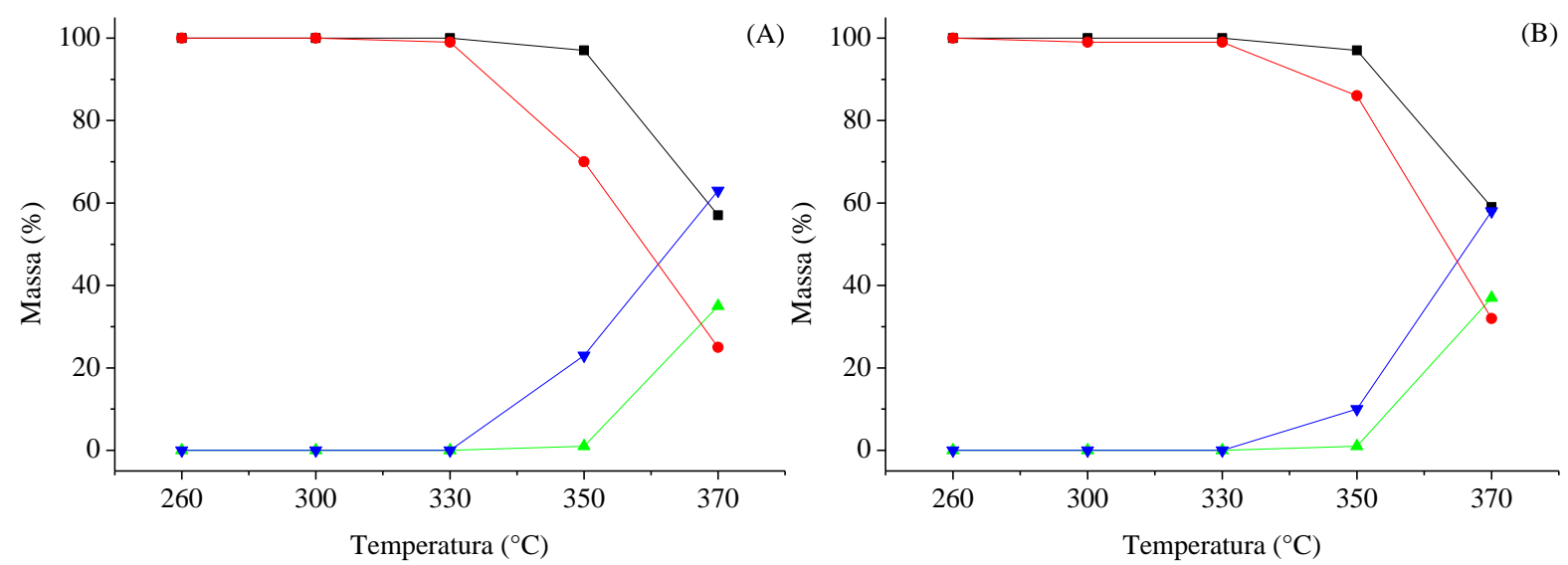

Figura 8.1 - Balanço de massa do processo de polimerização/pirólise por $1 \mathrm{~h}$ em sistema com agitação mecânica utilizando como matéria prima os (A) OGRs e (B) óleo de soja refinado. Massa percentual dos polímeros na (ausência e $(\bullet)$ presença de catalisador e bio-óleo $(\Delta)$ na ausência e $(\boldsymbol{\nabla})$ presença de catalisador. 


\subsection{Polímeros}

As alíquotas obtidas no interior do reator foram analisadas por viscosidade (Figura 8.2A) e IA (Figura 8.2B). Na ausência de catalisador, foi possível observar que OGRs geram polímeros com viscosidades superiores aos obtidos a partir do óleo refinado de soja. Ao avaliar os resultados obtidos na ausência e presença de catalisador, foi possível observar atividade catalítica no processo de polimerização, principalmente ao utilizar o óleo de soja refinado. Este perfil já se encontra descrito na literatura por Mello et al ${ }^{46}$.
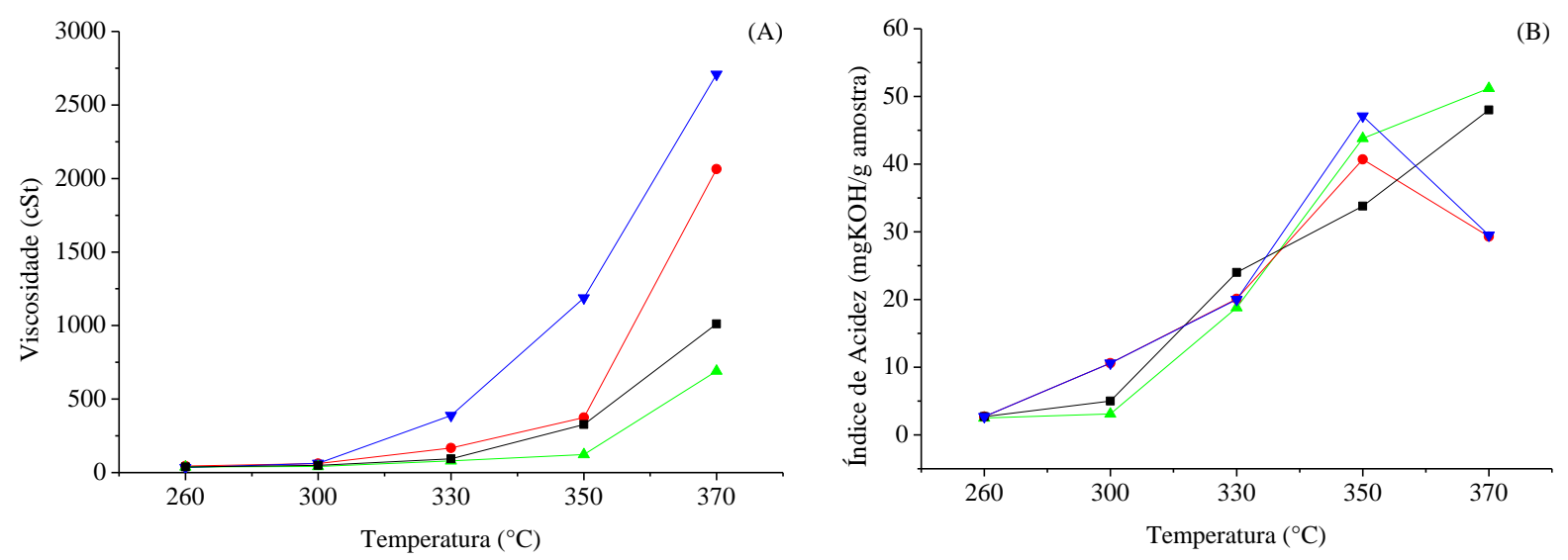

Figura 8.2 - Análises de (A) viscosidade e (B) índice de acidez dos polímeros obtidos nas reações com agitação mecânica utilizando como matéria prima os OGRs na (•) ausência e na $(\bullet)$ presença de catalisador e óleo de soja refinado na $(\Delta)$ ausência e $(\boldsymbol{\nabla})$ presença de catalisador.

O IA na ausência de catalisador aumenta ao incrementar a temperatura. Quando na presença de catalisador, o aumento ocorre até $350{ }^{\circ} \mathrm{C}$, com posterior redução em $370{ }^{\circ} \mathrm{C}$, o que pode ser indício da atividade catalítica na desoxigenação dos ácidos carboxílicos.

\subsection{Bio-Óleo}

Para se obterem informações detalhadas a respeito da composição dos bio-óleos, as amostras foram analisadas por CG-MS e os principais picos foram caracterizados. Assim, foi possível observar a presença de uma série de ácidos carboxílicos com cadeias entre 3 a 18 carbonos e hidrocarbonetos com cadeia variando entre 5 a 17 carbonos, demonstrando que o processo de pirólise pode produzir uma variada quantidade de compostos químicos. Os principais compostos encontrados são descritos na Tabela 8.1. 
Tabela 8.1 - Produtos detectados nos bio-óleos produzidos a partir da pirólise.

\begin{tabular}{cc|cc}
\hline Compostos Formados & Formula Química & Compostos Formados & Formula Química \\
Acroleína & $\mathrm{C}_{3} \mathrm{H}_{4} \mathrm{O}$ & Ácido hexanóico & $\mathrm{C}_{6} \mathrm{H}_{12} \mathrm{O}_{2}$ \\
1-Penteno & $\mathrm{C}_{5} \mathrm{H}_{10}$ & 1-Deceno & $\mathrm{C}_{10} \mathrm{H}_{20}$ \\
Pentano & $\mathrm{C}_{5} \mathrm{H}_{12}$ & Decano & $\mathrm{C}_{10} \mathrm{H}_{22}$ \\
Ácido acético & $\mathrm{C}_{2} \mathrm{H}_{4} \mathrm{O}_{2}$ & 2-Deceno & $\mathrm{C}_{10} \mathrm{H}_{20}$ \\
1-Hexeno & $\mathrm{C}_{6} \mathrm{H}_{12}$ & Ácido heptanóico & $\mathrm{C}_{7} \mathrm{H}_{14} \mathrm{O}_{2}$ \\
Hexano & $\mathrm{C}_{6} \mathrm{H}_{14}$ & Ácido octanóico & $\mathrm{C}_{8} \mathrm{H}_{16} \mathrm{O}_{2}$ \\
1-Hepteno & $\mathrm{C}_{7} \mathrm{H}_{14}$ & Ácido nonanóico & $\mathrm{C}_{9} \mathrm{H}_{18} \mathrm{O}_{2}$ \\
Heptano & $\mathrm{C}_{7} \mathrm{H}_{16}$ & Ácido decanóico & $\mathrm{C}_{10} \mathrm{H}_{20} \mathrm{O}_{2}$ \\
2-Hepteno & $\mathrm{C}_{7} \mathrm{H}_{14}$ & Pentadeceno & $\mathrm{C}_{15} \mathrm{H}_{30}$ \\
1-Octeno & $\mathrm{C}_{8} \mathrm{H}_{16}$ & Pentadecano & $\mathrm{C}_{15} \mathrm{H}_{32}$ \\
Octano & $\mathrm{C}_{8} \mathrm{H}_{18}$ & Heptadeceno & $\mathrm{C}_{17} \mathrm{H}_{34}$ \\
2-Octeno & $\mathrm{C}_{8} \mathrm{H}_{16}$ & Heptadecano & $\mathrm{C}_{17} \mathrm{H}_{36}$ \\
1-Noneno & $\mathrm{C}_{9} \mathrm{H}_{18}$ & Ácido palmítico & $\mathrm{C}_{16} \mathrm{H}_{32} \mathrm{O}_{2}$ \\
Nonano & $\mathrm{C}_{9} \mathrm{H}_{20}$ & & \\
\hline
\end{tabular}

Para efeito comparativo, foi construída a Tabela 8.2 relacionando as concentrações relativas (\%) dos ácidos carboxílicos, hidrocarbonetos saturados e hidrocarbonetos insaturados. Assim, observou-se que utilizando OGR e o óleo refinado de soja na ausência de catalisador são produzidas grandes quantidades de ácidos carboxílicos e uma menor porcentagem de hidrocarbonetos. Ao utilizar catalisador, ocorre a redução dos ácidos carboxílicos e um aumento considerável de hidrocarbonetos presentes nas amostras, assim como uma maior seletividade para hidrocarbonetos com grande cadeia carbônica (C15-C17).

Tabela 8.2 - Análises de composição química dos bio-óleos formados nas reações com agitação mecânca em diferentes temperaturas com OGRs e óleo de soja refinado sem catalisador e na presença de $\mathrm{Ni}^{2+}$.

\begin{tabular}{ccccccccc}
\hline \multicolumn{3}{c}{ Parâmetros } & \multicolumn{5}{c}{ Concentração Relativa (\%) } \\
\hline Matéria Prima & $\begin{array}{c}\text { Temp. } \\
\left({ }^{\circ} \mathrm{C}\right)\end{array}$ & Cat. & $\begin{array}{c}\text { Ác. } \\
\text { Carboxílico }\end{array}$ & $\begin{array}{c}\text { Hidro. } \\
\text { Saturado }\end{array}$ & $\begin{array}{c}\text { Hidro. } \\
\text { Insaturado }\end{array}$ & C5-C7 & C8-C10 & C15-C17 \\
\hline Óleo de Soja & 370 & Ausente & 31,1 & 13,4 & 14,5 & 7,64 & 23,53 & 5,48 \\
\hline OGRs & 370 & Ausente & 34,1 & 13,4 & 13,3 & 2,21 & 28,71 & 8,38 \\
\hline Óleo de Soja & 370 & $\mathrm{Ni}^{2+}$ & 13,5 & 23,4 & 19,9 & 7,92 & 20,32 & 17,55 \\
\hline OGRs & 370 & $\mathrm{Ni}^{2+}$ & 17,2 & 28,2 & 20,3 & 6,41 & 20,58 & 27,34 \\
\hline
\end{tabular}


Posteriormente, Os bio-óleos formados foram analisados de acordo com as normas para comercialização do Diesel estabelecida pela Agencia Nacional do Petróleo, Gás Natural e Biocombustíveis (ANP). ${ }^{63}$

Na Tabela 8.3, é possível observar que os bio-óleos obtidos apresentam valores de viscosidade e densidade na faixa do diesel de petróleo. Ao comparar as amostras obtidas na ausência e na presença de catalisador, foi notada uma redução na acidez e aumento no poder calorífico do produto obtido, provavelmente devido a seletividade na obtenção de compostos insaturados. Desta forma, foi possível observar que a presença de catalisador auxilia na decomposição dos ácidos carboxílicos e formação de hidrocarbonetos, principalmente os compostos insaturados.

Tabela 8.3 - Análises físico-químicas dos bio-óleos e valores de referência do Diesel de petróleo.

\begin{tabular}{ccccccc}
\hline Matéria Prima & Catalisador & $\begin{array}{c}\text { Temperatura } \\
\left({ }^{\circ} \mathrm{C}\right)\end{array}$ & $\begin{array}{c}\text { Viscosidade } \\
\left(\mathrm{mm}^{2} / \mathrm{s}\right)\end{array}$ & $\begin{array}{c}\text { Acidez } \\
\mathrm{mgKOH} / \mathrm{g}\end{array}$ & $\begin{array}{c}\text { M. Específica } \\
\left(\mathrm{kg} / \mathrm{m}^{3}\right)\end{array}$ & $\begin{array}{c}\text { P. Calorífico } \\
(\mathrm{kJ} / \mathrm{g})\end{array}$ \\
\hline Óleo de Soja & Ausente & 370 & 5,1 & 151 & 862 & 40,1 \\
\hline OGRs & Ausente & 370 & 4,8 & 151 & 861 & 39,1 \\
\hline Óleo de Soja & $\mathrm{Ni}^{2+}$ & 370 & 4,9 & 107 & 855 & 42,2 \\
\hline OGRs & $\mathrm{Ni}^{2+}$ & 370 & 4,8 & 107 & 851 & 42,2 \\
\hline Diesel & & & $2-5$ & - & $820-880$ & $\sim 41,8$ \\
\hline
\end{tabular}

\subsection{Considerações do Capítulo}

O estudo demonstrou a possibilidade de uso dos OGRs nas reações de polimerização e pirólise. No caso dos polímeros, os resultados demonstraram maior viscosidade para os produtos obtidos a partir dos OGRs quando comparados com os obtidos a partir dos óleos de soja refinado, sem diferenças significativas nos valores de IA. Ao utilizar o complexo de $\mathrm{Ni}^{2+}$, observou-se um maior aumento de viscosidade frente às reações sem catalisador.

As composições químicas dos bio-óleos demonstram a presença de considerável quantidade de hidrocarbonetos e ácidos carboxílicos na ausência do complexo de $\mathrm{Ni}^{2+}$. Ao utilizar catalisador, ocorre uma redução nos ácidos carboxílicos devido a atividade catalítica nas reações de desoxigenação. Ao comparar com as normas da Agencia Nacional do Petróleo, Gás Natural e Biodiesel (ANP), foi possível observar que a maior parte das propriedades físicoquímicas se encontram de acordo com as necessárias para a aplicação como substituinte do 
Diesel de petróleo. A acidez do bio-óleos ainda representa um desafio devido ao alto valor obtido, mesmo utilizando $\mathrm{Ni}^{2+}$ como catalisador para o processo de decomposição de ácidos. 
Discussão dos Resultados 
O estudo dos TAGs, EMs e AGs a temperaturas superiores a $260{ }^{\circ} \mathrm{C}$ possibilitou avaliar a formação de materiais com altas e baixas massas molares, nomeados genericamente como polímeros e bio-óleos. Os dados obtidos durante o trabalho demonstram que a polimerização e a decomposição ocorrem paralelamente e não de forma independente, como normalmente relatado na literatura. ${ }^{11-21}$

Ao avaliar o perfil de formação dos polímeros, notou-se que o aumento de viscosidade com relação ao tempo depende da matéria prima. No caso dos EMs, o aumento da viscosidade versus tempo possui perfil linear. Já para os AGs verifica-se um crescimento exponencial na viscosidade do meio. Finalmente, quando utilizado os TAGs ocorre um crescimento inicial exponencial com uma posterior redução. Estes diferentes tipos de cinética química geraram, durante o trabalho, incrementos de viscosidade de até 20, 200 e 70 vezes quando comparados aos valores dos EMs, AGs e TAGs puros, respectivamente.

Analises por espectroscopia de absorção na região do infravermelho indicaram que estes diferentes perfis estão relacionados com as diferentes reações que ocorrem em cada matéria prima. Avaliando os EMs, foi possível observar que existe uma estabilidade na carbonila do grupo éster e que o aumento de viscosidade se da pelo consumo das duplas, tendo como intermediários duplas ligações trans e trans-trans conjugadas. Ao adicionar AGs nos EMs, foi observado que as reações envolvendo as duplas são catalisadas e, por consequência, ocorre um aumento nos valores de viscosidade, com perfil da curva de viscosidade versus tempo passando de linear para exponencial Assim, foi possível inferir que os AGs, ou o produto de sua decomposição, são ativos nas reações envolvendo as duplas ligações e determinantes no aumento de viscosidade.

O tratamento térmico dos TAGs apresentou maior complexidade na variação da viscosidade e nas reações envolvendo duplas ligações e carbonilas. No caso da viscosidade, foi possível observar um aumento inicial e posterior redução dos valores, indicando que coexistem reações de aumento da cadeia, mais ativa nos períodos iniciais, e de decomposição, em tempos prolongados. As análises por IV-ATR indicaram que as duplas ligações se comportam da mesma forma que nos EMs, com o consumo durante todo o tempo reacional, tendo como intermediários as duplas trans-trans conjugadas. As carbonilas dos TAGs se decompõem e formam ácidos carboxílicos que posteriormente são decompostos.

Os resultados comparativos entre os TAGs puros e os obtidos com blendas de TAGs e AGs, indicam que os AGs, ou o produto da decomposição, favorecem a polimerização e a 
decomposição das cadeias, principalmente a quebra dos grupos ésteres para formação de novos compostos ácidos carboxílicos. Esta característica dos AGs catalisarem as reações de polimerização também pode ser observada nos resultados com os OGRs, que possuem maior acidez inicial, são mais ativos que os TAGs puros.

Para uma melhor compreensão das reações com EMs e TAGs, foram testados íons de metais e $\mathrm{H}_{3} \mathrm{PO}_{4}$, e avaliada a possibilidade do uso como catalisadores. Estes compostos foram selecionados devido que os primeiros apresentarem características de ácido de Lewis e o segundo de ácido de Brønsted. Assim, os resultados obtidos utilizando os EMs demonstraram que eles não atuam cataliticamente, ou atuam de forma limitada, nas reações envolvendo as duplas ligações. Assim, pode-se concluir que as reações de isomerização e conjugação das duplas ligações não ocorrem, ou ocorrem de forma limitada, por mecanismos de ácido Lewis ou Brønsted (catiônica). Por analogia é possível também concluir que a atividade catalítica dos AGs não se dá pela liberação de $\mathrm{H}^{+}$, más sim pela formação de radicais gerados de sua decomposição. ${ }^{55}$ Ao avaliar os íons de metais e o $\mathrm{H}_{3} \mathrm{PO}_{4}$ nas reações envolvendo TAGs, foram observadas atividades no processo de polimerização, aumentando a viscosidade nos períodos iniciais, e também na decomposição das cadeias, reduzindo os valores nos tempos finais. As análises por IV-ATR indicaram que a principal atividade dos íons de metais e o $\mathrm{H}_{3} \mathrm{PO}_{4}$ é acelerar a decomposição dos grupos ésteres e formação de grupos ácidos carboxílicos. Sugerindo, assim, que são os ácidos carboxílicos, produzidos pela decomposição dos grupos ésteres, os que favorecem o aumento da viscosidade. Outro fator observado durante o trabalho foi a redução dos íons de metais para o estado de oxidação zero, o que pode ser explicado devido a reações de oxirredução com os grupos ácidos carboxílicos. ${ }^{55}$

Ao avaliar a produção e composição dos bio-óleos obtidos com EMs, observou-se a produção de uma pequena quantidade em volume com composição majoritária de ésteres de diferentes tamanhos de cadeia. Utilizando os AGs, houve a formação de ácidos carboxílicos e hidrocarbonetos de diferentes tamanhos de cadeia, com tendência ao longo do tempo de formação de compostos menos ácidos e de menor tamanho. Uma característica observada tanto utilizando os EMs como os AGs foi a impossibilidade de aumentar a temperatura acima de 350 ${ }^{\circ} \mathrm{C}$ a pressão atmosférica devido ao refluxo no sistema. No caso dos TAGs, observou-se que nos tempos iniciais ocorre a formação de compostos de cadeia com mais de 10 carbonos, principalmente ácidos carboxílicos, e ao longo do tempo passam a ser formados hidrocarbonetos saturados e insaturados com cadeias com quantidades inferiores a 10 de 
carbonos. A presença de íons de metais favorece a quebra dos grupos ésteres, favorecendo a obtenção de bio-óleos mais ácidos e em maior quantidade.

Com base nas informações mencionadas, pode-se afirmar que o processo de polimerização é dependente da presença dos AGs, ou do produto de sua decomposição. Desta forma, todos os aditivos que favoreçam a quebra dos grupos ésteres e formação de ácidos atuarão na catálise destas reações, como por exemplo: ácidos de Lewis, bases, $\mathrm{H}_{2} \mathrm{O}$ ou compostos radicalares.

Com relação ao mecanismo de decomposição de ésteres, como mencionado na revisão bibliográfica, existem duas propostas na literatura: a beta e a gama eliminação. Como demonstrado neste estudo, a decomposição de ésteres de ácidos graxos só ocorre de forma espontânea a altas temperaturas, catalisada ou não, nos TAGs. De fato, a decomposição dos grupos ésteres de EM não ocorre nas temperaturas estudadas, mesmo na presença de ácidos de Lewis ou Brønsted. Assim, fica evidente a partir dos resultados deste estudo que a decomposição de ésteres de ácidos graxos ocorre via eliminação do $\mathrm{H}$ beta, isto é, para que a decomposição ocorra é necessário o resíduo de glicerol para a formação de grupos ácidos carboxílicos. Ou seja, o mecanismo de decomposição via gama eliminação pode ser descartado, pois quando há somente o $\mathrm{H}$ gama para a reação a decomposição da carbonila não ocorre.

Finalmente, pode-se concluir que para que ocorram os processos térmicos de decomposição de TAGs ocorram, seja para a formação de polímeros ou de hidrocarbonetos, é necessária a presença de ácidos graxos e seus produtos de decomposição. Estes ácidos graxos podem ser produzidos a partir da decomposição de TAGs via eliminação beta ou estarem presentes na matéria prima. 
Conclusões Gerais 
Neste trabalho foi possível avaliar o uso dos TAGs, EMs, AGs e OGRs. A metodologia empregada foi o tratamento térmico a temperaturas entre 260 a $380{ }^{\circ} \mathrm{C}$ visando avaliar os polímeros e bio-óleos formados. Em todos os capítulos que abordam o processo polimerização/pirólise foram observados que a temperatura, tempo e catalisador são determinantes para o aumento ou diminuição da viscosidade nos polímeros e na variação da composição dos bio-óleos.

Os dados obtidos utilizando óleo refinado de soja, relatado no Capítulo 4, demonstram que as cadeias dos TAGs tendem a reagir entre si aumentando sua massa molar. Em paralelo, a quebra das cadeias, a princípio são pouco perceptíveis, se tornam expressivas na medida em que a concentração de duplas ligações se reduz. No Capítulo 5 foi demonstrado que a polimerização do AG é sempre crescente e com perfil exponencial, o que sugere que possa estar havendo a polimerização em duas regiões: (1) nas duplas ligações e (2) na região em que houve a decomposição do ácido carboxílico. A polimerização do EM, cujos dados se encontram no Capítulo 6, sugere que a reação ocorreu apenas na região de duplas ligações, gerando um perfil linear de viscosidade com relação ao tempo. O Capítulo 7 demonstrou que a presença de AGs favorecem tanto a polimerização/pirólise dos EM como a dos TAGs. Demonstrou também que o $\mathrm{Ni}^{2+}$ atua na quebra dos ésteres dos triacilglicerídeos, e não nas reações envolvendo as duplas. O uso dos TAGs Residuais, relatado no Capítulo 7, demonstrou possuir maior atividade na polimerização quando comparado com o óleo refinado, o que sugere que óleos com maior IA inicial tendem a polimerizar de forma mais rápida, o que já foi previamente demonstrado no capítulo anterior.

Como conclusão do trabalho, acredita-se que o tratamento térmico dos TAGs possa ser explicado através três possíveis reações: (1) a polimerização promovida pelas duplas ligações presentes na cadeia, via Diels-Alder ou radicalar. (2) pela decomposição dos TAGs e formação de compostos de baixa massa molar, principalmente ácidos carboxílicos. (3) a reação relacionada com a decomposição dos ácidos carboxílicos formados na etapa (2), o que tende a auxiliar nas etapas (1) e (2). 
Referências 
1. USDA - United States Departamento of Agriculture. Disponível em: http:/www.fas.usda.gov/psdonline (atualizada em 12 de setembro de 2013).

2. Suarez, P. A. Z.; Meneghetti, S. M.; Meneghetti, M. R.; Wolf, C. R.; Quim. Nova, 2007, $30,3,667-676$.

3. Suarez, P. A. Z.; Santos, A. L. F.; Rodrigues, J. P.; Alves, M. B.; Quim. Nova, 2009, 32, $3,768-775$.

4. Weinert, A.; Bielansky, P.; Reichhold, A.; APCBEE Procedia, 2012, 1, 147-152.

5. Luo, Y.; Ahmed, I.; Kubátová, A.; St’avová, J.; Aulich, T.; Sadrameli, S. M.; Seames, W. S.; Fuel Processing Tecnoogy, 2010, 91, 613-617.

6. Ramalho, H. F.; Di Ferreira, K. M. C.; Machado, P. M. A.; Oliveira, R. S.; Silva, L. P.; Prauchner, M. J.; Suarez, P. A. Z.; Industrial Crops and Products, 2014, 52, 211-218.

7. van Gorkum, R.; Bouwman, E.; Coordination Chemistry Reviews, 2005, 249, 17091728.

8. OECD - Organisation for Economic Co-operation and Development. Disponível em: http:/www.oecd.org (atualizada em 10 de fevereiro de 2014)

9. Disponível em: http://www.neilaburns.com/wp-content/uploads/2011/12/ChemicalWeekly-Review.pdf; acessado em setembro de 2014.

10. http://site.sabesp.com.br/uploads/file/asabesp_doctos/programa_reciclagem_oleo_com pleto.pdf acessado em setembro de 2014.

11. Mello, V. M.; Suarez, P. A. Z.; Rev. Virtual Quim., 2012, 4, 2.

12. Martins, G. B. C.; Mello, V. M.; Suarez, P. A. Z.; Rev. Virtual Quim., 2013, 5, 1, 16-25.

13. Yamg, C.; Nie, R.; Fu, J.; Hou, Z.; Lu, X.; Bioresource Technology, 2013, 146, 569573.

14. Freitas, L.; Bueno, T.; Perez, V. H.; Santos, J. C.; de Castro, H. F.; World J. Microbiol. Biotechnol., 2007, 23, 1725.

15. Rerenblyum, T. A.; Podoplelova, R. S.; Katsman, E. A.; Danyushevsky, Y. Y.; Petroleum Chemistry, 2011, 51, 5, 336-341.

16. Jeremy G.; Immer, M.; Kelly, H. J.; Lamb; L. H.; J. Chem. Technol. Biotechnol., 2012, 87, 1041-1050.

17. Jimenez, E. S.; Crocker, M.; J. Chem. Technol. Biotechnol., 2012, 87, 1041-1050.

18. Immer, J. G.; Kelly, J.; Lamb, H. H.; Applied Catalysis A: General, 2010, 375, 134139. 
19. Lestari, S. P.; Arvela, M.; Beltramini, K. J. E.; Lu, G. Q. L.; Murzin, D. Y.; Catal. Lett., 2010, 134, 250-257.

20. Billaud, F.; Dominguez, V.; Broutin, P.; Busson, C.; J. Am. Oil Chem. Soc., 1995, 72, 1149-1154.

21. Billaud, F.; Dominguez, V.; Broutin, P.; Lipids, 1995, 2, 483-490.

22. Erhan, S. Z.; Bagby, M.; J. Am. Oil Chem. Soc., 1991, 68, 9, 635.

23. Erhan, S. Z.; Bagby, M. O.; The United States of América C09D 011/06; C08L 091/00; C09F 007/00 U.S. n. 5.122.188, 1992.

24. Moretto, E.; Fett, R.; Tecnologia de óleos e gorduras vegetais na indústria de alimentos, Varela: São Paulo, 1998.

25. Valores de Referência: RDC No482, de 23/09/1999, da Agência Nacional da Vigilância Sanitária - ANVISA.

26. Patil, T. A.; Butala, D. M.; Raghunathan, T. S; Sharnkar, H. S.; Ind. Eng. Chem. Res. 1988, $27,727$.

27. Freitas, L.; Bueno, T.; Perez, V. H.; Santos, J. C.; de Castro, H. F.; World J. Microbiol. Biotechnol. 2007, 23, 1725.

28. King, J. W.; Holliday, R. L.; List, G. R.; Green Chem. 1999, 1, 261.

29. Bhatkhande, B. S.; Samant, S. D.; Ultrason. Sonochen. 1998, 5, 7.

30. Mallégol, J.; Lemaire, J.; Gardette, J.-L.; Prog. Org. Coat., 2000, 39, 107.

31. Archer Daniels Midland Company US2213935, 1938.

32. Sims, R. P. A.; J. Am. Oil Chem. Soc., 1957, 34, 9, 466.

33. Demirbas, A. W.; Dykstra, G.; Selke, E.; Sorenson, S.; Pryde, E.; J. Am. Oil Chem. Soc., 1988, 65, 1781.

34. Fortes, I. C. P.; Baugh, P. J.; J. Anal. Appl. Pyrolysis, 1994, 29, 153.

35. Fabbri, D.; Baravelli, V.; Chiavari, G.; Prati, S. J.; Chromat, 2003, 1100, 218.

36. Parshall, G. W.; Ittel, S. D.; Hogeneous Catalysis, John Willey \& Sons: New York, 1992.

37. Demorest, M.; Mooberry, D.; Danfort, J. D.; Ind. Eng. Chem., 1951, 43, 11, 2569-2572.

38. Moynihan, J. T.; American Newspaper Publishers Association, U.S. Patent 4519841, 1985.

39. Moynihan, J. T.; American Newspaper Publishers Association, U.S. Patent 4554019, 1985. 
40. Erhan, S. Z.; Bagby, M. O.; Taga Proceedings, Chelsea: Technical Association of the Graphic Arts, 1993, 314-326.

41. Erhan, S. Z.; Bagby, M. O.; Taga Proceedings, Chelsea: Technical Association of the Graphic Arts, 1994, 313.

42. Erhan, S. Z.; Bagby, M. O.; The United States of America, C09D 011/06. U.S. n. 5.713.990, 1998.

43. Falkenburg, L. B.; DeJong, W.; Handeke, D. P.; Radlove, S. J.; J. Am. Oil Chem. Soc., 1948, 25, 237.

44. Spencer Kellog; Sons, Inc., Buffalo, N. Y. US2230470, 1939.

45. Mello, V. M.; Oliveira, G. V.; Mandarino, J. M. G.; Carrão-Panizzi, M. C.; Suarez, P. A. Z.; Industrial Crops and Products, 2013, 43, 56-60.

46. Mello, V.M.; Oliveira, G. V.; Suarez, P. A. Z.; J. Braz. Chem. Soc., 2013, 24, 2, 1-6.

47. Demirbas, A. Energy Convers. Manage. 2003, 44, 2093.

48. Maher, K. D.; Bressler, D. C. Bioresource Technol., 2007, 98, 2351.

49. Doll, K. M.; Sharma, B. K.; Suarez, P. A. Z.; Erhan, S. Z.; Energy Fuels, 2008, 22, 2061.

50. Fortes, I. C. P.; Baugh, P. J.; J. Anal. Appl. Pyrolysis, 1994, 29, 153.

51. Lima, D. G.; Soares, V. C. D.; Ribeiro, E. B.; Carvalho, D. A.; Cardoso, E. C. V.; Rassi, F. C.; Mundim, K. C.; Rubim, J. C.; Suarez, P. A. Z.; J. Anal. Appl. Pyrolysis, 2004, 71, 987.

52. Quirino, R. L.; Tavares, A. P.; Peres, A. C.; Rubim, J. C.; Suarez, P. A. Z.; J. Am. Oil Chem. Soc., 2009, 86, 167.

53. Gusmão, J.; Brodzki, D.; Djéga-Mariadassou, G.; Frety, R.; Catal. Today, 1989, 5, 533.

54. Seames, W.; Luo, Y.; Ahmed, I.; Aulich, T.; Kubátová, A.; Stávová, J.; Kozliak, E.; Biomass and Bioenergy, 2010, 34, 939-946.

55. Kochi, J. K.; J.Am. Chem. Soc., 1965, 87, 16, 3609-3619.

56. Miller, J. A.; Nelson, J. A.; Byrne, M. P.; U.S. Patent 5,077,447, 1991.

57. Vaska, L.; DiLuzio, J. W.; J. Am. Chem. Soc., 1961, 83, 2784.

58. Maetani, S.; Fukuyama, T.; Suzuki, N.; Ishihara, D.; Ryu, I.; Organometallics, 2011, 30, 1389-1394.

59. Snåre, M.; Kubic-ková, I.; Mäki-Arvela, P.; Eränen, K.; Murzin, D. Y.; Ind. Eng. Chem. Res., 2006, 45, 5708

60. Roha, H.-S.; Euma, I. H; Jeonga, D.-W.; Yib, B. E.; Nab, J. G.; Kob, G. H.; Catalysis Today, 2011, 164, 457-460. 
61. Feitoza, N. C.; Gonçalves, T. D.; Mesquita, J. J.; Menegucci, J. S.; Santos, M. K. M. M.; Charker, J. A.; Cunha, R.B.; Medeiros, A. M. M.; Rubim, J. C.; Sousa, M. H.; Journal of Hazardous Materials, 2014, v. 264, p. 153-160.

62. Jimenez, E. S.; Morgan, T.; Lacny, J.; Mohapatra, S.; Crocker, M.; Fuel, 2013, 103, 1010-1017.

63. ANP - Agencia Nacional do Petróleo; Brasil, 2006, portaría $\mathrm{N}^{\circ} 15$. 